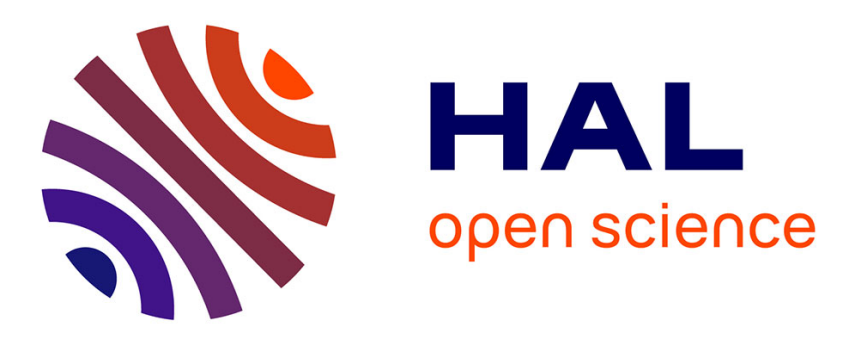

\title{
Near-infrared emissive \\ bacteriochlorin-diketopyrrolopyrrole triads: Synthesis and photophysical properties
}

Flavien Ponsot, Nicolas Desbois, Léo Bucher, Mathieu Berthelot, Pritam

Mondal, Claude P Gros, Anthony Romieu

\section{To cite this version:}

Flavien Ponsot, Nicolas Desbois, Léo Bucher, Mathieu Berthelot, Pritam Mondal, et al.. Near-infrared emissive bacteriochlorin-diketopyrrolopyrrole triads: Synthesis and photophysical properties. Dyes and Pigments, 2019, 160, pp.747-756. 10.1016/j.dyepig.2018.08.059 . hal-03476108

\section{HAL Id: hal-03476108 \\ https://hal.science/hal-03476108}

Submitted on 12 Dec 2021

HAL is a multi-disciplinary open access archive for the deposit and dissemination of scientific research documents, whether they are published or not. The documents may come from teaching and research institutions in France or abroad, or from public or private research centers.
L'archive ouverte pluridisciplinaire HAL, est destinée au dépôt et à la diffusion de documents scientifiques de niveau recherche, publiés ou non, émanant des établissements d'enseignement et de recherche français ou étrangers, des laboratoires publics ou privés. 


\title{
Near-infrared emissive bacteriochlorin-diketopyrrolopyrrole triads: Synthesis and photophysical properties
}

Flavien Ponsot ${ }^{\mathrm{a}}$, Nicolas Desbois ${ }^{\mathrm{a}}$, Léo Bucher ${ }^{\mathrm{a}}$, Mathieu Berthelot ${ }^{\mathrm{a}}$, Pritam Mondal ${ }^{\mathrm{a}}$, Claude P. Gros, ${ }^{\mathrm{a}, *}$, Anthony Romieu ${ }^{\mathrm{a}, \mathrm{b}, *}$

anstitut de Chimie Moléculaire de l'Université de Bourgogne, UMR 6302, CNRS, Univ. Bourgogne Franche-Comté, 9, Avenue Alain Savary, 21078 Dijon cedex, France

${ }^{b}$ Institut Universitaire de France, 1, Rue Descartes, Bâtiment MONGE, 75005 Paris, France

\begin{abstract}
The synthesis of unprecedented energy transfer triads containing a near-infrared (NIR) emissive bacteriochlorin subunit and two diketopyrrolopyrrole (DPP) moieties linked to each other via ethynyl or zero-carbon spacers is presented. Their optical and fluorescence properties were determined in $\mathrm{CHCl}_{3}$ and toluene. These photophysical measurements highlight the ability of DPP scaffold to act as an effective energy donor, which once excited in the range 450-550 nm resulting nearly exclusively NIR emission of hydroporphyrin (ETE > 96\%). Since DPP dyes are valuable structurally tunable fluorophores that may be used in the construction of high-performance multicomponent photoactive systems, their spectral compatibility with bacteriochlorin chromophore demonstrated through this work, is an important first step toward the rational design of novel and innovative hybrid NIR fluorophores inspired by (bacterio)chlorophylls and suitable for biomedical applications.
\end{abstract}

\section{Graphical abstract}

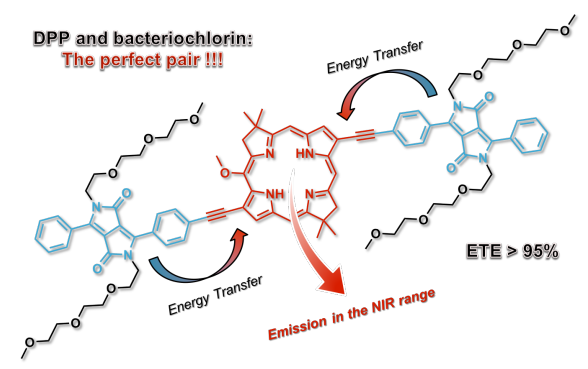

Keywords Bacteriochlorin, Diketopyrrolopyrrole, Energy-transfer triad, Fluorophore, Nearinfrared fluorescence

\section{Highlights}

Synthesis of first bacteriochlorin-DPP triads via Pd-catalyzed cross-coupling reactions

Investigation of photophysical properties in organic solvents

Nearly quantitative $\mathrm{S}_{1}-\mathrm{S}_{1}$ energy transfer between DPP and bacteriochlorin in triads

\footnotetext{
${ }^{*}$ Corresponding authors.

E-mail address: claude.gros@u-bourgogne.fr or anthony.romieu@u-bourgogne.fr
} 


\section{Introduction}

One of the growing trends in medicine is increased emphasis on early detection of disease in order to administer timely treatment that will improve the prognosis of the patient. Of the emerging diagnostic techniques, biomedical imaging has proven to be superior to traditional diagnostic methods due to its minimal invasiveness, absence of side effects, rapid results, and identification of possible mechanisms of pathological presentation through elucidation of internal biomolecular structure and shape[1,2]. Therefore, great efforts have been made to improve contrast agents and imaging techniques. Quite special interest was paid to fluorescence modality because of its numerous advantages (i.e., convenience, sensitivity, cost-effectiveness, safety, and non-radioactive material safety), especially for molecular imaging in preclinical studies. Indeed, illumination of receptors, enzymes, gene expression, in vitro live cells, and tumors cells in vivo is a valuable approach to gain a sound understanding of disease progression and therapeutic response at the molecular, cell, tissue, and whole-animal levels[3,4]. However, all or part of these valuable features are jeopardized when in vivo fluorescence imaging uses traditional wavelengths in the visible spectrum. Indeed, substantial photon scattering and/or photon absorption by biological tissues, coupled with significant interferences from tissue auto-fluorescence occur and contribute to the dramatic loss of signal and the gain of background noise. The use of near-infrared (NIR) fluorescent probes, having absorption/emission maxima in the spectral range 700-900 nm, often called "therapeutic optical window" (or NIR-I window), optimal brightness and photostability, has proven to be an effective way to overcome these limitations and to achieve deep-tissue analyses[5-7]. During the past two decades, intensive research efforts have been devoted to the development of a wide range of long wavelength photoactive (bio)molecular structures satisfying all or part of these specifications[8-10]. Among the different classes of NIR fluorescent labels currently available, organic-based fluorophores have a prominent place and are often preferred for bioimaging applications based on the use of activatable (or "'smart") fluorescent probes[11-13]. Indeed, the design of NIR analyte-responsive chemodosimeters on the basis of well-known photophysical processes and/or fluorogenic reactions is much easier (or only possible) with organic fluorophore platforms than with fluorescent proteins, semi-conductor nanocrystals (quantum dots) or nanomaterials (e.g., inorganic upconverting nanoparticles). The families of NIR fluorophores emitting above $700 \mathrm{~nm}$ have been so far dominated by the cyanine (i.e., Cy7 derivatives)[14,15] 
and (aza-)BODIPY dyes[16], even if silicon-substituted xanthene dyes and dihydroxanthenehemicyanine hybrids have recently emerged as valuable alternatives to these "golden imaging standards"[17-19]. Furthermore, design strategies inspired by biomolecules or natural products responsible of the far-red or NIR fluorescence observed in some biological systems, have recently emerged[15],[20-22]. The major contribution of the Lindsey group focused on the development of biocompatible fluorophores with a chemical structure that is related to the photosynthetic pigments (i.e., chlorins[23] and bacteriochlorins (BC)[24]) deserves to be highlighted[25-34]. However, the synthetic access to these hydroporphyrin derivatives and their site-specific functionalization(s) are often a true priesthood[35-38]. Thus, in order to simplify the preparation of high-performance engineered NIR fluorophores based on a (bacterio)chlorin scaffold without resorting to tedious de novo syntheses, we plan to explore a chromophore merging-based strategy leading to unprecedented hybrids structures between hydroporphyrin and diketopyrrolopyrrole (DPP) photoactive units (Fig. 1)[39-48]. Indeed, in view of their oustanding properties (high fluorescence quantum yields, large two-photon absorption cross-sections and exceptional chemical, light and thermal stability) and their facile synthesis and functionalization, DPP dyes have recently emerged as valuable alternatives to conventional visible fluorophores[49,50]. Their integration with porphyrin-like molecules should facilitate the introduction of specific functionalities usually required for biosensing/bioimaging (i.e., a bioconjugatable tether, water-solubilizing groups and possibly an optically tunable reactive group for modulation of fluorescence properties), and through a highly modular approach. Furthermore, depending on the linker chosen for the attachment of 3,6-diaryl-substituted DPP units to 13- (or 3,13-) positions of hydrophorphyrin (i.e., alkynyl, dimethine or zero-carbon bridge), we intend to obtain either energy transfer (ET) dyads/triads characterized by a negligible electronic conjugation between chromophores, or strongly $\pi$-conjugated BC-DPP hybrids with extended NIR absorption/emission compared to those of more conventional synthetic BCs (Fig. 1). To the best of our knowledge, this proposed novel class of NIR organic-based fluorophores has never been reported in the literature although in recent years, there is a growing interest for the synthesis and overall photophysical and redox characterization of energy transfer dyads bearing a synthetic BC unit as the energy acceptor, with the aim of providing efficient panchromatic molecular assemblies for light-harvesting and solar cells applications[51-56]. The vast majority of these ET dyads involve a chlorin, a BODIPY or a perylene-monoimide unit as the energy donor. Interestingly, this ET strategy is also particularly 
suited to artificially and dramatically increase the Stokes' shift (pseudo-Stokes' shift in the range $85-110 \mathrm{~nm}$ ) of BCs which is typically less than $10 \mathrm{~nm}$, regardless of the solvent, substitution pattern and metalation state of these macrocycles. This is a valuable and essential feature to minimize selfquenching and fluorescence detection errors stemming from excitation backscattering effects, and for possible applications of hydroporphyrins in NIR fluorescence molecular imaging[20-22,27].

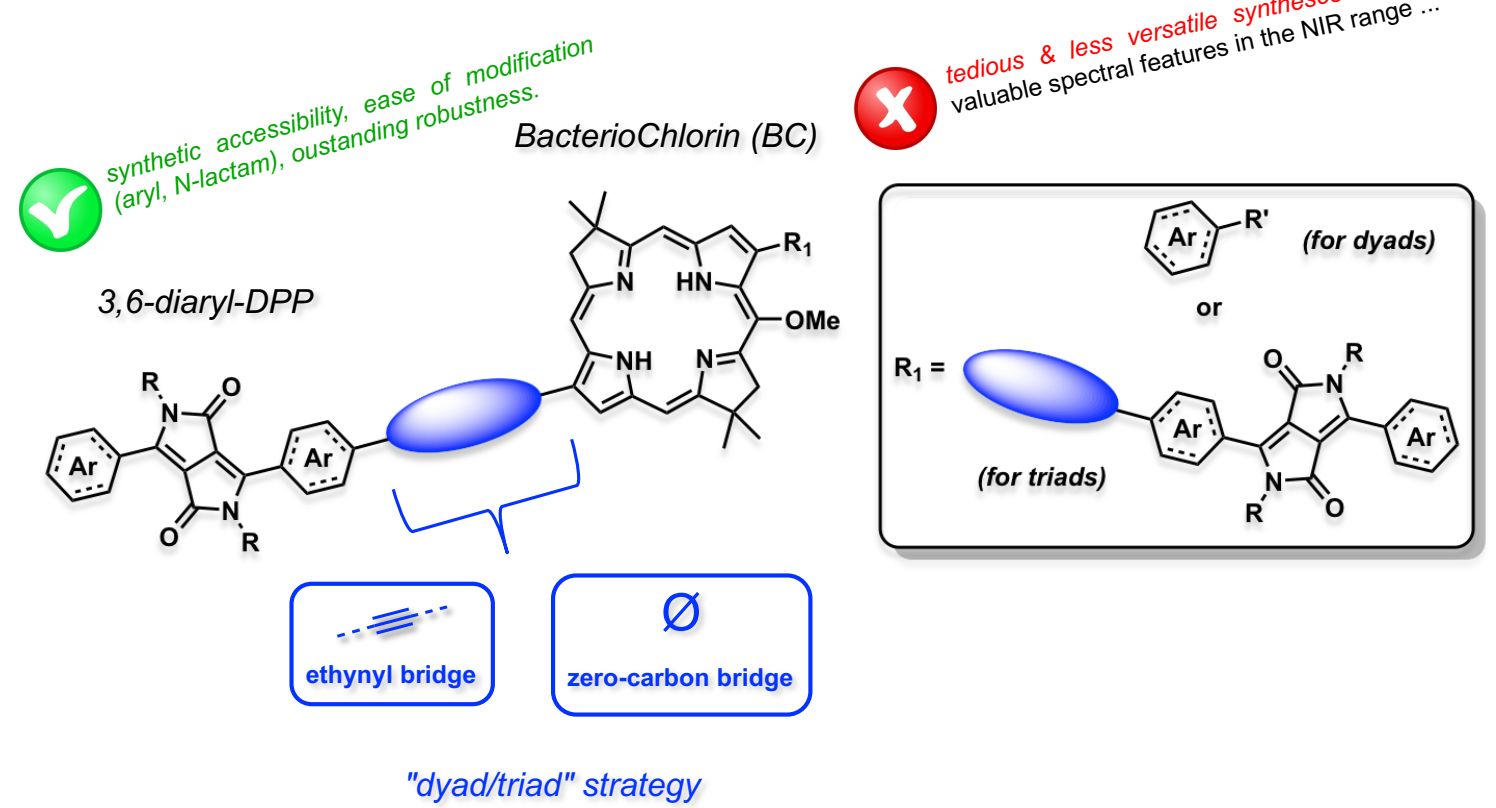

Fig. 1. Schematic overview of the molecular design strategy toward BC-DPP hydrid NIR fluorophores. Please note: the term "zero-carbon bridge" means that the covalent connection between bacteriochlorin and DPP units involves the sole aryl substituent of this latter chromophore. The present work only discloses the synthesis of triads involving two donor DPP units and not dyads.

It is in this context that we report herein the first synthesis and basic photophysical studies of three BC-DPP energy transfer triads differentiated by the linker connecting the chromophoric units (i.e., ethynyl or zero-carbon bridge) and/or DPP substitution pattern (i.e., 3,6-diaryl and $N$-lactam substituents).

\section{Experimental}

\subsection{Chemicals and instruments}

Unless otherwise noted, all commercially available reagents and solvents were used without 
further purification. TLC were carried out on Merck DC Kieselgel 60 F-254 aluminum sheets. The spots were directly visualized or through illumination with UV lamp $(\lambda=254 / 365 \mathrm{~nm})$. Column chromatography purifications were performed on silica gel (40-63 $\mu \mathrm{m}$ and 63-200 $\mu \mathrm{m})$ from Sigma-Aldrich (technical grade). Size-exclusion chromatography purifications were performed with Bio-Beads ${ }^{\circledR}$ S-X3 support (ca. $125 \mathrm{~g}$ for up to $200 \mathrm{mg}$ of dye, $40 \times 450 \mathrm{~mm}$ bed) from BioRad (\#152-2750). THF (HPLC-grade, Biosolve) was dried over alumina cartridges using a solvent purification system PureSolv PS-MD-5 model from Innovative Technology. Dry TEA was obtained by distillation over $\mathrm{CaH}_{2}$ and stored under argon on $3 \AA$ molecular sieves. The following compounds were prepared according to literature procedure: 3,13-dibromo-5-methoxy-8,8,18,18tetramethyl-bacteriochlorin (diBr-BC, [CAS: 1006370-88-2])[57], TMS-ethynyl thienyl-DPP dye 1 (CAS: 1637582-58-1)[58], unsymmetrical phenyl-DPP pigment 2 [CAS: 112026-72-9][59] and 3,6-diphenyl-DPP pigment [CAS: 54660-00-3][60].

${ }^{1} \mathrm{H}$ - and ${ }^{13} \mathrm{C}-\mathrm{NMR}$ spectra were recorded on a Bruker Avance 500 spectrometer. Chemical shifts are expressed in parts per million (ppm) from the residual non-deuterated $\mathrm{CHCl}_{3}$ signal[61]. $J$ values are expressed in Hz. IR spectra were recorded with a Bruker Alpha FT-IR spectrometer equipped with a universal ATR sampling accessory. The bond vibration frequencies are expressed in reciprocal centimeters $\left(\mathrm{cm}^{-1}\right)$. Low- and high-resolution mass spectra (LRMS and HRMS) were recorded either with a Bruker Daltonics Ultraflex II LRF 2000 mass spectrometer (MALDI-TOF, matrix: dithranol) or a Bruker Amazon SL instrument equipped with an electrospray (ESI) source or a Thermo Scientific MSQ Plus single quadrupole equipped with an ESI source (parameters for the ESI-MS analysis of BC-DPP triads: probe temperature: $350^{\circ} \mathrm{C}$, needle: $3.0 \mathrm{kV}$, detector: 1153 V and cone voltage: $200 \mathrm{~V}$ ). UV-visible spectra were obtained either on a Varian Cary 50 scan (single-beam) or an Agilent Cary 5000 UV-VIS-NIR (double beam) spectrophotometer by using a rectangular quartz cell (Hellma, 100-QS, $45 \times 12.5 \times 12.5 \mathrm{~mm}$, pathlength: $10 \mathrm{~mm}$, chamber volume: $3.5 \mathrm{~mL}$ ), at $25{ }^{\circ} \mathrm{C}$ (using a temperature control system combined with water circulation). Fluorescence spectroscopic studies (Em./Ex. spectra and kinetics) were performed with an HORIBA Jobin Yvon Fluorolog spectrofluorometer (software FluorEssence) at $25{ }^{\circ} \mathrm{C}$ (using a temperature control system combined with water circulation), with a standard fluorometer cell (Labbox, LB Q, light path: $10 \mathrm{~mm}$, width: $10 \mathrm{~mm}$, chamber volume: $3.5 \mathrm{~mL}$ ). See ESI for all experimental details related to photophysical characterizations of DPP dyes and BC-DPP triads. 


\subsection{Synthesis of functionalized BC and DPP derivatives}

\subsubsection{Ethynyl-functionalized thienyl-DPP [CAS: 1637582-59-2] (1)}

To a solution of TMS-ethynyl thienyl-DPP[58] (37.0 mg, $59.6 \mu \mathrm{mol}, 1.0$ equiv) in THF ( $8 \mathrm{~mL}$ ) and deionized water $(4 \mathrm{~mL})$, solid $\mathrm{KF}(17.3 \mathrm{mg}, 298 \mu \mathrm{mol}, 5.0$ equiv) was added. The resulting mixture was stirred at $\mathrm{RT}$ and under argon for $3 \mathrm{~h}$. Then, aq. saturated $\mathrm{NH}_{4} \mathrm{Cl}(50 \mathrm{~mL})$ was added and the desired product was extracted thrice with $\mathrm{CH}_{2} \mathrm{Cl}_{2}$. The combined organic layers were washed with brine, dried over anhydrous $\mathrm{Na}_{2} \mathrm{SO}_{4}$, filtered and finally evaporated to dryness. The resulting crude product was purified over Bio-Beads ${ }^{\circledR}$ S-X3 stationary phase and using THF as eluent. Ethynyl-functionalized thienyl-DPP 1 was obtained as a dark pink solid $(29.5 \mathrm{mg}, 54 \mu \mathrm{mol}$, yield $90 \%) . \mathrm{R}_{\mathrm{f}}=0.38\left(\mathrm{CH}_{2} \mathrm{Cl}_{2} /\right.$ heptane $\left.7: 3, \mathrm{v} / \mathrm{v}\right) ;{ }^{1} \mathrm{H} \mathrm{NMR}\left(300 \mathrm{MHz}, \mathrm{CDCl}_{3}\right): \delta 8.92\left(\mathrm{dd},{ }^{3} J=\right.$ $\left.4.1 \mathrm{~Hz},{ }^{4} J=1.2 \mathrm{~Hz}, 1 \mathrm{H}\right), 8.79\left(\mathrm{~d},{ }^{3} J=4.1 \mathrm{~Hz}, 1 \mathrm{H}\right), 7.65\left(\mathrm{dd},{ }^{3} J=5.0 \mathrm{~Hz},{ }^{4} J=1.2 \mathrm{~Hz}, 1 \mathrm{H}\right), 7.38(\mathrm{~d}$, $\left.{ }^{3} J=4.1 \mathrm{~Hz}, 1 \mathrm{H}\right), 7.30-7.27(\mathrm{~m}, 1 \mathrm{H}), 4.01(\mathrm{~m}, 4 \mathrm{H}), 3.58(\mathrm{~s}, 1 \mathrm{H}), 1.85(\mathrm{~m}, 2 \mathrm{H}), 1.46-1.10(\mathrm{~m}, 16 \mathrm{H})$, $0.87(\mathrm{~m}, 12 \mathrm{H})$. Other spectroscopic data are identical to those reported by $\mathrm{Yu}$ et al.[58]

\subsubsection{Unsymmetrical phenyl-DPP N,N'-TEG (3)}

To a suspension of unsymmetrical phenyl-DPP pigment 2[59] (703 mg, $1.91 \mathrm{mmol}, 1.0$ equiv), tetrabutylammonium chloride (TBACl, $27.0 \mathrm{mg}, 97.0 \mu \mathrm{mol}, 0.05$ equiv) and $\mathrm{K}_{2} \mathrm{CO}_{3}(1.45 \mathrm{~g}, 10.5$ mmol, 5.5 equiv) in DMF (15.5 mL), 1-chloro-2-(2-(2-methoxyethoxy)ethoxy)ethane[62] (3.50 g, $19.1 \mathrm{mmol}, 10.0$ equiv) was added dropwise, at $120^{\circ} \mathrm{C}$ and under argon. The resulting reaction mixture was heated at $120^{\circ} \mathrm{C}$ overnight. Thereafter, deionized water $(21 \mathrm{~mL})$ was added and the solution was filtered over a dicalite 4158 pad and washed with $\mathrm{CHCl}_{3}$ until the filtrate was not fluorescent anymore. The aqueous layer was extracted four times with $\mathrm{CHCl}_{3}$. The combined organic layers were washed with deionized water twice, dried over anhydrous $\mathrm{MgSO}_{4}$, filtered and finally evaporated to dryness. The product was recrystallized in EtOH and was obtained as an orange solid (370 mg, $0.56 \mathrm{mmol}$, yield 29\%). $\mathrm{R}_{\mathrm{f}}=0.62\left(\mathrm{CH}_{2} \mathrm{Cl}_{2} /\right.$ acetone $\left.8: 2, \mathrm{v} / \mathrm{v}\right)$; IR (ATR): $v$ 3060, $2872\left(\mathrm{CH}_{2}, \mathrm{CH}_{3}\right), 1670(\mathrm{C}=\mathrm{O}), 1605,1593,1559,1489,1446,1424,1405,1382,1350,1294$, 1263, 1350, 1294, 1263, 1201, 1149, 1104, 1087 (C-O-C), 1067, 1056, 1016, 919, 838, 778, 763, 743, 732, 712, 688, 644; ${ }^{1} \mathrm{H}$ NMR (500 MHz, $\left.\mathrm{CDCl}_{3}\right): \delta 7.97(\mathrm{~m}, 2 \mathrm{H}), 7.94\left(\mathrm{~d},{ }^{3} J=8.5 \mathrm{~Hz}, 2 \mathrm{H}\right)$, $7.67\left(\mathrm{~d},{ }^{3} J=8.5 \mathrm{~Hz}, 2 \mathrm{H}\right), 7.52(\mathrm{~m}, 3 \mathrm{H}), 3.94\left(\mathrm{t},{ }^{3} J=5.5 \mathrm{~Hz}, 2 \mathrm{H}\right), 3.90\left(\mathrm{t},{ }^{3} J=5.5 \mathrm{~Hz}, 2 \mathrm{H}\right), 3.74$ (m, 4H), 3.60-3.54 (m, 12H), $3.50(\mathrm{~m}, 4 \mathrm{H}), 3.36(\mathrm{~s}, 3 \mathrm{H}), 3.34(\mathrm{~s}, 3 \mathrm{H}) ;{ }^{13} \mathrm{C} \mathrm{NMR}\left(126 \mathrm{MHz}, \mathrm{CDCl}_{3}\right)$ : 


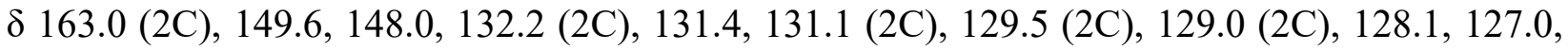
125.9, 109.9, 109.7, 72.1 (2C), 70.7 (6C), 69.1, 69.0, 59.2 (2C), 42.5, 42.2; LRMS (ESI, positive mode): $m / z=659.2[\mathrm{M}+\mathrm{H}]^{+}$and $681.2[\mathrm{M}+\mathrm{Na}]^{+}$, calcd for $\mathrm{C}_{32} \mathrm{H}_{40} \mathrm{BrN}_{2} \mathrm{O}_{8}{ }^{+} 659.2$.

\subsubsection{TMS-ethynyl-functionalized phenyl-DPP N,N'-TEG (4)}

To a solution of para-bromoaryl DPP derivative 3 ( $250 \mathrm{mg}, 0.38 \mathrm{mmol}, 1.0$ equiv), $\mathrm{Pd}_{2}\left(\mathrm{dba}_{3}\right.$ (104 mg, $0.11 \mathrm{mmol}, 0.3$ equiv) and $\mathrm{AsPh}_{3}(290 \mathrm{mg}, 0.95 \mathrm{mmol}, 2.5$ equiv) in dry THF (50 mL) and kept under argon, dry TEA $(12.5 \mathrm{~mL})$ was added. The mixture was heated at $60{ }^{\circ} \mathrm{C}$ and trimethylsilylacetylene ( $214 \mu \mathrm{L}, 1.52 \mathrm{mmol}, 4.0$ equiv) was added. The resulting reaction mixture was kept at $60{ }^{\circ} \mathrm{C}$ overnight. According to TLC $\left(\mathrm{CH}_{2} \mathrm{Cl}_{2} /\right.$ acetone $\left.8: 2, \mathrm{v} / \mathrm{v}, \mathrm{R}_{\mathrm{f}}=0.74\right)$, the reaction was found to be not complete. Further equivalents of trimethylsilylacetylene (ca. 100 equiv) and $\mathrm{Pd}_{2}(\mathrm{dba})_{3}$ (1.0 equiv) were added until the reaction was completed. Thereafter, $\mathrm{CH}_{2} \mathrm{Cl}_{2}$ and deionized water were added. The organic layer was collected and the aqueous layer was extracted thrice with $\mathrm{CH}_{2} \mathrm{Cl}_{2}$. The combined organic layers were dried over anhydrous $\mathrm{Na}_{2} \mathrm{SO}_{4}$, filtered and finally evaporated to dryness. The resulting crude product was purified by size-exclusion column chromatography over Bio-Beads ${ }^{\circledR}$ S-X3 stationary phase and using THF as eluent. Compound 4 was obtained as an orange solid (193 mg, $0.29 \mathrm{mmol}$, yield 75\%). IR (ATR): v3062, $2872\left(\mathrm{CH}_{2}\right.$, $\left.\mathrm{CH}_{3}\right), 2154(\mathrm{C} \equiv \mathrm{C}), 1670(\mathrm{C}=\mathrm{O}), 1606,1591,1496,1447,1425,1382,1349,1248\left(\mathrm{Si}_{-} \mathrm{CH}_{3}\right), 1199$, 1088 (C-O-C), 1053, 952, 838 ( $\mathrm{Si}^{\left.-\mathrm{CH}_{3}\right)}$ ) 783, 760, 737, 716, 692, 661, 643, 608; ${ }^{1} \mathrm{H}$ NMR (500 $\left.\mathrm{MHz}, \mathrm{CDCl}_{3}\right): \delta 8.00-7.94(\mathrm{~m}, 4 \mathrm{H}), 7.58\left(\mathrm{~d},{ }^{3} J=8.5 \mathrm{~Hz}, 2 \mathrm{H}\right), 7.51(\mathrm{~m}, 3 \mathrm{H}), 3.93(\mathrm{~m}, 4 \mathrm{H}), 3.73(\mathrm{~m}$, 4H), 3.58-3.53 (m, 12H), 3.49 (m, 4H), 3.35 (s, 3H), 3.34 (s, 3H), $0.26(\mathrm{~s}, 9 \mathrm{H}) ;{ }^{13} \mathrm{C}$ NMR $(126$ $\left.\mathrm{MHz}, \mathrm{CDCl}_{3}\right): \delta 163.0$ (2C), 149.5, 148.2, 132.3 (2C), 131.3, 129.5 (2C), 129.3 (2C), 128.9 (2C), 128.1, 127.9, 126.1, 110.1, 109.8, 104.6, 97.5, 72.1 (2C), 70.7 (6C), 69.1, 69.0, 59.1 (2C), 42.4, 42.2, 0.0 (3C); LRMS (ESI, positive mode): $m / z=677.4[\mathrm{M}+\mathrm{H}]^{+}$and $699.4[\mathrm{M}+\mathrm{Na}]^{+}$, calcd for $\mathrm{C}_{37} \mathrm{H}_{49} \mathrm{~N}_{2} \mathrm{O}_{8} \mathrm{Si}^{+} 677.3$.

\subsubsection{Ethynyl-functionalized phenyl-DPP N,N'-TEG (5)}

To a solution of TMS-ethynyl derivative 4 (50 mg, $74.0 \mu \mathrm{mol}, 1.0$ equiv) in acetone ( $4 \mathrm{~mL})$ and deionized water $(1 \mathrm{~mL})$, solid CsF (112 mg, $740 \mu \mathrm{mol}, 10.0$ equiv) was added. The resulting reaction mixture was stirred at RT for $48 \mathrm{~h}$. Then, deionized water $(100 \mathrm{~mL})$ was added and the desired product was extracted thrice with $\mathrm{CH}_{2} \mathrm{Cl}_{2}$. The combined organic layers were dried over 
anhydrous $\mathrm{Na}_{2} \mathrm{SO}_{4}$, filtered and finally evaporated to dryness. The resulting crude product was purified over Bio-Beads ${ }^{\circledR} \mathrm{S}-\mathrm{X} 3$ stationary phase and using $\mathrm{CHCl}_{3}$ as eluent. Ethynyl-functionalized phenyl-DPP derivative 5 was obtained as an orange solid (44 mg, $73 \mu$ mol, yield $98 \%$ ). $R_{f}=0.61$ $\left(\mathrm{CH}_{2} \mathrm{Cl}_{2} /\right.$ acetone $\left.8: 2, \mathrm{v} / \mathrm{v}\right)$; IR (ATR): v3235 (C $\left.\equiv C-H\right), 3060,2922\left(\mathrm{CH}_{2}, \mathrm{CH}_{3}\right), 2872\left(\mathrm{CH}_{2}, \mathrm{CH}_{3}\right)$, $1670(\mathrm{C}=\mathrm{O}), 1607,1592,1574,1555,1490,1447,1427,1383,1351,1294,1269,1200,1086$ (CO-C), $1056,1019,923,843,783,756,737,714,690,647 ;{ }^{1} \mathrm{H}$ NMR (500 MHz, $\left.\mathrm{CDCl}_{3}\right): \delta 8.00$ (d, $\left.{ }^{3} J=8.5 \mathrm{~Hz}, 2 \mathrm{H}\right), 7.97(\mathrm{~m}, 2 \mathrm{H}), 7.62\left(\mathrm{~d},{ }^{3} J=8.5 \mathrm{~Hz}, 2 \mathrm{H}\right), 7.52(\mathrm{~m}, 3 \mathrm{H}), 3.93(\mathrm{~m}, 4 \mathrm{H}), 3.74(\mathrm{~m}, 4 \mathrm{H})$, 3.60-3.52 (m, 12H), $3.49(\mathrm{~m}, 4 \mathrm{H}), 3.35(\mathrm{~s}, 3 \mathrm{H}), 3.34(\mathrm{~s}, 3 \mathrm{H}), 3.22(\mathrm{~s}, 1 \mathrm{H}) ;{ }^{13} \mathrm{C}$ NMR (126 MHz, $\left.\mathrm{CDCl}_{3}\right): \delta 163.0$ (2C), 149.7, 148.0, 132.5 (2C), 131.4, 129.5 (2C), 129.4 (2C), 128.9 (2C), 128.3, 128.0, 124.9, 110.2, 109.7, 83.3, 79.8, 72.0 (2C), 70.7 (5C), 69.0, 68.9, 59.1 (2C), 42.4, 42.2, 29.8; LRMS (ESI, positive mode): $m / z=605.3[\mathrm{M}+\mathrm{H}]^{+}$and $627.3[\mathrm{M}+\mathrm{Na}]^{+}$, calcd for $\mathrm{C}_{34} \mathrm{H}_{41} \mathrm{~N}_{2} \mathrm{O}_{8}{ }^{+}$ 605.3 .

\subsubsection{Pinacol boronate-functionalized phenyl-DPP $N, N^{\prime}-T E G(6)$}

To a solution of para-bromoaryl DPP derivative 3 (50 mg, $76 \mu$ mol, 1.0 equiv), $\mathrm{PdCl}_{2}\left(\mathrm{PPh}_{3}\right)_{2}$ ( $8 \mathrm{mg}, 11.4 \mu \mathrm{mol}, 0.15$ equiv) and KOAc (30 mg, $304 \mu \mathrm{mol}, 4.0$ equiv) in 1,4-dioxane ( $5 \mathrm{~mL}$ ), bis(pinacolato)diboron ( $29 \mathrm{mg}, 114 \mu \mathrm{mol}, 1.5$ equiv) was added. The mixture was refluxed under argon for $4 \mathrm{~h}$. Thereafter, deionized water $(20 \mathrm{~mL})$ was added and the solution was filtered over a dicalite 4158 pad and washed with $\mathrm{CH}_{2} \mathrm{Cl}_{2}$ until the filtrate was not fluorescent anymore. The aqueous layer was extracted thrice with $\mathrm{CH}_{2} \mathrm{Cl}_{2}$. The combined organic layers were washed with brine, dried over anhydrous $\mathrm{Na}_{2} \mathrm{SO}_{4}$, filtered and finally evaporated to dryness. The resulting crude product was purified by size-exclusion column chromatography over Bio-Beads ${ }^{\circledR} \mathrm{S}-\mathrm{X} 3$ stationary phase and using $\mathrm{CHCl}_{3}$ as eluent. Pinacol boronate-functionalized phenyl-DPP derivative 6 was obtained as an orange solid (49 mg, $69.3 \mu \mathrm{mol}$, yield $92 \%)$. $\mathrm{R}_{\mathrm{f}}=0.62\left(\mathrm{CH}_{2} \mathrm{Cl}_{2} /\right.$ acetone $\left.8: 2, \mathrm{v} / \mathrm{v}\right)$; IR (ATR): $v 2870\left(\mathrm{CH}_{2}, \mathrm{CH}_{3}\right), 1673(\mathrm{C}=\mathrm{O}), 1605,1592,1492,1448,1356$ (B-C), 1272, 1198, 1140, 1085 (C-O-C), 1019, 962, 929, 855, 786, 768, 752, 731, 696, 655; ${ }^{1} \mathrm{H}$ NMR (500 MHz, $\left.\mathrm{CHCl}_{3}\right): \delta$ 7.99-7.89 (m, 6H), 7.54-7.48 (m, 3H), $3.94(\mathrm{~m}, 4 \mathrm{H}), 3.72\left(\mathrm{t},{ }^{3} \mathrm{~J}=5.7 \mathrm{~Hz}, 2 \mathrm{H}\right), 3.70\left(\mathrm{t},{ }^{3} \mathrm{~J}\right.$ $=5.7 \mathrm{~Hz}, 2 \mathrm{H}), 3.58-3.52(\mathrm{~m}, 12 \mathrm{H}), 3.49(\mathrm{~m}, 4 \mathrm{H}), 3.35(\mathrm{~s}, 3 \mathrm{H}), 3.34(\mathrm{~s}, 3 \mathrm{H}), 1.36(\mathrm{~s}, 12 \mathrm{H}) ;{ }^{13} \mathrm{C}$ NMR (126 MHz, $\left.\mathrm{CDCl}_{3}\right): \delta 162.9$ (2C), 149.4, 148.8, 135.1 (2C), 131.2, 130.5, 129.4 (2C), 128.8 (2C), 128.3 (2C), 128.1, 110.0, 109.7, 84.1 (2C), 72.0 (2C), 70.6 (6C), 68.9 (2C), 59.1 (2C), 42.0 
(2C), 24.9 (4C); LRMS (ESI, positive mode): $m / z=707.4[\mathrm{M}+\mathrm{H}]^{+}$and $729.4[\mathrm{M}+\mathrm{Na}]^{+}$, calcd for $\mathrm{C}_{38} \mathrm{H}_{52} \mathrm{BN}_{2} \mathrm{O}_{10}{ }^{+}$707.4.

\subsubsection{Symmetrical phenyl-DPP N,N'-TEG (7)}

To a suspension of 3,6-diphenyl-DPP pigment[60] (100 mg, $0.35 \mathrm{mmol}, 1.0$ equiv), TBACl (5.0 $\mathrm{mg}, 17.3 \mu \mathrm{mol}, 0.05$ equiv) and $\mathrm{K}_{2} \mathrm{CO}_{3}$ (264 mg, $1.91 \mathrm{mmol}$, 5.5 equiv) in $\mathrm{DMF}$ ( $5 \mathrm{~mL}$ ), 1-chloro2-(2-(2-methoxyethoxy)ethoxy)ethane[60] (633 mg, $3.47 \mathrm{mmol}, 10.0$ equiv) was added dropwise, at $120{ }^{\circ} \mathrm{C}$ and under argon. The resulting reaction mixture was heated at $120{ }^{\circ} \mathrm{C}$ overnight. Thereafter, deionized water $(10 \mathrm{~mL})$ was added and the solution was filtered over a dicalite 4158 pad and washed with $\mathrm{CH}_{2} \mathrm{Cl}_{2}$ until the filtrate was not fluorescent anymore. The aqueous layer was extracted with $\mathrm{CH}_{2} \mathrm{Cl}_{2}$ twice. The combined organic layers were washed with brine, dried over anhydrous $\mathrm{Na}_{2} \mathrm{SO}_{4}$, filtered and finally evaporated to dryness. The product was purified by silica gel column chromatography using a step gradient of acetone in $\mathrm{CH}_{2} \mathrm{Cl}_{2}$ as eluent (from $0 \%$ to $20 \%$ ). Compound 7 was obtained as an orange solid $(27 \mathrm{mg}, 46.5 \mu$ mol, yield $13 \%)$. $\mathrm{R}_{\mathrm{f}}=0.59$ $\left(\mathrm{CH}_{2} \mathrm{Cl}_{2} /\right.$ acetone $\left.8: 2, \mathrm{v} / \mathrm{v}\right)$; IR (ATR): v 3057, 2966, 2912, 2868, $2804\left(\mathrm{CH}_{2}, \mathrm{CH}_{3}\right), 1667(\mathrm{C}=\mathrm{O})$, 1606, 1592, 1567, 1498, 1473, 1446, 1385, 1369, 1359, 1324, 1304, 1271, 1242, 1197, 1158, 1134 , 1089 (C-O-C), 1036, 1021, 1001, 984, 927, 892, 863, 851, 840, 792, 764, 743, 722, 690, 637; ${ }^{1} \mathrm{H}$ NMR (500 MHz, $\left.\mathrm{CHCl}_{3}\right): \delta$ 7.98-7.93 (m, 4H), 7.53-7.48 (m, 6H), $3.93\left(\mathrm{t},{ }^{3} J=5.7 \mathrm{~Hz}, 4 \mathrm{H}\right), 3.72$ $\left(\mathrm{t},{ }^{3} \mathrm{~J}=5.7 \mathrm{~Hz}, 4 \mathrm{H}\right), 3.57-3.53(\mathrm{~m}, 12 \mathrm{H}), 3.49-3.46(\mathrm{~m}, 4 \mathrm{H}), 3.33(\mathrm{~s}, 6 \mathrm{H}) ;{ }^{13} \mathrm{C} \mathrm{NMR}(126 \mathrm{MHz}$, $\left.\mathrm{CDCl}_{3}\right) \delta 163.0(2 \mathrm{C}), 149.1(2 \mathrm{C}), 131.2(2 \mathrm{C}), 129.4(4 \mathrm{C}), 128.9$ (4C), $128.2(2 \mathrm{C}), 109.7(2 \mathrm{C}), 72.0$ (2C), 70.7 (6C), 68.9 (2C), 59.1 (2C), 42.1 (2C); LRMS (ESI, positive mode): $\mathrm{m} / \mathrm{z}=581.3[\mathrm{M}+$ $\mathrm{H}]^{+}$and $603.3[\mathrm{M}+\mathrm{Na}]^{+}$, calcd for $\mathrm{C}_{32} \mathrm{H}_{41} \mathrm{~N}_{2} \mathrm{O}_{8}{ }^{+}$581.3.

\subsection{Synthesis of BC-DPP energy transfer triads}

\subsubsection{Synthesis of $\boldsymbol{B C}-\mathbf{D P P}-1$}

3,13-Dibromo-5-methoxy-8,8,18,18-tetramethylbacteriochlorin diBr-BC[57] (10 mg, 18.3 $\mu \mathrm{mol}, 1.0$ equiv), $\mathrm{Pd}_{2}(\mathrm{dba})_{3}\left(10 \mathrm{mg}, 11.0 \mu \mathrm{mol}, 0.6\right.$ equiv) and $\mathrm{AsPh}_{3}(28 \mathrm{mg}, 91.3 \mu \mathrm{mol}, 5.0$ equiv) were placed in a $25 \mathrm{~mL}$ two-neck round-bottom flask and three vacuum-argon cycles were performed. Dry THF $(4 \mathrm{~mL})$ and TEA $(4 \mathrm{~mL})$ were sequentially added and the mixture was heated at $60{ }^{\circ} \mathrm{C}$. Then, a solution of ethynyl-functionalized thienyl DPP 1 (24 mg, $44 \mu \mathrm{mol}, 2.4$ equiv) in 
dry THF ( $4 \mathrm{~mL}$ ) was added dropwise over $1 \mathrm{~h}$. The resulting reaction mixture was stirred at $60{ }^{\circ} \mathrm{C}$ and under argon overnight. The solution was cooled to RT and aq. saturated $\mathrm{NH}_{4} \mathrm{Cl}$ was added. The desired product was extracted thrice with $\mathrm{CH}_{2} \mathrm{Cl}_{2}$. The combined organic layers were dried over anhydrous $\mathrm{Na}_{2} \mathrm{SO}_{4}$, filtered over a dicalite 4158 pad and the filtrate was evaporated to dryness. The resulting crude residue was purified by size-exclusion column chromatography over BioBeads ${ }^{\circledR} \mathrm{S}-\mathrm{X} 3$ stationary phase and using THF as eluent. The product was washed with $\mathrm{MeOH}$ to remove 2,6-di-tert-butyl-4-methylphenol (BHT, stabilizer in THF). Bacteriochlorin-DPP hybrid BC-DPP-1 was obtained as a dark-purple solid (10.6 mg, $7.1 \mu \mathrm{mol}$, yield 39\%). ${ }^{1} \mathrm{H}$ NMR (500 $\left.\mathrm{MHz}, \mathrm{CDCl}_{3}\right): \delta 9.10\left(\mathrm{~d},{ }^{3} J=4.0 \mathrm{~Hz}, 1 \mathrm{H}\right), 9.03\left(\mathrm{~d},{ }^{3} J=4.0 \mathrm{~Hz}, 1 \mathrm{H}\right), 8.95\left(\mathrm{dd},{ }^{3} J=4.0 \mathrm{~Hz},{ }^{4} J=1.2\right.$ $\mathrm{Hz}, 2 \mathrm{H}), 8.85(\mathrm{~s}, 1 \mathrm{H}), 8.81\left(\mathrm{~d},{ }^{4} \mathrm{~J}=2.2 \mathrm{~Hz}, 1 \mathrm{H}\right), 8.78\left(\mathrm{~d},{ }^{4} \mathrm{~J}=2.2 \mathrm{~Hz}, 1 \mathrm{H}\right), 8.55(\mathrm{~s}, 1 \mathrm{H}), 8.53(\mathrm{~s}$, 1H), $7.70\left(\mathrm{~d},{ }^{3} \mathrm{~J}=4.0 \mathrm{~Hz}, 1 \mathrm{H}\right), 7.66(\mathrm{~m}, 3 \mathrm{H}), 7.30(\mathrm{~m}, 2 \mathrm{H}), 4.49(\mathrm{~s}, 3 \mathrm{H}), 4.43(\mathrm{~s}, 4 \mathrm{H}), 4.11(\mathrm{~m}, 8 \mathrm{H})$, 2.11-2.00 (m, 4H), $1.96(2 \mathrm{~s}, 12 \mathrm{H}), 1.50-1.34(\mathrm{~m}, 32 \mathrm{H}), 0.96-0.87(\mathrm{~m}, 24 \mathrm{H}),-1.35(\mathrm{~s}, 1 \mathrm{H}),-1.55(\mathrm{~s}$, $1 \mathrm{H}) ;{ }^{13} \mathrm{C} \mathrm{NMR}\left(126 \mathrm{MHz}, \mathrm{CDCl}_{3}\right)$ : quantity isolated was too small for vizualization of all carbon peaks, despite of extended acquisition time on a $500 \mathrm{MHz}$ spectrometer equipped with a BBI probe (four times more sensitive in carbon than a standard $300 \mathrm{MHz}$ spectrometer); LRMS (MALDITOF, positive mode): $\mathrm{m} / z=1492.5[\mathrm{M}]^{+\bullet}$, calcd for $\mathrm{C}_{89} \mathrm{H}_{104} \mathrm{~N}_{8} \mathrm{O}_{5} \mathrm{~S}_{4} 1492.7$; HRMS (MALDI-TOF, positive mode): $m / z=1492.7085$ [M] $]^{+*}$, calcd for $\mathrm{C}_{89} \mathrm{H}_{104} \mathrm{~N}_{8} \mathrm{O}_{5} \mathrm{~S}_{4}$ 1492.7007; LRMS (ESI, positive mode, cone voltage $200 \mathrm{~V}): \mathrm{m} / z=1492.9$ (55), 1493.9 (100), 1496.0 (50) and 1497.0 (30) [M] ${ }^{+\bullet}$, calcd for $\mathrm{C}_{89} \mathrm{H}_{104} \mathrm{~N}_{8} \mathrm{O}_{5} \mathrm{~S}_{4} 1492.7$.

\subsubsection{Synthesis of $\boldsymbol{B C}$-DPP-2}

BC-DPP-2 was synthesized following the same procedure as described for BC-DPP-1 except that the product was washed with pentane to remove BHT. Ethynyl-functionalized phenyl-DPP $N, N^{\prime}$-TEG 5 was used as starting material. Bacteriochlorin-DPP hybrid BC-DPP-2 was obtained as a dark-red solid ( $3 \mathrm{mg}, 1.9 \mu \mathrm{mol}$, yield $10 \%$ ). ${ }^{1} \mathrm{H}$ NMR (500 MHz, $\mathrm{CDCl}_{3}$ ): $\delta 8.91$ (s, 1H), 8.82 $\left(\mathrm{d},{ }^{4} J=2.2 \mathrm{~Hz}, 1 \mathrm{H}\right), 8.81\left(\mathrm{~d},{ }^{4} J=2.2 \mathrm{~Hz}, 1 \mathrm{H}\right), 8.56(\mathrm{~s}, 1 \mathrm{H}), 8.54(\mathrm{~s}, 1 \mathrm{H}), 8.21(\mathrm{~m}, 4 \mathrm{H}), 8.03-8.00$ (m, 8H), 7.55 (m, 6H), 4.51 (s, 3H), $4.44(\mathrm{~m}, 4 \mathrm{H}), 4.07-3.99(\mathrm{~m}, 8 \mathrm{H}), 3.84(\mathrm{~m}, 4 \mathrm{H}), 3.79(\mathrm{~m}, 4 \mathrm{H})$, 3.66-3.63 (m, 12H), $3.59(\mathrm{~m}, 8 \mathrm{H}), 3.58-3.55(\mathrm{~m}, 8 \mathrm{H}), 3.53-3.51(\mathrm{~m}, 4 \mathrm{H}), 3.40(2 \mathrm{~s}, 6 \mathrm{H}), 3.37(2 \mathrm{~s}$, $6 \mathrm{H}), 1.97(2 \mathrm{~s}, 12 \mathrm{H}),-1.42(\mathrm{~s}, 1 \mathrm{H}),-1.62(\mathrm{~s}, 1 \mathrm{H}) ;{ }^{13} \mathrm{C} \mathrm{NMR}\left(126 \mathrm{MHz}, \mathrm{CDCl}_{3}\right)$ : quantity isolated was too small for vizualization of all carbon peaks, despite of extended acquisition time on a 500 MHz spectrometer equipped with a BBI probe (four times more sensitive in carbon than a standard 
$300 \mathrm{MHz}$ spectrometer); LRMS (MALDI-TOF, positive mode): $\mathrm{m} / z=1604.4[\mathrm{M}]^{+\bullet}$, calcd for $\mathrm{C}_{93} \mathrm{H}_{104} \mathrm{~N}_{8} \mathrm{O}_{17}$ 1604.8; HRMS (MALDI-TOF, positive mode): $m / z=1604.7496$ [M] $^{+\bullet}$, calcd for $\mathrm{C}_{93} \mathrm{H}_{104} \mathrm{~N}_{8} \mathrm{O}_{17}$ 1604.7514; LRMS (ESI, positive mode, cone voltage $200 \mathrm{~V}$ ): $\mathrm{m} / z=1605.9$ (90), 1606.9 (100) and $1608.1(60)[\mathrm{M}+\mathrm{H}]^{+}$, calcd for $\mathrm{C}_{93} \mathrm{H}_{105} \mathrm{~N}_{8} \mathrm{O}_{17}{ }^{+} 1605.8$.

\subsubsection{Synthesis of $\boldsymbol{B C}-\mathbf{D P P}-3$}

diBr-BC (9 mg, $16.5 \mu \mathrm{mol}, 1.0$ equiv), pinacol boronate-functionalized phenyl-DPP 6 (28 mg, $39.5 \mu \mathrm{mol}, 2.4$ equiv), $\mathrm{PdCl}_{2}\left(\mathrm{PPh}_{3}\right)_{2}\left(2.5 \mathrm{mg}, 3.3 \mu \mathrm{mol}, 0.2\right.$ equiv), $\mathrm{PPh}_{3}$ (1.5 mg, $4.9 \mu \mathrm{mol}, 0.3$ equiv) and $\mathrm{K}_{2} \mathrm{CO}_{3}(23 \mathrm{mg}, 165 \mu \mathrm{mol}, 10.0 \mathrm{eq})$ were placed in a $10 \mathrm{~mL}$ two-neck round-bottom flask and three vacuum-argon cycles were performed. Dry toluene $(3 \mathrm{~mL})$ and dry DMF (1.5 mL) and the mixture was heated at $85{ }^{\circ} \mathrm{C}$ overnight. The mixture was then diluted with $\mathrm{CH}_{2} \mathrm{Cl}_{2}$ and deionized water was added. The product was extracted thrice with $\mathrm{CH}_{2} \mathrm{Cl}_{2}$. The combined organic layers were washed twice with brine, dried over anhydrous $\mathrm{Na}_{2} \mathrm{SO}_{4}$, filtered and finally evaporated to dryness. The resulting crude residue was purified by size-exclusion column chromatography over Bio-Beads ${ }^{\circledR}$ S-X3 stationary phase and using THF as eluent. The product was washed with pentane to remove BHT. Bacteriochlorin-DPP hybrid BC-DPP-3 was obtained as a dark-orange solid (2 mg, $1.3 \mu \mathrm{mol}$, yield 8\%). ${ }^{1} \mathrm{H}$ NMR (500 MHz, $\left.\mathrm{CDCl}_{3}\right): \delta 8.87$ (s, 1H), 8.83 (s, 1H), 8.68$8.64(\mathrm{~m}, 2 \mathrm{H}), 8.43\left(\mathrm{~d},{ }^{3} \mathrm{~J}=8.1 \mathrm{~Hz}, 2 \mathrm{H}\right), 8.36\left(\mathrm{~d},{ }^{3} \mathrm{~J}=8.1 \mathrm{~Hz}, 2 \mathrm{H}\right), 8.30\left(\mathrm{~d},{ }^{4} \mathrm{~J}=2.0 \mathrm{~Hz}, 3 \mathrm{H}\right), 8.05$ (m, 4H), 7.59-7.51 (m, 8H), $4.43(\mathrm{~s}, 2 \mathrm{H}), 4.39(\mathrm{~s}, 2 \mathrm{H}), 4.17(\mathrm{~m}, 3 \mathrm{H}), 4.06-4.02(\mathrm{~m}, 4 \mathrm{H}), 3.93\left(\mathrm{t},{ }^{3} J\right.$ $=5.8 \mathrm{~Hz}, 3 \mathrm{H}), 3.89\left(\mathrm{t},{ }^{3} J=5.8 \mathrm{~Hz}, 3 \mathrm{H}\right), 3.83\left(\mathrm{q},{ }^{3} J=5.8 \mathrm{~Hz}, 4 \mathrm{H}\right), 3.71(\mathrm{~s}, 4 \mathrm{H}), 3.68-3.59(\mathrm{~m}, 24 \mathrm{H})$, 3.54-3.48 (m, 12H), 3.37 (s, 6H), $3.28(\mathrm{~s}, 2 \mathrm{H}), 3.25(\mathrm{~s}, 2 \mathrm{H}), 1.99\left(\mathrm{~d},{ }^{3} J=7.0 \mathrm{~Hz}, 8 \mathrm{H}\right),-1.50(\mathrm{~s}, 1 \mathrm{H})$, $-1.75(\mathrm{~s}, 1 \mathrm{H}) ;{ }^{13} \mathrm{C} \mathrm{NMR}\left(126 \mathrm{MHz}, \mathrm{CDCl}_{3}\right)$ : quantity isolated was too small for vizualization of all carbon peaks, despite of extended acquisition time on a $500 \mathrm{MHz}$ spectrometer equipped with a BBI probe (four times more sensitive in carbon than a standard $300 \mathrm{MHz}$ spectrometer); HRMS (MALDI-TOF, positive mode): $m / z=1556.7459$ [M] $]^{+}$, calcd for $\mathrm{C}_{89} \mathrm{H}_{104} \mathrm{~N}_{8} \mathrm{O}_{17}$ 1556.7514; LRMS (ESI, positive mode, cone voltage $200 \mathrm{~V}): m / z=1557.8(40), 1558.9$ (40) and 1560.0 (20) [M + $\mathrm{H}]^{+}$, calcd for $\mathrm{C}_{89} \mathrm{H}_{105} \mathrm{~N}_{8} \mathrm{O}_{17}{ }^{+} 1557.8$.

\section{Results and discussion}

A survey of the literature related to hydroporphyrin-containing dyads clearly shows that the preferred strategy to readily access to these NIR-emissive two-component arrays is often based on 
Pd-catalyzed cross-coupling reactions (typically, Sonogashira or Suzuki-Miyaura-type reactions)[53,55,63-65], even if other methods such as amide coupling and oxidative dimerization have been occasionally implemented[52,66,67]. This has been particularly useful in diversifying structure of the bridging unit between the two chromophores, and thus altering the electronic and photophysical properties of the resulting dyad. Since these coupling chemistries are versatile, reliable and well-mastered, synthetic difficulties are often associated only with the preparation of selected monomeric photoactive building blocks to covalently link together and/or the purification of the resulting hydroporphyrin-based conjugates. The availability of a set of orthogonal reactive functional groups within the core structure of coupling partners, required for both synthesis and fine-tuning the properties of these multi-chromophore systems, is a prerequisite, easier to achieve with small molecule fluorophores structurally simpler than (bacterio)chlorins. In this context, we opted for 3,6-diaryl-substituted DPP derivatives as fluorescent organic dyes spectrally compatible with bacteriochlorins and easily derivatizable platform molecules for rapid and effective postsynthetic functionalization of the targeted hybrid NIR fluorophores. This choice was supported by the recent and valuable advances in the chemistry of DPP-based fluorescent probes for applications in analyte sensing and molecular imaging[49,50]. Indeed, they highlight effective and easily implementable synthetic methodologies for the site-specific introduction of various chemical moieties including reporters, water-solubilizing groups and targeting ligands onto the DPP scaffold. Furthermore, it is well established that the simple replacement of 3,6-phenyl substituents by aromatic five-membered ring heteroayl groups (typically, furyl or thienyl) leads to significant and desirable changes in their optical properties (e.g., bathochromic shift of absorption/emission maxima, stronger charge transfer and larger two-photon absorption cross-sections). For the synthesis of first BC-DPP conjugates, assumed as model compounds to obtain a proof-of-concept for this novel class of hybrid NIR fluorophores, we have chosen to work with 3,6-diphenyl- and 3,6-dithienyl-substituted DPP dyes. Further introduction of branched alkyl (i.e., 2-ethylhexyl groups) or oligoethylene glycol side-chains attached onto the $N$-positions of their lactam moieties was also planned in order to enhance the solubility of the DPP-based coupling partners in a wide range of organic solvents (Fig. 2). Interestingly, in the field of DPP-based conjugated polymers for bulk heterojunction solar cells, solubilizing chains play a critical role on the efficiency of the material. In particular, the 2-ethylhexyl group was found well-adapted as short bulky branched 
chain to form films with suitable morphology leading to higher carrier mobility, and the synthesis of DPP derivative 1 has already been regarded in this context, especially by us[68,69].

Synthetic routes devised for preparing the 3,6-diphenyl-DPP dyes and installing the reactive functional group required for their covalent conjugation to 3,13-dibromo-5-methoxy-8,8,18,18tetramethylbacteriochlorin[57] diBr-BC (i.e., terminal alkyne for Sonogashira-type coupling and pinacol boronate ester for Suzuki-Miyaura reaction)[70] are first discussed. Emphasis is next placed on the optimization of both Pd-catalyzed cross-coupling reactions between these "ready-touse" functionalized DPP derivatives and diBr-BC and purification protocols of the hybrid fluorophores obtained. Finally, fluorescence behavior of BC-DPP triads in solution, especially in the NIR range, is studied in details.

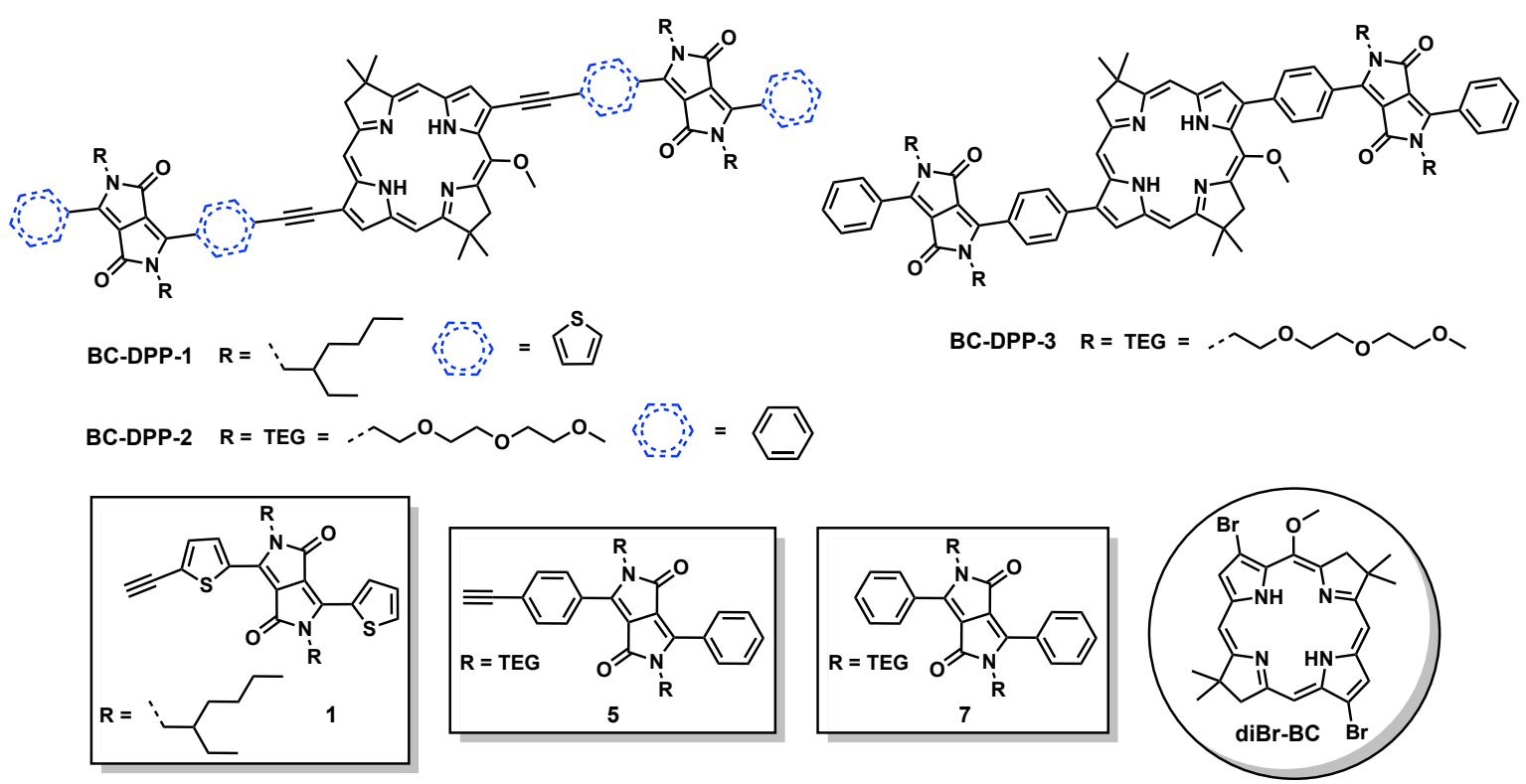

Fig. 2. Structures of DPP dyes and BC-DPP triads studied in this work.

\subsection{Synthesis of "ready-to-use" functionalized DPP derivatives}

The synthetic routes used to prepare the 3,6-diphenyl-DPP derivatives functionalized either with a pinacol boronate ester or a terminal alkyne are depicted in Scheme 1. The common starting unsymmetrical DPP pigment 2 was prepared according to literature procedures.[59] $\mathrm{N}$-Alkylation of its lactam moieties was performed using an excess of 1-chloro-2-(2-(2methoxyethoxy)ethoxy)ethane and under phase-transfer conditions to give organic-soluble DPP dye 3 in modest 29\% yield. Short oligo(ethyleneglycol) moieties (abbreviated here TEG) were 
chosen as $\mathrm{N}$-substituents to partially counterbalance the assumed great hydrophobicity of BC-DPP conjugates and thus considering spectral and photophysical measurements in solution conditions that limit or prevent aggregate formation. Copper-free Sonogashira cross-coupling reaction (also known as Heck alkynylation) between $\mathbf{3}$ and trimethylsilylacetylene provided the compound $\mathbf{4}$ in good $75 \%$ yield. In our optimizations of this Pd-catalyzed alkynylation, very sensitive precatalysts and ligands were avoided, the objective being to develop very simple, reliable and robust conditions. Therefore, we have chosen to use the air-stable $\operatorname{Pd}_{2}(\mathrm{dba})_{3}$ with triphenylarsine as a dative ligand[71]. $\mathrm{AsPh}_{3}$ is a relatively inexpensive ligand that is easy to handle, and stable in air. It is also important to specify that all our attempts to purify TMS-protected alkyne 4 by conventional column chromatography over regular silica gel failed. Conversely, we found that the use of a styrene-divinylbenzene gel with a pore size of $50 \AA$ and an exclusion limit of $2000 \mathrm{Da}$ (Bio-Beads ${ }^{\circledR}$ S-X3), was particularly effective to recover this functionalized-DPP in a pure form, through size-exclusion chromatography process. Final step toward ethynyl-functionalized phenylDPP dye 5 involved the deprotection of TMS group. Once again, optimization of the reaction conditions was required because the use of conventional source of fluoride anions (i.e., TBAF) led to degradation of the functionalized DPP dye. Furthermore, alkaline deprotection with $\mathrm{K}_{2} \mathrm{CO}_{3}$ was found to be relatively ineffective because a major amount of starting compound was recovered after $12 \mathrm{~h}$ of reaction. Finally, the use of cesium fluoride $(\mathrm{CsF})$ in an acetone- $\mathrm{H}_{2} \mathrm{O}$ mixture led to quantitative removal of the TMS group[72] and the resulting terminal alkyne was easily purified by size-exclusion chromatography. 


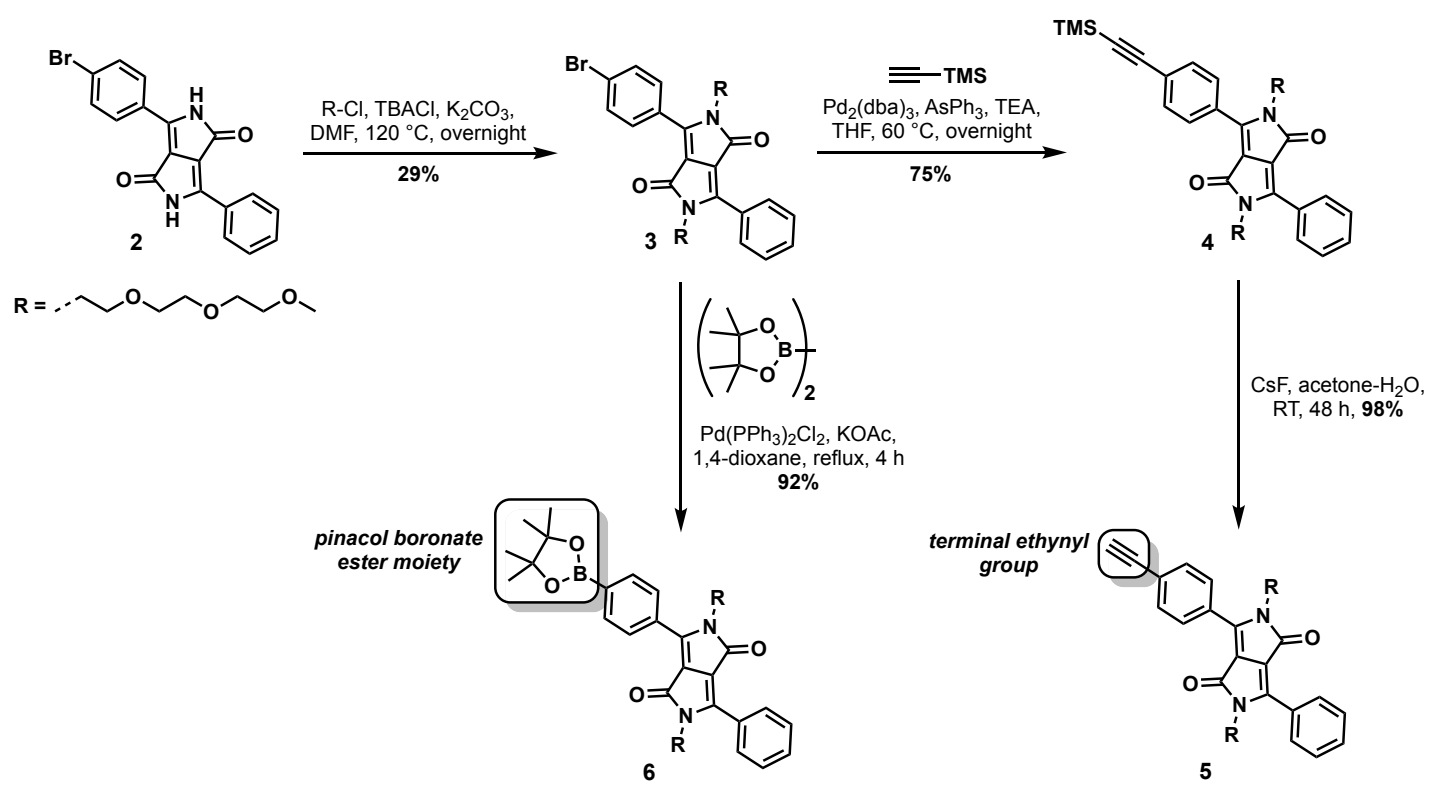

Scheme 1. Synthetic routes toward "ready-to-use" functionalized DPP derivatives 5 and $\mathbf{6}$.

The synthetic access to functionalized DPP $\mathbf{6}$ was facilitated by the availability of unsymmetrical DPP dye 3 whose the para-bromophenyl substituent can be readily converted into the corresponding phenyl-boronic acid pinacol ester through a Suzuki-Miyaura cross-coupling reaction with bis(pinacolato)diboron in the presence of catalytic amounts of $\mathrm{PdCl}_{2}\left(\mathrm{PPh}_{3}\right)_{2}$ and potassium acetate (KOAc), in refluxing 1,4-dioxane. Once again, purification by size-exclusion chromatography enabled us to readily recover the sophisticated DPP derivative in a pure form and with an excellent $92 \%$ yield.

The structures of all synthesized DPP-based fluorophores were proven by IR, NMR and mass spectra (see ESI for the corresponding spectra, Fig. S1-S21).

\subsection{Synthesis of BC-DPP triads through optimized Pd-catalyzed cross-coupling reactions}

Once the "ready-to-use" functionalized DPP building blocks available, their reaction with the known bromobacteriochlorin diBr-BC[57] was next explored to access targeted BC-DPP triads. We have developed optimized protocols for these cross-coupling procedures[70] and conditions employed to achieve them are detailed in Scheme 2. 

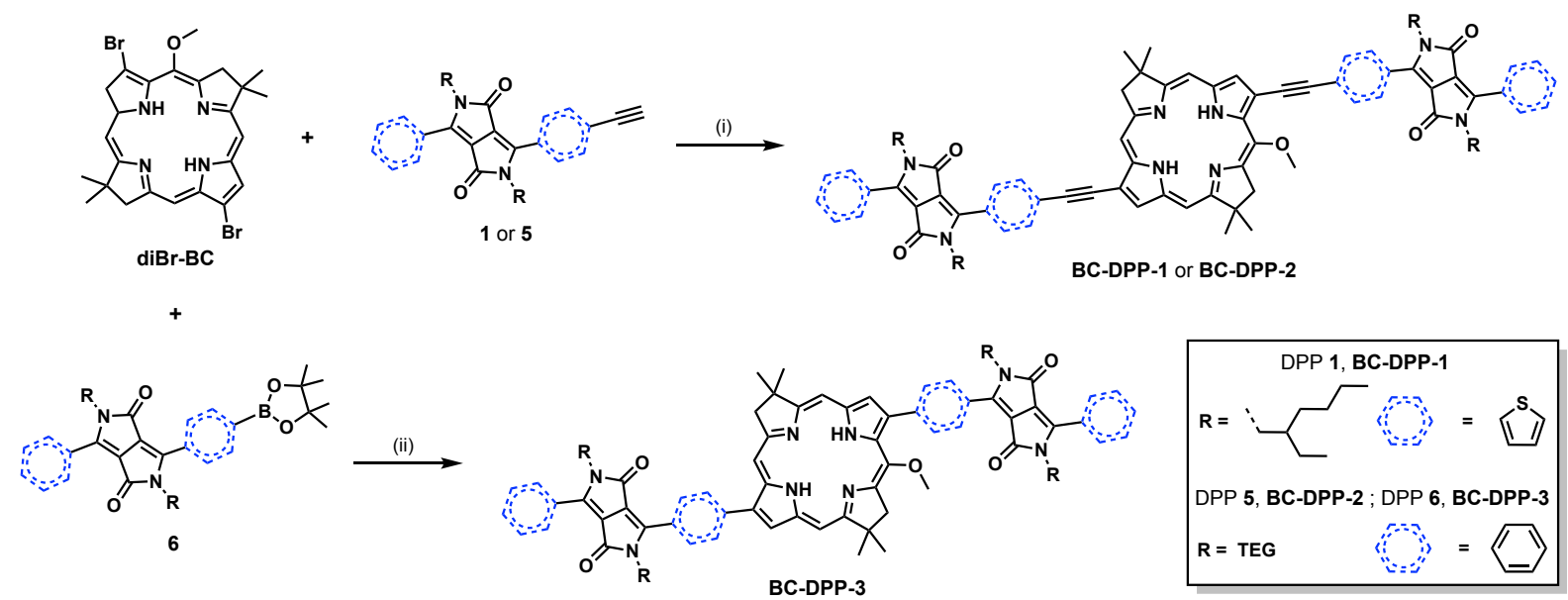

Scheme 2. Synthetic routes toward DPP-BC triads. Reagents and conditions: (i) $\mathrm{Pd}_{2}(\mathrm{dba})_{3}, \mathrm{AsPh}_{3}, \mathrm{TEA}, \mathrm{THF}, 60{ }^{\circ} \mathrm{C}$, Ar atmosphere, overnight, yield 39\% (BC-DPP-1) and 10\% (BC-DPP-2); (ii) $\mathrm{Pd}\left(\mathrm{PPh}_{3}\right)_{2} \mathrm{Cl}_{2}, \mathrm{PPh}_{3}, \mathrm{~K}_{2} \mathrm{CO}_{3}$, toluene$\operatorname{DMF}(1: 1, \mathrm{v} / \mathrm{v}), 85^{\circ} \mathrm{C}$, Ar atmosphere, overnight, yield 8\% (BC-DPP-3).

With ethynyl-functionalized DPP derivatives $\mathbf{1}$ and $\mathbf{5}$ as the starting material, the copper-free Sonogashira cross-coupling reaction with diBr-BC worked properly using $\mathrm{Pd}_{2}(\mathrm{dba})_{3} / \mathrm{AsPh}_{3}$ as catalyst system, in a TEA-THF mixture at $60{ }^{\circ} \mathrm{C}$. However, it is important to point out that the success of this Pd-catalyzed heterocoupling greatly depend on the purity level of diBr-BC that must be isolated with the utmost care. The resulting high-molecular photoactive molecular triads BC-DPP-1 and BC-DPP-2 were readily purified by size-exclusion chromatography, using the same resin as that employed for isolation of functionalized DPP derivatives (vide supra). Moderate to low yields (39\% and 10\% respectively) are partly due material losses inherent to the small scale of syntheses (ca. $20 \mu \mathrm{mol}$ of diBr-BC, the limiting starting material). Gratifyingly, the SuzukiMiyaura cross-coupling between pinacol boronate ester $\mathbf{6}$ and diBr-BC was found to work under standard conditions to afford after purification by size-exclusion chromatography the triad BCDPP-3 in 8\% yield.

The three BC-DPP triads were fully characterized by ${ }^{1} \mathrm{H}$ NMR and low- and high-resolution mass spectrometry (see ESI for the corresponding spectra, Fig. S22-S32). Spectroscopic data were in agreement with the structures assigned. In particular, ${ }^{1} \mathrm{H}$ NMR spectrum of each triad shows a set of proton resonance signals that can be assumed as the overall sum of ${ }^{1} \mathrm{H}$ NMR spectra of its chromophoric units (BC and $2 \times \mathrm{DPP})$, even if some aromatic protons' signals of DPP scaffold spatially close to the bacteriochlorin $\pi$ framework are significantly shifted downfield in comparison with the parent DPP derivative (e.g., doublet assigned to one thienyl proton of $\mathbf{1}$ is shifted from 7.38 to $7.70 \mathrm{ppm}$, doublet assigned to two phenyl protons of $\mathbf{5}$ is shifted from 7.62 to $8.00 \mathrm{ppm}$, 
see ESI for the corresponding NMR spectra, Fig. S1, S11, S22 and S26). Since these polycyclic aromatic molecules are assumed to be poorly ionizable, MALDI was the preferred ionization method for their facile mass analysis (both low- and high-resolution). However, we also explored the feasibility of performing these mass spectometry characterizations by ESI and we found that the tuning of cone voltage parameter $(200 \mathrm{~V}$ instead of $75 \mathrm{~V}$, typical value for the MSQ mass spectrometer currently used by us) allowed to obtain also good-quality mass spectra in the positive mode (see ESI for the corresponding mass spectra, Fig. S25, S29, and S32).

\subsection{Photophysical properties of BC-DPP triads}

The photophysical properties of bacteriochlorin-based triads as well as parent monomeric chromophores were evaluated in weakly polar solvents namely $\mathrm{CHCl}_{3}$ and toluene, with a choice being made according to solubility criteria. Absorption and emission properties are gathered in Tables 1 and 2, and selected examples of spectra of BC-DPP-2 and BC-DPP-3 are available in Fig. 3 (see ESI for the other absorption/excitation/emission spectra, Fig. S33-S52). As expected, the UV-vis absorption spectra are essentially the sum of those of DPP and bacteriochlorin scaffolds as revealed by a set of maxima assigned to $\mathrm{B}$ (in the range $357-375 \mathrm{~nm}$ ), $\mathrm{Q}_{\mathrm{x}}$ (in the range 515-533 $\mathrm{nm}$ ), Q $\mathrm{Q}_{\mathrm{y}}$ (in the range 746-795 $\mathrm{nm}$ ) bands of hydroporphyrin and S0 $\rightarrow \mathrm{S} 1$ band of energy donor (in the range $482-593 \mathrm{~nm}$ ). Effect of both distinct solvents on these electronic absorption spectra is not really significant (Table 2, columns 3 and 4). Interestingly, the simultaneous substitution of 3,13positions of bacteriochlorin macrocycle by ethynyl or phenyl moieties causes a dramatic bathochromic shift of the $\mathrm{Q}_{\mathrm{y}}$ band within the NIR range $(+72 \mathrm{~nm},+45 \mathrm{~nm},+23 \mathrm{~nm}$ for BC-DPP1, BC-DPP-2 and BC-DPP-3 respectively and compared to diBr-BC, $+86 \mathrm{~nm},+59 \mathrm{~nm}$ and +37 $\mathrm{nm}$ compared to $\mathbf{B C}[57])$.

Table 1. Absorption and emission properties of diBr-BC and DPP monomers in selected organic solvents.

\begin{tabular}{cccccc}
\hline \multirow{2}{*}{ Fluorophore } & Solvent & Abs $\lambda_{\max }(\mathrm{nm})$ & $\varepsilon\left(\mathrm{M}^{-1} \mathrm{~cm}^{-1}\right)$ & $\operatorname{Em~} \lambda_{\max }(\mathrm{nm})$ & $\Phi_{\mathrm{F}}(\%)^{\mathrm{a}}$ \\
\hline & & 91700, & \\
& & 85350, & \\
diBr-BC $^{\mathrm{b}}$ & $\mathrm{CHCl}_{3}$ & $350,355,371,505,723$ & $90300, \quad$ non-fluorescent non-fluorescent \\
& & & 29650, & \\
& & 94550
\end{tabular}


82450 ,

81400

diBr-BC toluene $351,358,371,506,723 \quad 86300$

29300 ,

95255

$\begin{array}{lccccc}\mathbf{1} & \mathrm{CHCl}_{3} & 530,568 & 18475, & 587,637 & 55 \\ \mathbf{1} & & 20350 & & \\ & \text { toluene } & 532,573 & 22950, & 588,642 & 77 \\ \mathbf{5} & \mathrm{CHCl}_{3} & 475 & 16200 & 539^{\mathrm{c}} & 100 \\ \mathbf{5} & \text { toluene } & 479 & 16350 & 546^{\mathrm{c}} & 95 \\ 7 & \mathrm{CHCl}_{3} & 470 & 21750 & 522^{\mathrm{c}} & 89 \\ 7 & \text { toluene } & 470 & 20270 & 528^{\mathrm{c}} & 88\end{array}$

${ }^{a}$ Fluorescence quantum yields were determined at $25^{\circ} \mathrm{C}$ by a relative method using the following standards[73]: sulforhodamine $101\left(\mathrm{SR} 101, \Phi_{\mathrm{F}}=95 \%\right.$ in EtOH) for DPP dye $\mathbf{1}$ and fluorescein $\left(\Phi_{\mathrm{F}}=90 \%\right.$ in $\left.0.1 \mathrm{M} \mathrm{NaOH}\right)$ for DPP dyes 5 and 7.

${ }^{\mathrm{b}}$ Absorption maximum ( $\mathrm{Q}_{\mathrm{y}}$ band) of parent non-brominated bacteriochlorin is $709 \mathrm{~nm}$ in $\mathrm{CH}_{2} \mathrm{Cl}_{2}$ [57].

c Shoulder peak was observed on the emission spectrum: around $570 \mathrm{~nm}$ and $580 \mathrm{~nm}$ for $\mathbf{5}$ in $\mathrm{CHCl}_{3}$ and toluene respectively; 550 $\mathrm{nm}$ and $560 \mathrm{~nm}$ for 7 in $\mathrm{CHCl}_{3}$ and toluene respectively.

It should be borne in mind that the relative large width and poorly structured shape noted for B band are the result of an overlay with $\mathrm{S} 0 \rightarrow \mathrm{S} 2$ band of DPP chromophore, not electronic interactions between the two distinct fluorophore units in the ground state. Indeed, the ethynyl linker (for triads BC-DPP1 and BC-DPP-2) or the connecting phenyl moiety (for triad BC-DPP-3) prevents the donors and acceptor fragments from becoming planar and thus extended $\pi$-electronic conjugation. Excitation at each absorption band of the triads results in an emission in the NIR spectral window (Table 2, column 5 for the corresponding emission maxima depending upon triad and solvent).

Table 2. Absorption and emission properties of BC-DPP triads and published BC-BODIPY dyads, in selected organic solvents.

\begin{tabular}{ccccccc}
\hline \multirow{2}{*}{ Dyad / Triad } & Solvent & Abs $\lambda_{\max }(\mathrm{nm})$ & $\varepsilon\left(\mathrm{M}^{-1} \mathrm{~cm}^{-1}\right)$ & $\operatorname{Em~} \lambda_{\max }(\mathrm{nm})$ & $\Phi_{\mathrm{F}}(\%)^{\mathrm{a}}$ & ETE (\%) \\
\hline \multirow{2}{*}{ BC-DPP-1 } & \multirow{2}{*}{$\mathrm{CHCl}_{3}$} & $364,590,795$ & 94300, & 811 & 7.5 & 98 \\
& & & 132760 & & \\
BC-DPP-1 & toluene & $364,593,795$ & 94260, & 811 & 8 & 97
\end{tabular}


91400,

BC-DPP-2 $\quad \mathrm{CHCl}_{3} \quad 370,490,533, \quad 34300$

38800 ,

$779-11$

99

92970

89450 ,

BC-DPP-2 toluene 375, 490, 533, 34520 ,

43700 ,

776

12

99

97800

67180 ,

69350 ,

BC-DPP-3 $\quad \mathrm{CHCl}_{3} \quad \begin{gathered}358,370,482, \\ 515,746\end{gathered} \quad 24360$

24300 ,

47420

73200 ,

73200 ,

BC-DPP-3 toluene

$357,370,484$,

25900 ,

760

13

96

29400 ,

58000

$\begin{array}{llc}\underset{\text { 1[55] }}{\text { BC-BODIPY- }} & \text { toluene } & 371,504,735 \\ \underset{\text { [C-BDIPY- }}{\text { BC5] }} & \text { toluene } & -, 505,745\end{array}$

744

93

${ }^{\text {a }}$ Fluorescence quantum yields were determined at $25{ }^{\circ} \mathrm{C}$ by a relative method using indocyanine green as standard (ICG, $\Phi_{\mathrm{F}}=$ 10.6\% in DMSO, Ex. at their $\mathrm{Q}_{\mathrm{y}}$ band: $720 \mathrm{~nm}, 690 \mathrm{~nm}$ and $680 \mathrm{~nm}$ for BC-DPP-1, BC-DPP-2 and BC-DPP-3 respectively)[73].

${ }^{b}$ Energy transfer efficiency was calculated based on the equation $\left\{100 \times\left[1-\left(\Phi_{\mathrm{F}}\right.\right.\right.$ donor in triad $) /\left(\Phi_{\mathrm{F}}\right.$ free donor $\left.\left.)\right]\right\}$. The following DPP dyes were used as free donors: 1 for BC-DPP-1 (Ex. at $550 \mathrm{~nm}$, Em. $560-725 \mathrm{~nm}$ ), $\mathbf{5}$ for BC-DPP-2 (Ex. at $450 \mathrm{~nm}$, Em. $470-$ $710 \mathrm{~nm}$ ) and 7 for BC-DPP-3 (Ex. $450 \mathrm{~nm}$, Em. $470-710 \mathrm{~nm}$ ).

Emission spectra displayed in Fig. 3 and Fig. S40, S42, S44 and S46 clearly illustrate the ability of the DPP parts of these triads to transfer energy to the bacteriochlorin moiety. This was also supported by the excitation spectra that perfectly match with the absorption curves of the triads (see Fig. S47-S52). Energy transfer efficiency, calculated based on the equation $\left\{100 \times\left[1-\left(\Phi_{\mathrm{F}}\right.\right.\right.$ donor in triad $) /\left(\Phi_{\mathrm{F}}\right.$ free donor) $\left.]\right\}$ exceeds $96 \%$ for each triad (Table 2 , column 6$)$. The sole difficulty associated with these measurements, was to find both an appropriate excitation wavelength of DPP donors for which the residual absorption of bacteriochlorin (i.e., $\mathrm{Q}_{\mathrm{x}}$ band) was negligible and an emission spectral range for DPP dye not hindered by NIR emission of BC 
acceptor (see caption of Table 2 and ESI for experimental details). These results thus indicate that DPP dyes are efficient donors to bacteriochlorins and the ethynyl moiety is a proper twisted conjugate linker to promote energy transfer between these donor and acceptor units. Interestingly, three-chromophore systems such as triads BC-DPP-1-3 enable to achieve large pseudo-Stokes shift upon excitation in the blue-green region: $260 \mathrm{~nm}\left(5850 \mathrm{~cm}^{-1}\right)$ for BC-DPP-1 (Ex. at $\left.550 \mathrm{~nm}\right)$ and 310-330 nm (9 $065 \mathrm{~cm}^{-1}$ - $\left.9385 \mathrm{~cm}^{-1}\right)$ for BC-DPP-2-3 (Ex. at $\left.450 \mathrm{~nm}\right)$. This spectral behavior is quite similar to that of some bacterichlorin-BODIPY dyads recently published by the Ptaszek group (see Fig. 4 and Table 2, entries 7-8). Indeed, excitation at the maximum of BODIPY absorbance (ca. $500 \mathrm{~nm}$ ) resulted in nearly exclusive NIR emission of bacterichlorin component (744-754 nm). A slight difference in ETE values was obtained in view of the nature of linker connecting the two chromophoric units (93\% with phenylene and 96\% with phenylacetylene). Finally, satisfactory values of fluorescence quantum yields, in the range 6-13\%, were obtained upon direct excitation of the triads at their $\mathrm{Q}_{\mathrm{y}}$ band. These emission features associated with attractive red-shifted absorption properties in the range 745-795 $\mathrm{nm}$ (vide supra), are particular of interest for considering the forthcoming use of these triads as valuable building blocks in the rational design of NIR fluorophores for biomedical applications.
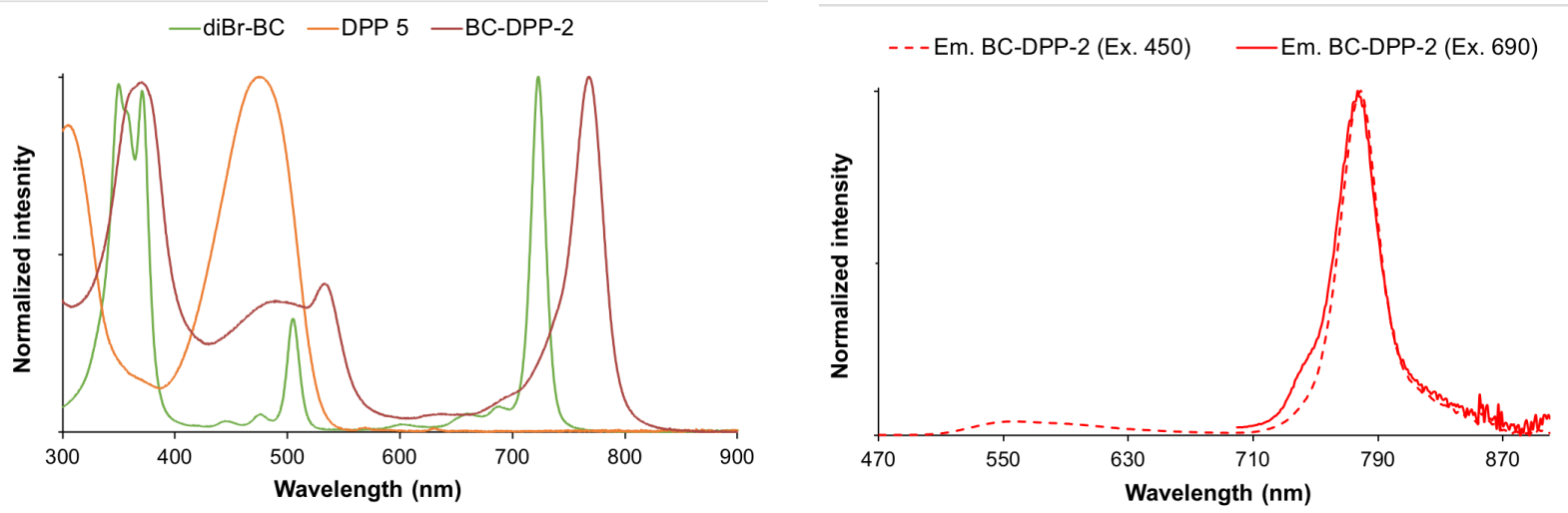

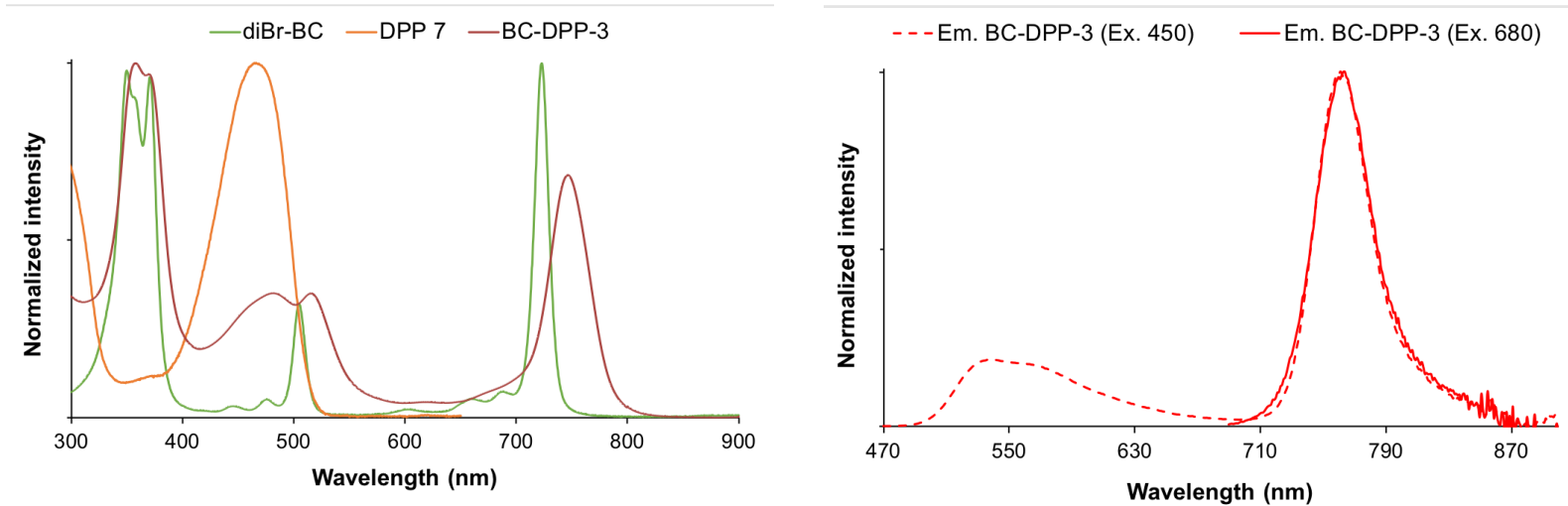

Fig. 3. Normalized absorption and emission spectra of BC-DPP triads in $\mathrm{CHCl}_{3}$ at $25^{\circ} \mathrm{C}$. (Top left) Overlay of the absorbance spectra of diBr-BC, DPP 5 and BC-DPP-2; (Top right) Overlay of the emission spectra of BC-DPP-2 upon excitation at $450 \mathrm{~nm}$ (slit $5 \mathrm{~nm}$, Em. 470-900 nm, slit $5 \mathrm{~nm}$ ) and $690 \mathrm{~nm}$ (slit $5 \mathrm{~nm}$, Em. 700-900 nm, slit $5 \mathrm{~nm}$ ); (Bottom left) Overlay of the absorbance spectra of diBr-BC, DPP 7 and BC-DPP-3; (Bottom right) Overlay of the emission spectra of BC-DPP-3 upon excitation at $450 \mathrm{~nm}$ (slit $5 \mathrm{~nm}$, Em. 470-900 nm, slit $5 \mathrm{~nm}$ ) and $680 \mathrm{~nm}$ (slit 5 $\mathrm{nm}$, Em. 690-900 nm, slit $5 \mathrm{~nm}$ ). Please note: emission spectra cannot be corrected in the range 850-900 nm, which explains the artificat observed at $850 \mathrm{~nm}$.
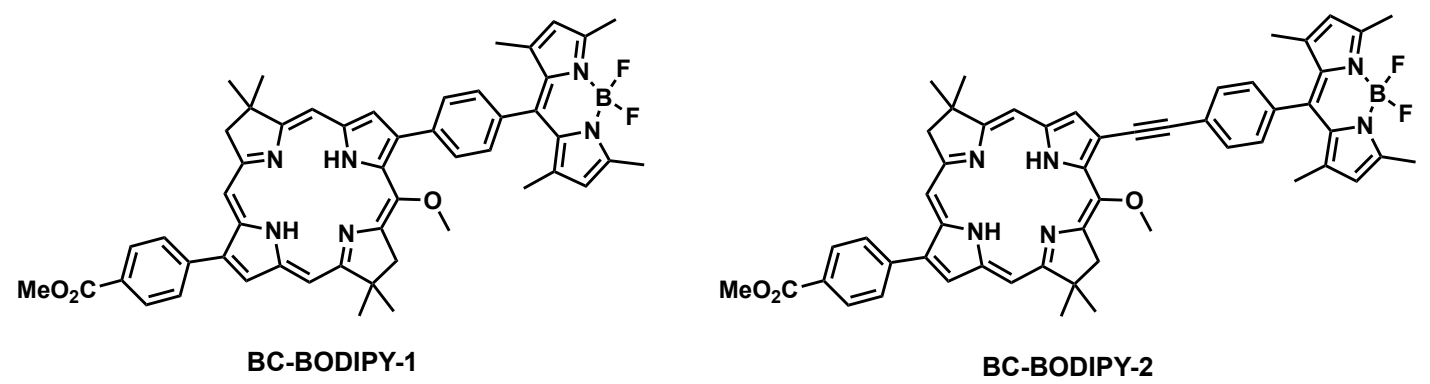

Fig. 4. Structures of BC-BODIPY dyads recently reported by the Ptaszek group[65,55].

\section{Conclusion}

In summary, unprecedented donor-acceptor-donor systems based on DPP dyes and a bioinspired porphyrin-like fluorophore were successfully synthesized for the first time, through concise and convergent synthetic routes. Very efficient energy transfer (ETE $>96 \%$ ) is observed from DPP to NIR absorbing bacteriochlorin, for two different DPP with absorption spanning 470-575 nm, and results in an intense emission within the "therapeutic optical window". Compared to energy transfer dyads involving a bateriochlorin as acceptor, and already reported in the literature, the availability of DPP moieties within the core structure of these fluorescent molecular hybrids, offers a unique opportunity to easily tailor properties of hydroporphyrins for specific biomedical or energy-related applications. Indeed, these structurally compact chromophores possess an 
unsurpassed range of valuable features including: straightforward synthesis, ease of modification, outstanding robustness (both (photo)chemical and thermal stability) and attractive spectroscopic properties[49,50]. In this context, site-specific functionalizations of DPP fragments with the aim of introducing some water-solubilizing groups, a bioconjugatable tether or an optically tunable group within the structure of triads is currently under investigation in our laboratory. Indeed, this will pave the way for a next generation of high-performance NIR-I fluorophores that will facilitate biosensing/bioimaging in complex biological systems.

\section{Acknowledgments}

This work is supported by the CNRS, Université de Bourgogne and Conseil Régional de Bourgogne through the "Plan d'Actions Régional pour l'Innovation (PARI)" and the "Fonds Européen de Développement Régional (FEDER)" programs, especially for post-doctoral fellowship of Dr. Pritam Mondal. Flavien Ponsot gratefully acknowledges the French Research Ministry for his Ph. D. grant. Financial support from Institut Universitaire de France (IUF), the Burgundy region ("FABER" programme, PARI Action 6, SSTIC 6 "Imagerie, instrumentation, chimie et applications biomédicales") and GDR CNRS "Agents d'Imagerie Moléculaire" (AIM) 2037 are also greatly acknowledged. The authors thank the "Plateforme d'Analyse Chimique et de Synthèse Moléculaire de l'Université de Bourgogne" (PACSMUB, http://www.wpcm.fr) for access to analytical instrumentation. COBRA lab (UMR CNRS 6014) and Iris Biotech company are warmly thanked for the generous gift of some chemical reagents used in this work. The authors also thank Mrs. Sandrine Pacquelet (University of Burgundy, ICMUB, UMR CNRS 6302), Mrs. Julie Mathey (student at the University Technology Institute in Besançon, 2017) and Mrs. Gracia Loma Kikobo (undergraduate student form the University of Burgundy, Dijon, 2018) for their technical assistance during the synthesis of diBr-BC and some DPP derivatives.

\section{Appendix A. Supplementary data}

Supplementary data related to this article can be found online at 


\section{References}

[1] Weissleder R, Mahmood U. Molecular Imaging Radiology 2001; 219: 316-33.

[2] Pysz MA, Gambhir SS, Willmann JK. Molecular imaging: current status and emerging strategies Clin. Radiol. 2010; 65: 500-16.

[3] Bremer C, Ntziachristos V, Weissleder R. Optical-based molecular imaging: contrast agents and potential medical applications Eur. Radiol. 2003; 13: 231-43.

[4] Weissleder R, Ntziachristos V. Shedding light onto live molecular targets Nat. Med. 2003; 9: 123-8.

[5] Frangioni JV. In vivo near-infrared fluorescence imaging Curr. Opin. Chem. Biol. 2003; 7: 626-34.

[6] Rao J, Dragulescu-Andrasi A, Yao H. Fluorescence imaging in vivo: recent advances Curr. Opin. Chem. Biol. 2007; 18: 17-25.

[7] Sevick-Muraca EM. Translation of near-infrared fluorescence imaging technologies: emerging clinical applications Annu. Rev. Med. 2012; 63: 217-31.

[8] Pansare VJ, Hejazi S, Faenza WJ, Prud'homme RK. Review of Long-Wavelength Optical and NIR Imaging Materials: Contrast Agents, Fluorophores, and Multifunctional Nano Carriers Chem. Mater. 2012; 24: 81227.

[9] Hong G, Antaris AL, Dai H. Near-infrared fluorophores for biomedical imaging Nat. Biomed. Eng. 2017; 1 : 0010, DOI: $10.1038 / \mathrm{s} 41551-016-0010$.

[10] Martinić I, Eliseeva SV, Petoud S. Near-infrared emitting probes for biological imaging: Organic fluorophores, quantum dots, fluorescent proteins, lanthanide(III) complexes and nanomaterials J. Lumin. 2017; 189: 19-43.

[11] Chan J, Dodani SC, Chang CJ. Reaction-based small-molecule fluorescent probes for chemoselective bioimaging Nat. Chem. 2012; 4: 973-84.

[12] Grimm JB, Heckman LM, Lavis LD. The chemistry of small-molecule fluorogenic probes Prog. Mol. Biol. Transl. Sci. 2013; 113: 1-34.

[13] Luby BM, Charron DM, MacLaughlin CM, Zheng G. Activatable fluorescence: From small molecule to nanoparticle Adv. Drug Deliv. Rev. 2017; 113: 97-121.

[14] Ballou B, Ernst LA, Waggoner AS. Fluorescence imaging of tumors in vivo Curr. Med. Chem. 2005; 12: 795805.

[15] Ptaszek M. Rational design of fluorophores for in vivo applications Prog. Mol. Biol. Transl. Sci. 2013; 113 : 59-108.

[16] Umezawa K, Citterio D, Suzuki K. New Trends in Near-Infrared Fluorophores for Bioimaging Anal. Sci. 2014; 30: 327-49.

[17] Kushida Y, Nagano T, Hanaoka K. Silicon-substituted xanthene dyes and their applications in bioimaging Analyst 2015; 140: 685-95.

[18] Ikeno T, Nagano T, Hanaoka K. Silicon-substituted Xanthene Dyes and Their Unique Photophysical Properties for Fluorescent Probes Chem. - Asian J. 2017; 12: 1435-46.

[19] Chen H, Dong B, Tang Y, Lin W. A Unique "Integration" Strategy for the Rational Design of Optically Tunable Near-Infrared Fluorophores Acc. Chem. Res. 2017; 50: 1410-22.

[20] Ptaszek M, Kee H-L, Muthiah C, Nothdurft R, Akers W, Achilefu S, Culver JP, Holten D. Near-infrared molecular imaging probes based on chlorin-bacteriochlorin dyads Proc. SPIE 2010; 7576: 75760E/1-E/9.

[21] Alexander VM, Sano K, Yu Z, Nakajima T, Choyke PL, Ptaszek M, Kobayashi H. Galactosyl Human Serum Albumin-NMP1 Conjugate: A Near Infrared (NIR)-Activatable Fluorescence Imaging Agent to Detect Peritoneal Ovarian Cancer Metastases Bioconjugate Chem. 2012; 23: 1671-9.

[22] Harada T, Sano K, Sato K, Watanabe R, Yu Z, Hanaoka H, Nakajima T, Choyke PL, Ptaszek M, Kobayashi H. Activatable Organic Near-Infrared Fluorescent Probes Based on a Bacteriochlorin Platform: Synthesis and Multicolor in Vivo Imaging with a Single Excitation Bioconjugate Chem. 2014; 25 : 362-9.

[23] de Oliveira KT, Momo PB, de Assis FF, Ferreira MAB, Brocksom TJ. Chlorins: Natural Sources, Synthetic Developments and Main Applications Curr. Org. Synth. 2014; 11: 42-58.

[24] Grin MA, Mironov AF. Synthetic and natural bacteriochlorins: synthesis, properties and applications In: Chemical Processes with Participation of Biological and Related Compounds, Boca Raton: CRS Press; 2008, p. 5-43.

[25] Ruzié C, Krayer M, Balasubramanian T, Lindsey JS. Tailoring a Bacteriochlorin Building Block with Cationic, Amphipathic, or Lipophilic Substituents J. Org. Chem. 2008; 73: 5806-20.

[26] Taniguchi M, Cramer DL, Bhise AD, Kee HL, Bocian DF, Holten D, Lindsey JS. Accessing the near-infrared spectral region with stable, synthetic, wavelength-tunable bacteriochlorins New J. Chem. 2008; 32: 947-58. 
[27] Kee HL, Diers JR, Ptaszek M, Muthiah C, Fan D, Lindsey JS, Bocian DF, Holten D. Chlorin-bacteriochlorin energy-transfer dyads as prototypes for near-infrared molecular imaging probes: controlling charge-transfer and fluorescence properties in polar media Photochem. Photobiol. 2009; 85: 909-20.

[28] Lindsey JS, Mass O, Chen C-Y. Tapping the near-infrared spectral region with bacteriochlorin arrays New J. Chem. 2011; 35: 511-6.

[29] Yang E, Kirmaier C, Krayer M, Taniguchi M, Kim H-J, Diers JR, Bocian DF, Lindsey JS, Holten D. Photophysical Properties and Electronic Structure of Stable, Tunable Synthetic Bacteriochlorins: Extending the Features of Native Photosynthetic Pigments J. Phys. Chem. B 2011; 115: 10801-16.

[30] Jiang J, Chen C-Y, Zhang N, Vairaprakash P, Lindsey JS. Polarity-tunable and wavelength-tunable bacteriochlorins bearing a single carboxylic acid or NHS ester. Use in a protein bioconjugation model system New J. Chem. 2015; 39: 403-19.

[31] Jiang J, Taniguchi M, Lindsey JS. Near-infrared tunable bacteriochlorins equipped for bioorthogonal labeling New J. Chem. 2015; 39: 4534-50.

[32] Jiang J, Yang E, Reddy KR, Niedzwiedzki DM, Kirmaier C, Bocian DF, Holten D, Lindsey JS. Synthetic bacteriochlorins bearing polar motifs (carboxylate, phosphonate, ammonium and a short PEG). Watersolubilization, bioconjugation, and photophysical properties New J. Chem. 2015; 39: 5694-714.

[33] Mandal AK, Sahin T, Liu M, Lindsey JS, Bocian DF, Holten D. Photophysical comparisons of PEGylated porphyrins, chlorins and bacteriochlorins in water New J. Chem. 2016; 40: 9648-56.

[34] Liu R, Liu M, Hood D, Chen C-Y, MacNevin C, Holten D, Lindsey J. Chlorophyll-Inspired Red-Region Fluorophores: Building Block Synthesis and Studies in Aqueous Media Molecules 2018; 23: 130.

[35] Kim H-J, Lindsey JS. De Novo Synthesis of Stable Tetrahydroporphyrinic Macrocycles: Bacteriochlorins and a Tetradehydrocorrin J. Org. Chem. 2005; 70: 5475-86.

[36] Fan D, Taniguchi M, Lindsey JS. Regioselective 15-Bromination and Functionalization of a Stable Synthetic Bacteriochlorin J. Org. Chem. 2007; 72: 5350-7.

[37] Liu Y, Lindsey JS. Northern-Southern Route to Synthetic Bacteriochlorins J. Org. Chem. 2016; 81: 1188297.

[38] Liu Y, Zhang S, Lindsey JS. Total synthesis campaigns toward chlorophylls and related natural hydroporphyrins - diverse macrocycles, unrealized opportunities Nat. Prod. Rep. 2018: in press, see DOI: $10.1039 / \mathrm{c} 8 \mathrm{np00020d}$.

[39] For selected examples of porphyrin-DPP hybrids, see: Warnan J, Favereau L, Meslin F, Severac M, Blart E, Pellegrin Y, Jacquemin D, Odobel F. Diketopyrrolopyrrole-Porphyrin Conjugates as Broadly Absorbing Sensitizers for Dye-Sensitized Solar Cells ChemSusChem 2012; 5: 1568-77 and references [40-48].

[40] Favereau L, Warnan J, Anne FB, Pellegrin Y, Blart E, Jacquemin D, Odobel F. Diketopyrrolopyrrole-zinc porphyrin, a tuned panchromatic association for dye-sensitized solar cells J. Mater. Chem. A 2013; 1: 75725.

[41] Gao K, Li L, Lai T, Xiao L, Huang Y, Huang F, Peng J, Cao Y, Liu F, Russell TP, Janssen RAJ, Peng X. Deep Absorbing Porphyrin Small Molecule for High-Performance Organic Solar Cells with Very Low Energy Losses J. Am. Chem. Soc. 2015; 137: 7282-5.

[42] Schmitt J, Heitz V, Sour A, Bolze F, Ftouni H, Nicoud J-F, Flamigni L, Ventura B. DiketopyrrolopyrrolePorphyrin Conjugates with High Two-Photon Absorption and Singlet Oxygen Generation for Two-Photon Photodynamic Therapy Angew. Chem., Int. Ed. 2015; 54: 169-73.

[43] Liang T, Xiao L, Liu C, Gao K, Qin H, Cao Y, Peng X. Porphyrin small molecules containing furan- and selenophene-substituted diketopyrrolopyrrole for bulk heterojunction organic solar cells Org. Electron. 2016; 29: $127-34$.

[44] Schmitt J, Heitz V, Sour A, Bolze F, Kessler P, Flamigni L, Ventura B, Bonnet CS, Toth E. A Theranostic Agent Combining a Two-Photon-Absorbing Photosensitizer for Photodynamic Therapy and a Gadolinium(III) Complex for MRI Detection Chem. - Eur. J. 2016; 22: 2775-86.

[45] Sour A, Jenni S, Orti-Suarez A, Schmitt J, Heitz V, Bolze F, Loureiro de Sousa P, Po C, Bonnet CS, Pallier A, Toth E, Ventura B. Four Gadolinium(III) Complexes Appended to a Porphyrin: A Water-Soluble Molecular Theranostic Agent with Remarkable Relaxivity Suited for MRI Tracking of the Photosensitizer Inorg. Chem. 2016; 55: 4545-54.

[46] Ogumi K, Nakagawa T, Okada H, Sakai R, Wang H, Matsuo Y. Substituent effects in magnesium tetraethynylporphyrin with two diketopyrrolopyrrole units for bulk heterojunction organic solar cells J. Mater. Chem. A 2017; 5: 23067-77. 
[47] Ohta K, Tokonami S, Takahashi K, Tamura Y, Yamada H, Tominaga K. Probing Charge Carrier Dynamics in Porphyrin-Based Organic Semiconductor Thin Films by Time-Resolved THz Spectroscopy J. Phys. Chem. B 2017; 121: 10157-65.

[48] Schmitt J, Heitz V, Jenni S, Sour A, Bolze F, Ventura B. $\pi$-extended porphyrin dimers as efficient nearinfrared emitters and two-photon absorbers Supramol. Chem. 2017; 29: 769-75.

[49] Grzybowski M, Gryko DT. Diketopyrrolopyrroles: Synthesis, Reactivity, and Optical Properties Adv. Optical Mater. 2015; 3: 280-320.

[50] Kaur M, Choi DH. Diketopyrrolopyrrole: brilliant red pigment dye-based fluorescent probes and their applications Chem. Soc. Rev. 2015; 44: 58-77.

[51] Wang J, Yang E, Diers JR, Niedzwiedzki DM, Kirmaier C, Bocian DF, Lindsey JS, Holten D. Distinct Photophysical and Electronic Characteristics of Strongly Coupled Dyads Containing a Perylene Accessory Pigment and a Porphyrin, Chlorin, or Bacteriochlorin J. Phys. Chem. B 2013; 117: 9288-304.

[52] Yu Z, Ptaszek M. Near-IR Emissive Chlorin-Bacteriochlorin Energy-Transfer Dyads with a Common Donor and Acceptors with Tunable Emission Wavelength J. Org. Chem. 2013; 78: 10678-91.

[53] Hu G, Liu R, Alexy EJ, Mandal AK, Bocian DF, Holten D, Lindsey JS. Panchromatic chromophoretetrapyrrole light-harvesting arrays constructed from Bodipy, perylene, terrylene, porphyrin, chlorin, and bacteriochlorin building blocks New J. Chem. 2016; 40: 8032-52.

[54] Mandal AK, Diers JR, Niedzwiedzki DM, Hu G, Liu R, Alexy EJ, Lindsey JS, Bocian DF, Holten D. Tailoring Panchromatic Absorption and Excited-State Dynamics of Tetrapyrrole-Chromophore (Bodipy, Rylene) Arrays-Interplay of Orbital Mixing and Configuration Interaction J. Am. Chem. Soc. 2017; 139: 17547-64.

[55] Meares A, Satraitis A, Ptaszek M. BODIPY-Bacteriochlorin Energy Transfer Arrays: Toward Near-IR Emitters with Broadly Tunable, Multiple Absorption Bands J. Org. Chem. 2017; 82: 13068-75.

[56] Esemoto NN, Satraitis A, Wiratan L, Ptaszek M. Symmetrical and Nonsymmetrical Meso-Meso Directly Linked Hydroporphyrin Dyads: Synthesis and Photochemical Properties Inorg. Chem. 2018; 57: 2977-88.

[57] Krayer M, Ptaszek M, Kim H-J, Meneely KR, Fan D, Secor K, Lindsey JS. Expanded Scope of Synthetic Bacteriochlorins via Improved Acid Catalysis Conditions and Diverse Dihydrodipyrrin-Acetals J. Org. Chem. 2010; 75: 1016-39.

[58] Yu C, Liu Z, Yang Y, Yao J, Cai Z, Luo H, Zhang G, Zhang D. New dithienyl-diketopyrrolopyrrole-based conjugated molecules entailing electron withdrawing moieties for organic ambipolar semiconductors and photovoltaic materials J. Mater. Chem. C 2014; 2: 10101-9.

[59] Ftouni H, Bolze F, de Rocquigny H, Nicoud J-F. Functionalized Two-Photon Absorbing Diketopyrrolopyrrole-Based Fluorophores for Living Cells Fluorescent Microscopy Bioconjugate Chem. 2013; 24: 942-50.

[60] Heyer E, Lory P, Leprince J, Moreau M, Romieu A, Guardigli M, Roda A, Ziessel R. Highly fluorescent, water-soluble, bioconjugable diketopyrrolopyrrole dyes Angew. Chem., Int. Ed. 2015; 54: 2995-9.

[61] Fulmer GR, Miller AJM, Sherden NH, Gottlieb HE, Nudelman A, Stoltz BM, Bercaw JE, Goldberg KI. NMR Chemical Shifts of Trace Impurities: Common Laboratory Solvents, Organics, and Gases in Deuterated Solvents Relevant to the Organometallic Chemist Organometallics 2010; 29: 2176-9.

[62] Baek P, Kerr-Phillips T, Damavandi M, Chaudhary OJ, Malmstrom J, Chan EWC, Shaw P, Burn P, Barker D, Travas-Sejdic J. Highly processable, rubbery poly(n-butyl acrylate) grafted poly(phenylene vinylene)s Eur. Polym. J. 2016; 84: 355-65.

[63] Yu Z, Pancholi C, Bhagavathy GV, Kang HS, Nguyen JK, Ptaszek M. Strongly Conjugated Hydroporphyrin Dyads: Extensive Modification of Hydroporphyrins' Properties by Expanding the Conjugated System J. Org. Chem. 2014; 79: 7919-34.

[64] de Assis FF, Ferreira MAB, Brocksom TJ, de Oliveira KT. NIR bacteriochlorin chromophores accessed by Heck and Sonogashira cross-coupling reactions on a tetrabromobacteriochlorin derivative Org. Biomol. Chem. 2016; 14: 1402-12.

[65] Meares A, Satraitis A, Akhigbe J, Santhanam N, Swaminathan S, Ehudin M, Ptaszek M. Amphiphilic BODIPY-Hydroporphyrin Energy Transfer Arrays with Broadly Tunable Absorption and Deep Red/NearInfrared Emission in Aqueous Micelles J. Org. Chem. 2017; 82: 6054-70.

[66] Meares A, Satraitis A, Santhanam N, Yu Z, Ptaszek M. Deep-Red Emissive BODIPY-Chlorin Arrays Excitable with Green and Red Wavelengths J. Org. Chem. 2015; 80: 3858-69.

[67] Esemoto NN, Yu Z, Wiratan L, Satraitis A, Ptaszek M. Bacteriochlorin Dyads as Solvent Polarity Dependent Near-Infrared Fluorophores and Reactive Oxygen Species Photosensitizers Org. Lett. 2016; 18: 4590-3.

[68] Bucher L, Tanguy L, Fortin D, Desbois N, Harvey PD, Sharma GD, Gros CP. An ultra-low bandgap (diketopyrrolopyrrole-porphyrin) conjugated polymer ChemPlusChem 2017; 82: 625-30. 
[69] Bucher L, Desbois N, Koukaras EN, Devillers CH, Biswas S, Sharma GD, Gros CP. BODIPYdiketopyrrolopyrrole-porphyrin conjugate Small Molecules for Use in Bulk Heterojunction Solar Cells J. Mater. Chem. A 2018; 6: 8449-61.

[70] Yu Z, Ptaszek M. Multifunctional Bacteriochlorins from Selective Palladium-Coupling Reactions Org. Lett. 2012; 14: 3708-11.

[71] Ljungdahl T, Pettersson K, Albinsson B, Maartensson J. Solvent and Base Dependence of Copper-Free Palladium-Catalyzed Cross-Couplings between Terminal Alkynes and Arylic Iodides: Development of Efficient Conditions for the Construction of Gold(III)/Free-Base Porphyrin Dimers J. Org. Chem. 2006; 71 : 1677-87.

[72] Wakabayashi R, Ikeda T, Kubo Y, Shinkai S, Takeuchi M. Unexpected Effects of Terminal Olefins on a Cooperative Recognition System that Implicate Olefin-Olefin Interactions Angew. Chem., Int. Ed. 2009; 48: 6667-70.

[73] Brouwer AM. Standards for photoluminescence quantum yield measurements in solution Pure Appl. Chem. 2011; 83: 2213-28. 


\section{Near-infrared emissive bacteriochlorin-diketopyrrolopyrrole triads: Synthesis and photophysical properties}

Flavien Ponsot ${ }^{\mathrm{a}}$, Nicolas Desbois ${ }^{\mathrm{a}}$, Léo Bucher ${ }^{\mathrm{a}}$, Mathieu Berthelot ${ }^{\mathrm{a}}$, Pritam Mondal $^{\mathrm{a}}$, Claude P. Gros ${ }^{\mathrm{a}, *}$, Anthony Romieu ${ }^{\mathrm{a}, \mathrm{b},{ }^{*}}$

anstitut de Chimie Moléculaire de l'Université de Bourgogne, UMR 6302, CNRS, Univ. Bourgogne Franche-Comté, 9 Avenue Alain Savary, 21078 Dijon, France

Tel: +33 (0)3 80396112 or $+33(0) 380393624$

E-mail: claude.gros@u-bourgognbe.fr or anthony.romieu@u-bourgogne.fr

Lab homepage: http://www.icmub.fr

${ }^{b}$ Institut Universitaire de France, 1 Rue Descartes, Bâtiment MONGE, 75231 Paris, France

\section{Supplementary Data}




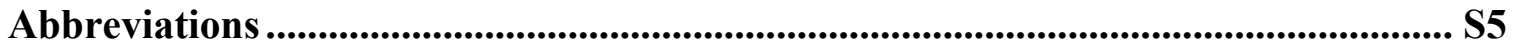

S1 Photophyscial characterizations - Experimental details........................................... S5

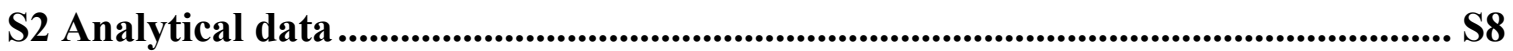

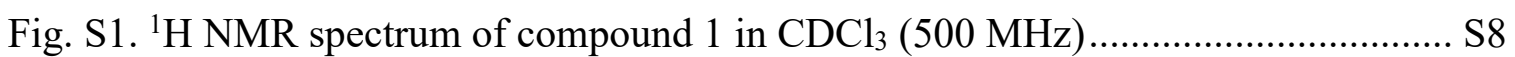

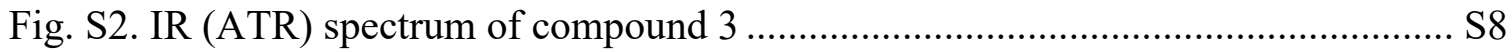

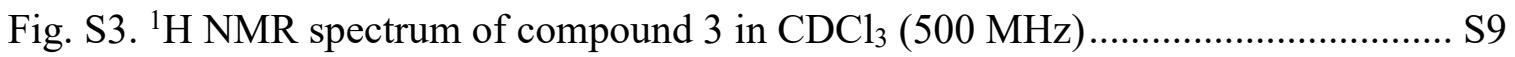

Fig. S4. ${ }^{13} \mathrm{C}$ NMR spectrum (JMOD) of compound 3 in $\mathrm{CDCl}_{3}(126 \mathrm{MHz})$................... S9

Fig. S5. ESI+ mass spectrum (low resolution) of compound 3 .................................... S10

Fig. S6. IR (ATR) spectrum of compound 4 ........................................................... S10

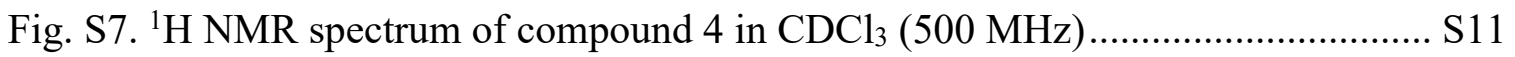

Fig. S8. ${ }^{13} \mathrm{C}$ NMR spectrum (JMOD) of compound 4 in $\mathrm{CDCl}_{3}(126 \mathrm{MHz})$................. S11

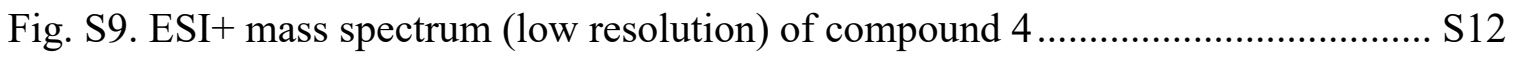

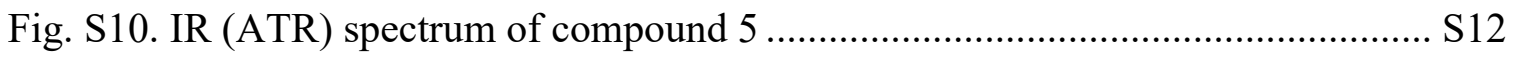

Fig. S11. ${ }^{1} \mathrm{H}$ NMR spectrum of compound 5 in $\mathrm{CDCl}_{3}(500 \mathrm{MHz}) \ldots \ldots \ldots \ldots \ldots \ldots \ldots \ldots \ldots \ldots . . . . . . . . . . . . . . . . .313$

Fig. S12. ${ }^{13} \mathrm{C}$ NMR spectrum (JMOD) of compound 5 in $\mathrm{CDCl}_{3}(126 \mathrm{MHz})$............... S13

Fig. S13. ESI+ mass spectrum (low resolution) of compound 5 …………................... S14

Fig. S14. IR (ATR) spectrum of compound 6 ......................................................... S14

Fig. S15. ${ }^{1} \mathrm{H}$ NMR spectrum of compound 6 in $\mathrm{CDCl}_{3}(500 \mathrm{MHz}) \ldots \ldots \ldots \ldots \ldots \ldots \ldots \ldots \ldots \ldots . . . . . . . . . . . . . . . .515$

Fig. S16. ${ }^{13} \mathrm{C}$ NMR spectrum (JMOD) of compound 6 in $\mathrm{CDCl}_{3}(126 \mathrm{MHz})$............... S15

Fig. S17. ESI+ mass spectrum (low resolution) of compound 6 ………….................... S16

Fig. S18. IR (ATR) spectrum of compound 7 .......................................................... S16

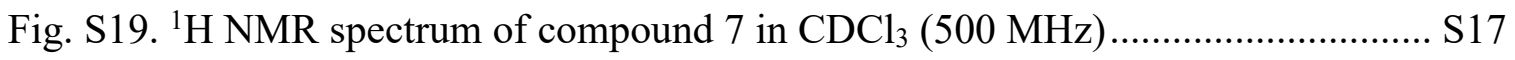

Fig. S20. ${ }^{13} \mathrm{C}$ NMR spectrum (JMOD) of compound 7 in $\mathrm{CDCl}_{3}(126 \mathrm{MHz})$............... S17

Fig. S21. ESI+ mass spectrum (low resolution) of compound 7 ………....................... S18

Fig. S22. ${ }^{1} \mathrm{H}$ NMR spectrum of triad BC-DPP-1 in $\mathrm{CDCl}_{3}(500 \mathrm{MHz})$........................ S18

Fig. S23. MALDI-TOF mass spectrum (low resolution, positive mode) of triad BC-DPP-1

Fig. S24. MALDI-TOF mass spectrum (high resolution, positive mode) of triad BC-DPP1

Fig. S25. ESI+ mass spectrum (low resolution) of triad BC-DPP-1 ….......................... S20

Fig. S26. ${ }^{1} \mathrm{H}$ NMR spectrum of triad BC-DPP-2 in $\mathrm{CDCl}_{3}(500 \mathrm{MHz})$....................... S20 
Fig. S27. MALDI-TOF mass spectrum (low resolution, positive mode) of triad BC-DPP-2

Fig. S28. MALDI-TOF mass spectrum (high resolution, positive mode) of triad BC-DPP2 S21

Fig. S29. ESI+ mass spectrum (low resolution) of triad BC-DPP-2 …...................... S22

Fig. S30. ${ }^{1} \mathrm{H}$ NMR spectrum of triad BC-DPP-3 in $\mathrm{CDCl}_{3}(500 \mathrm{MHz})$....................... S22

Fig. S31. MALDI-TOF mass spectrum (high resolution, positive mode) of triad BC-DPP3 . S23

Fig. S32. ESI+ mass spectrum (low resolution) of triad BC-DPP-3 $\mathrm{S} 23$

S3 Photophyscial characterizations - Spectra S24

Fig. S33. Normalized absorption, excitation (Em. 675 nm, slit 5 nm ; Ex. 300-650 nm, slit $12 \mathrm{~nm}$ ) and emission (Ex. $550 \mathrm{~nm}$, slit $5 \mathrm{~nm}$; Em. 560-725 nm, slit $5 \mathrm{~nm}$ ) spectra of ethynylfunctionalized thienyl-DPP 1 in $\mathrm{CHCl}_{3}$ at $25^{\circ} \mathrm{C}$ S24 Fig. S34. Normalized absorption, excitation (Em. 675 nm, slit 5 nm ; Ex. 300-650 nm, slit $12 \mathrm{~nm}$ ) and emission (Ex. $550 \mathrm{~nm}$, slit $5 \mathrm{~nm}$; Em. 560-725 nm, slit $5 \mathrm{~nm}$ ) spectra of ethynylfunctionalized thienyl-DPP 1 in toluene at $25^{\circ} \mathrm{C}$. S24 Fig. S35. Normalized absorption, excitation (Em. 650 nm, slit $5 \mathrm{~nm}$; Ex. 300-620 nm, slit $12 \mathrm{~nm}$ ) and emission (Ex. $450 \mathrm{~nm}$, slit $5 \mathrm{~nm}$; Em. 470-710 nm, slit $5 \mathrm{~nm}$ ) spectra of ethynylfunctionalized phenyl-DPP 5 in $\mathrm{CHCl}_{3}$ at $25^{\circ} \mathrm{C}$ S25 Fig. S36. Normalized absorption, excitation (Em. 650 nm, slit 5 nm ; Ex. 300-620 nm, slit $12 \mathrm{~nm}$ ) and emission (Ex. $450 \mathrm{~nm}$, slit $5 \mathrm{~nm}$; Em. 470-710 nm, slit $5 \mathrm{~nm}$ ) spectra of ethynylfunctionalized phenyl-DPP 5 in toluene at $25^{\circ} \mathrm{C}$ S25

Fig. S37. Normalized absorption, excitation (Em. 650 nm, slit 5 nm ; Ex. 300-620 nm, slit $12 \mathrm{~nm}$ ) and emission (Ex. $450 \mathrm{~nm}$, slit $5 \mathrm{~nm}$; Em. 470-710 nm, slit $5 \mathrm{~nm}$ ) spectra of 3,6diphenyl-DPP 7 in $\mathrm{CHCl}_{3}$ at $25^{\circ} \mathrm{C}$ S26

Fig. S38. Normalized absorption, excitation (Em. 650 nm, slit 5 nm ; Ex. 300-620 nm, slit $12 \mathrm{~nm}$ ) and emission (Ex. $450 \mathrm{~nm}$, slit $5 \mathrm{~nm}$; Em. 470-710 nm, slit $5 \mathrm{~nm}$ ) spectra of 3,6diphenyl-DPP 7 in toluene at $25^{\circ} \mathrm{C}$. S26

Fig. S39. Overlay of the absorbance spectra of diBr-BC, DPP 1 and BC-DPP-1 recorded in $\mathrm{CHCl}_{3}$ at $25^{\circ} \mathrm{C}$ S27 
Fig. S40. Overlay of the emission spectra of BC-DPP-1 upon excitation at $550 \mathrm{~nm}$ (slit 5 nm, Em. 560-900 nm, slit $5 \mathrm{~nm}$ ) and $720 \mathrm{~nm}$ (slit $5 \mathrm{~nm}$, Em. 730-900 nm, slit $5 \mathrm{~nm}$ ), recorded in $\mathrm{CHCl}_{3}$ at $25{ }^{\circ} \mathrm{C}$

Fig. S41. Overlay of the absorbance spectra of diBr-BC, DPP 1 and BC-DPP-1 recorded in toluene at $25^{\circ} \mathrm{C}$ S28

Fig. S42. Overlay of the emission spectra of BC-DPP-1 upon excitation at $550 \mathrm{~nm}$ (slit 5 nm, Em. 560-900 nm, slit $5 \mathrm{~nm}$ ) and $720 \mathrm{~nm}$ (slit $5 \mathrm{~nm}$, Em. 730-900 nm, slit $5 \mathrm{~nm}$ ), recorded in toluene at $25^{\circ} \mathrm{C}$ S28

Fig. S43. Overlay of the absorbance spectra of diBr-BC, DPP 5 and BC-DPP-2 recorded in toluene at $25^{\circ} \mathrm{C}$ S29

Fig. S44. Overlay of the emission spectra of BC-DPP-2 upon excitation at $450 \mathrm{~nm}$ (slit 5 nm, Em. 470-900 nm, slit $5 \mathrm{~nm}$ ) and $690 \mathrm{~nm}$ (slit $5 \mathrm{~nm}$, Em. 700-900 nm, slit $5 \mathrm{~nm}$ ), recorded in toluene at $25^{\circ} \mathrm{C}$ S29

Fig. S45. Overlay of the absorbance spectra of diBr-BC, DPP 7 and BC-DPP-3 recorded in toluene at $25^{\circ} \mathrm{C}$ S30

Fig. S46. Overlay of the emission spectra of BC-DPP-3 upon excitation at $450 \mathrm{~nm}$ (slit 5 nm, Em. 470-900 nm, slit $5 \mathrm{~nm}$ ) and $680 \mathrm{~nm}$ (slit $5 \mathrm{~nm}$, Em. 690-900 nm, slit $5 \mathrm{~nm}$ ), recorded in toluene at $25^{\circ} \mathrm{C}$ S30

Fig. S47. Overlay of the absorbance and excitation (Em. 835 nm, slit 5 nm ; Ex. 300-825 $\mathrm{nm}$, slit $12 \mathrm{~nm}$ ) spectra of BC-DPP-1 recorded in $\mathrm{CHCl}_{3}$ at $25^{\circ} \mathrm{C}$ S31 Fig. S48. Overlay of the absorbance and excitation (Em. 835 nm, slit 5 nm ; Ex. 300-825 $\mathrm{nm}$, slit $12 \mathrm{~nm}$ ) spectra of BC-DPP-1 recorded in toluene at $25^{\circ} \mathrm{C}$ S31 Fig. S49. Overlay of the absorbance and excitation (Em. 835 nm, slit 5 nm ; Ex. 300-825 $\mathrm{nm}$, slit $12 \mathrm{~nm}$ ) spectra of BC-DPP-2 recorded in $\mathrm{CHCl}_{3}$ at $25^{\circ} \mathrm{C}$ S32 Fig. S50. Overlay of the absorbance and excitation (Em. 835 nm, slit 5 nm ; Ex. 300-825 $\mathrm{nm}$, slit $12 \mathrm{~nm}$ ) spectra of BC-DPP-2 recorded in toluene at $25^{\circ} \mathrm{C}$ S32 Fig. S51. Overlay of the absorbance and excitation (Em. 835 nm, slit $5 \mathrm{~nm}$; Ex. 300-825 $\mathrm{nm}$, slit $12 \mathrm{~nm}$ ) spectra of BC-DPP-3 recorded in $\mathrm{CHCl}_{3}$ at $25{ }^{\circ} \mathrm{C}$ S33

Fig. S52. Overlay of the absorbance and excitation (Em. $835 \mathrm{~nm}$, slit $5 \mathrm{~nm}$; Ex. 300-825 $\mathrm{nm}$, slit $12 \mathrm{~nm}$ ) spectra of BC-DPP-3 recorded in toluene at $25^{\circ} \mathrm{C}$ S33 


\section{Abbreviations}

The following abbreviations are used throughout the text of the SI file: Abs., absorption; ATR, attenuated total reflectance; BC, bacteriochlorin; DMSO, dimethylsulfoxide; DPP, diketopyrrolopyrrole; Em., emission; EtOH, ethanol; ESI, electrospray ionisation; Ex., excitation; ICG, indocyanine green; IR, infrared; JMOD, J modulation pulse sequence; NMR, nuclear magnetic resonance; SR101, sulforhodamine 101.

\section{S1 Photophyscial characterizations - Experimental details}

Fluorescein disodium salt hydrate was provided by Alfa Aesar (\#A11659). SR101 (free acid, 99\%) and ICG (IR-125, pure, laser grade) were purchased from Acros (\#419945000 and \#412541000). DMSO (+99.9\% for spectroscopy was provided by Acros. $\mathrm{CHCl}_{3}$ (RPE - ISO - for analysis, stabilized with $\mathrm{EtOH}$ ), EtOH (absolute anhydrous RE) and toluene (HPLC grade) were purchased from Carlo Erba (for the first two mentioned) and Biosolve respectively.

Stock solutions $(1.0 \mathrm{mg} / \mathrm{mL})$ of DPP derivatives were prepared either in $\mathrm{CHCl}_{3}$ (DPP dye 1) or in DMSO (DPP dyes 5 and 7) and subsequently diluted with the corresponding solvent for UV-vis absorption and fluorescence measurements.

Stock solutions $(1.0 \mathrm{mg} / \mathrm{mL})$ of triad BC-DPP were prepared in $\mathrm{CHCl}_{3}$ and subsequently diluted with the corresponding solvent for UV-vis absorption and fluorescence measurements.

Emission spectra were recorded with the following parameters (shutter: Auto Open):

- DPP dye 1, Ex. $550 \mathrm{~nm}$, slit $5 \mathrm{~nm}$; Em. 560-725 nm, slit $5 \mathrm{~nm}$,

- DPP dye 5, Ex. $450 \mathrm{~nm}$, slit $5 \mathrm{~nm}$; Em. 470-710 nm, slit $5 \mathrm{~nm}$,

- DPP dye 7, Ex. $450 \mathrm{~nm}$, slit $5 \mathrm{~nm}$; Em. 470-710 nm, slit $5 \mathrm{~nm}$,

- BC-DPP-1, excitation Qy band, Ex. $720 \mathrm{~nm}$, slit $5 \mathrm{~nm}, \mathrm{Em} .730-900 \mathrm{~nm}$, slit $5 \mathrm{~nm}$,

- BC-DPP-2, excitation Qy band, Ex. $690 \mathrm{~nm}$, slit $5 \mathrm{~nm}$; Em. 700-900 nm, slit $5 \mathrm{~nm}$,

- BC-DPP-3, excitation Qy band, Ex. $680 \mathrm{~nm}$, slit $5 \mathrm{~nm}$; Em. 690-900 nm, slit $5 \mathrm{~nm}$.

- BC-DPP-1, excitation DPP, Ex. $550 \mathrm{~nm}$, slit $5 \mathrm{~nm}$, Em. 560-900 nm, slit $5 \mathrm{~nm}$,

- BC-DPP-2, excitation DPP, Ex. $450 \mathrm{~nm}$, slit $5 \mathrm{~nm}$; Em. 470-900 nm, slit $5 \mathrm{~nm}$,

- BC-DPP-3, excitation DPP, Ex. 450 nm, slit $5 \mathrm{~nm}$; Em. 470-900 nm, slit $5 \mathrm{~nm}$.

Excitation spectra were recorded with the following parameters (shutter: Auto Open):

- DPP dye 1, Em. 675 nm, slit $5 \mathrm{~nm}$; Ex. 300-650 nm, slit $12 \mathrm{~nm}$,

- DPP dye 5, Em. $650 \mathrm{~nm}$, slit $5 \mathrm{~nm}$; Ex. 300-630 nm, slit $12 \mathrm{~nm}$,

- DPP dye 7, Em. 650 nm, slit $5 \mathrm{~nm}$; Ex. 300-630 nm, slit $12 \mathrm{~nm}$,

- BC-DPP-1, Em. 835 nm, slit $5 \mathrm{~nm}$, Ex. 300-825 nm, slit $12 \mathrm{~nm}$,

- BC-DPP-2, Em. 835 nm, slit $5 \mathrm{~nm}$, Ex. 300-825 nm, slit $12 \mathrm{~nm}$,

- BC-DPP-3, Em. 835 nm, slit 5 nm, Ex. 300-825 nm, slit 12 nm.

All fluorescence spectra were corrected until $850 \mathrm{~nm}$. 
Fluorescence quantum yields were measured at $25^{\circ} \mathrm{C}$ by a relative method using the suitable standard (see Table S1, dilution by a factor of 30 between absorption and fluorescence measurements except those peformed in the NIR range for ICG and triads, no dilution). The following equation was used to determine the relative fluorescence quantum yield:

$$
\Phi_{\mathrm{F}}(\mathrm{x})=\left(\mathrm{A}_{\mathrm{S}} / \mathrm{A}_{\mathrm{X}}\right)\left(\mathrm{F}_{\mathrm{X}} / \mathrm{F}_{\mathrm{S}}\right)\left(\mathrm{n}_{\mathrm{X}} / \mathrm{n}_{\mathrm{S}}\right)^{2} \Phi_{\mathrm{F}}(\mathrm{s})
$$

where $\mathrm{A}$ is the absorbance (in the range of 0.01-0.1 A.U.), $\mathrm{F}$ is the area under the emission curve, $\mathrm{n}$ is the refractive index of the solvents (at $25{ }^{\circ} \mathrm{C}$ ) used in measurements, and the subscripts $\mathrm{s}$ and $\mathrm{x}$ represent standard and unknown, respectively.

Table S1. Experimental conditions used for the determination of fluorescence quantum yields.

\begin{tabular}{|c|c|c|c|c|c|}
\hline Fluorophore & Solvent ${ }^{\mathrm{a}}$ & $\lambda \operatorname{Ex}(\mathrm{nm})$ & $\begin{array}{c}\text { Standard } \\
(\text { std })^{\mathrm{b}}\end{array}$ & $\begin{array}{c}\Phi_{\mathrm{F}(\mathrm{std})} / \\
\text { solvent }^{\mathrm{b}}\end{array}$ & $\Phi_{\mathrm{F}}$ \\
\hline 1 & $\mathrm{CHCl}_{3}$ & 550 & SR101 & $0.95 / \mathrm{EtOH}$ & 0.55 \\
\hline 1 & toluene & 550 & SR101 & $0.95 / \mathrm{EtOH}$ & 0.77 \\
\hline 5 & $\mathrm{CHCl}_{3}$ & 450 & Fluorescein & $\begin{array}{c}0.90 / 0.1 \mathrm{M} \\
\mathrm{NaOH}\end{array}$ & 1.00 \\
\hline 5 & toluene & 450 & Fluorescein & $\begin{array}{c}0.90 / 0.1 \mathrm{M} \\
\mathrm{NaOH}\end{array}$ & 0.95 \\
\hline 7 & $\mathrm{CHCl}_{3}$ & 450 & Fluorescein & $\begin{array}{c}0.90 / 0.1 \mathrm{M} \\
\mathrm{NaOH}\end{array}$ & 0.89 \\
\hline 7 & toluene & 450 & Fluorescein & $\begin{array}{c}0.90 / 0.1 \mathrm{M} \\
\mathrm{NaOH}\end{array}$ & 0.88 \\
\hline BC-DPP-1 & $\mathrm{CHCl}_{3}$ & 720 & ICG & $\begin{array}{l}0.106 / \\
\text { DMSO }\end{array}$ & 0.075 \\
\hline BC-DPP-1 & toluene & 720 & $\mathrm{ICG}$ & $\begin{array}{l}0.106 / \\
\text { DMSO }\end{array}$ & 0.08 \\
\hline BC-DPP-2 & $\mathrm{CHCl}_{3}$ & 690 & $\mathrm{ICG}$ & $\begin{array}{l}0.106 / \\
\text { DMSO }\end{array}$ & 0.11 \\
\hline BC-DPP-2 & toluene & 690 & ICG & $\begin{array}{l}0.106 / \\
\text { DMSO }\end{array}$ & 0.12 \\
\hline BC-DPP-3 & $\mathrm{CHCl}_{3}$ & 680 & ICG & $\begin{array}{l}0.106 / \\
\text { DMSO }\end{array}$ & 0.065 \\
\hline
\end{tabular}


$\begin{array}{lllll}\text { BC-DPP-3 toluene } & 680 & \text { ICG } & 0.106 / & 0.13\end{array}$

a The following refractive index values were used: 1.446 for $\mathrm{CHCl}_{3}, 1.479$ for DMSO, 1.361 for EtOH, 1.497 for toluene and 1.337 for $0.1 \mathrm{M}$ aq. $\mathrm{NaOH}$.

${ }^{\mathrm{b}}$ Brouwer AM. Standards for photoluminescence quantum yield measurements in solution Pure Appl. Chem. 2011; 83: 2213-28.

Energy transfer efficiency was calculated based on the equation $\left\{100 \times\left[1-\left(\Phi_{\mathrm{F}}\right.\right.\right.$ donor in triad $) /\left(\Phi_{\mathrm{F}}\right.$ free donor $\left.\left.)\right]\right\}$.

The following DPP dyes were used as free donors and their fluorescence quantum yields within the triads were determined as previously described:

1 for BC-DPP-1 (Ex. at 550 nm, Em. 560-725 nm, slit $5 \mathrm{~nm}), \Phi_{\mathrm{F}}(\mathbf{1}$ in BC-DPP-1) $=0.013$ in $\mathrm{CHCl}_{3}$ and 0.02 in toluene,

5 for BC-DPP-2 (Ex. at 450 nm, Em. 470-710 nm, slit $5 \mathrm{~nm}), \Phi_{\mathrm{F}}(\mathbf{5}$ in BC-DPP-2) $=0.013$ in $\mathrm{CHCl}_{3}$ and 0.013 in toluene,

7 for BC-DPP-3 (Ex. 450 nm, Em. 470-710 nm), $\Phi_{\mathrm{F}}\left(7\right.$ in BC-DPP-3) $=0.04$ in $\mathrm{CHCl}_{3}$ and 0.036 in toluene, 


\section{S2 Analytical data}

Fig. S1. ${ }^{1} \mathrm{H}$ NMR spectrum of compound 1 in $\mathrm{CDCl}_{3}(500 \mathrm{MHz})$

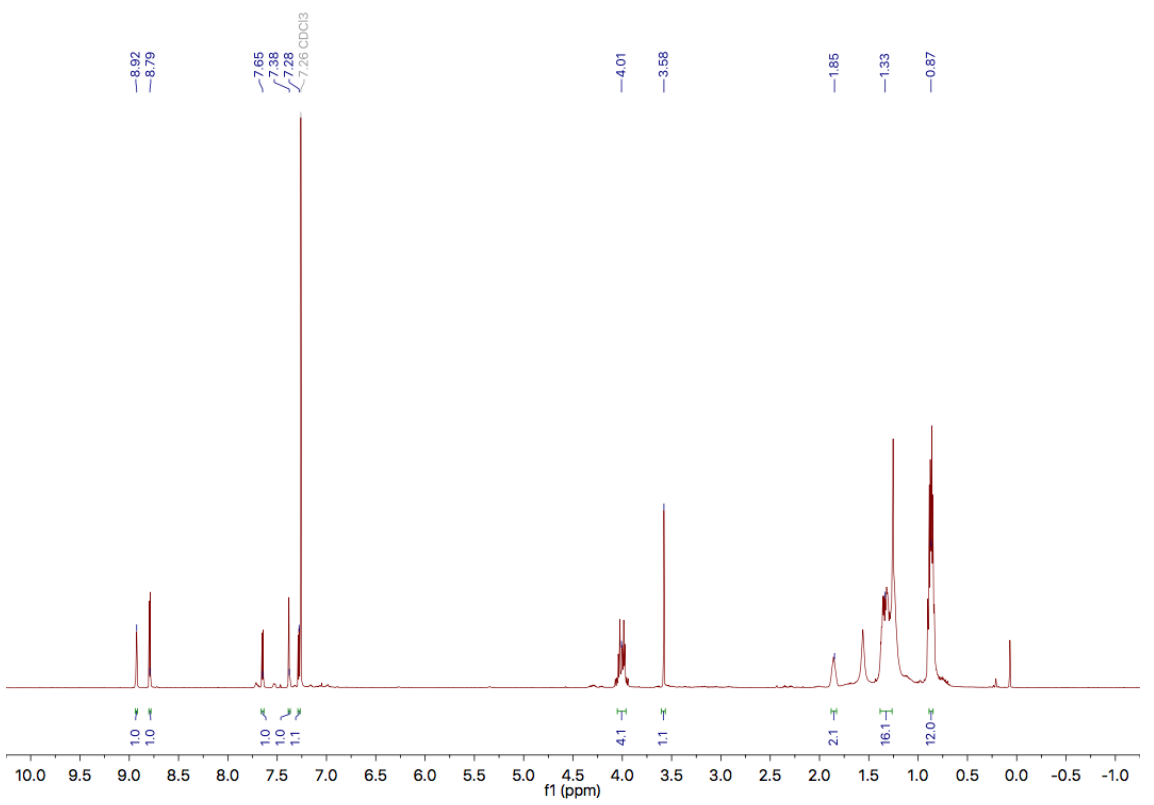

Fig. S2. IR (ATR) spectrum of compound 3

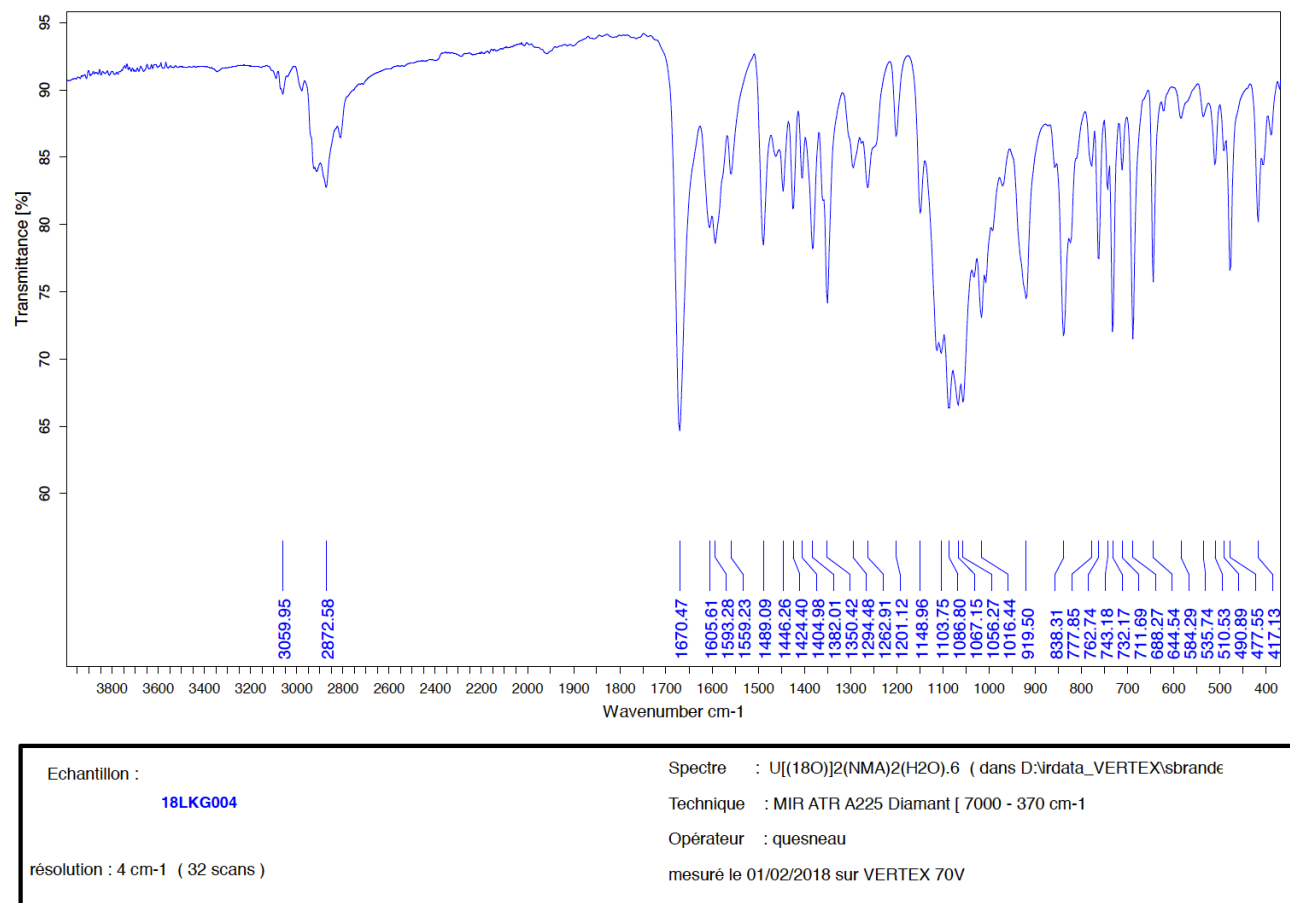


Fig. S3. ${ }^{1} \mathrm{H}$ NMR spectrum of compound 3 in $\mathrm{CDCl}_{3}(500 \mathrm{MHz})$

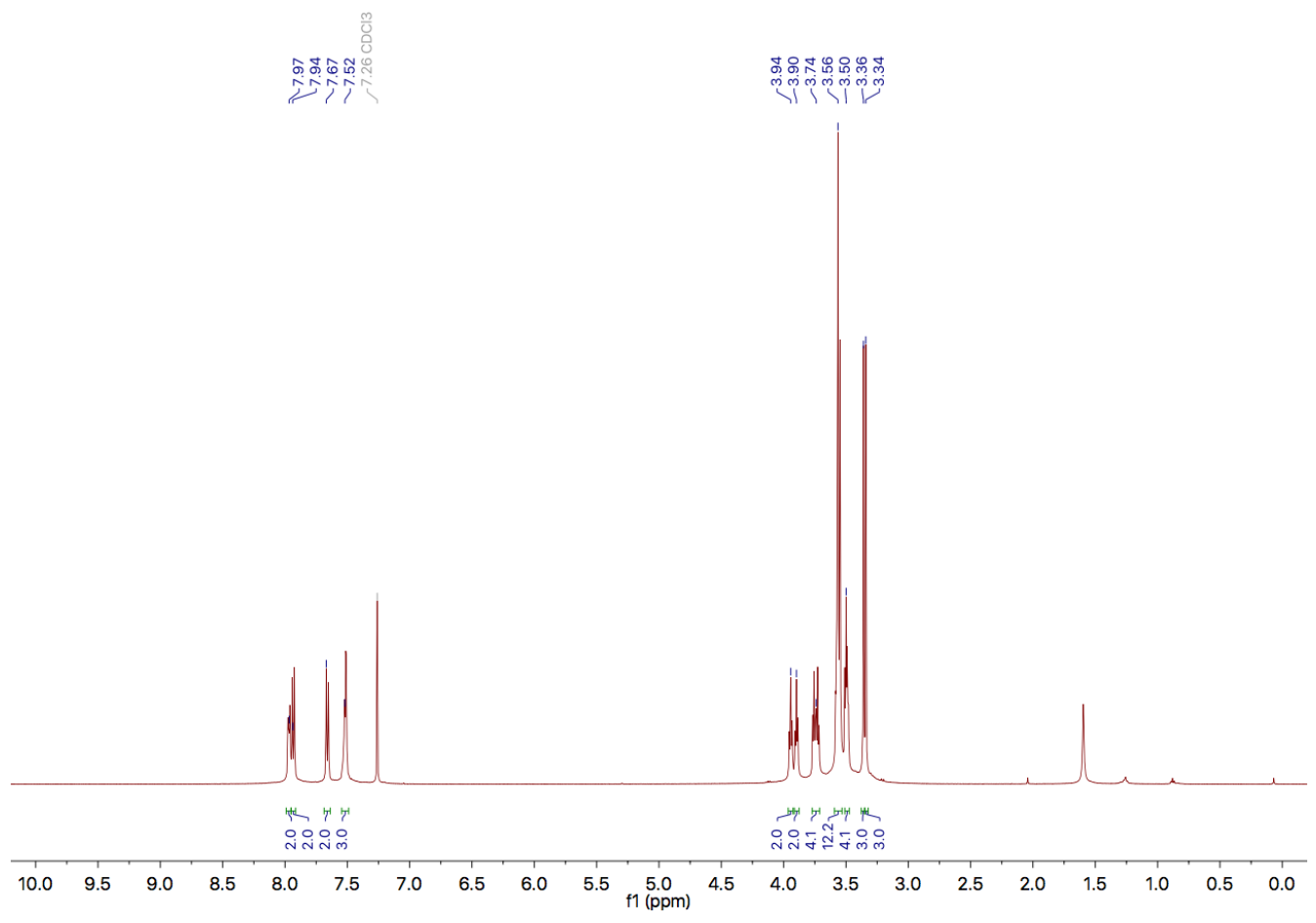

Fig. S4. ${ }^{13} \mathrm{C}$ NMR spectrum (JMOD) of compound 3 in $\mathrm{CDCl}_{3}(126 \mathrm{MHz})$

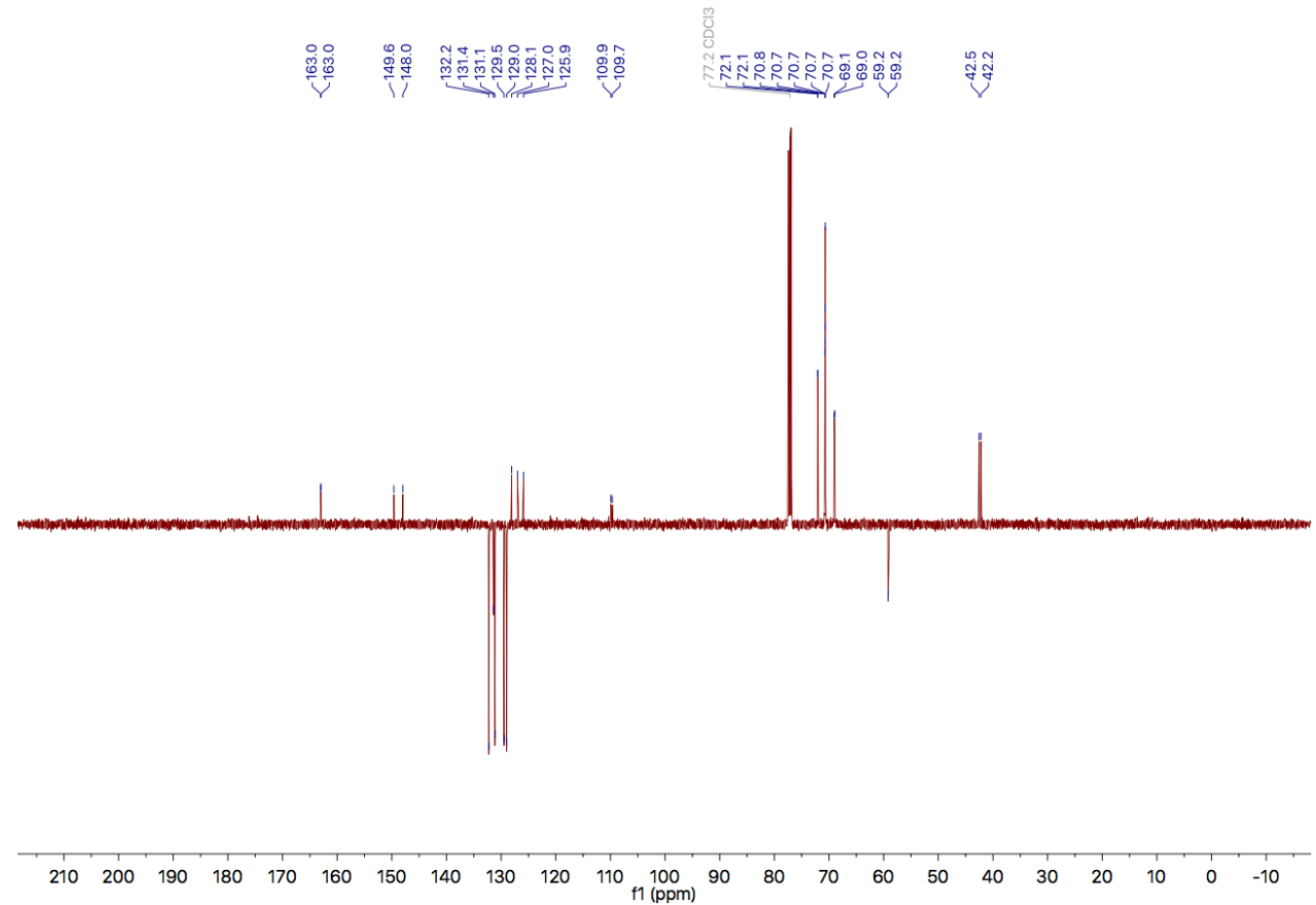


Fig. S5. ESI+ mass spectrum (low resolution) of compound 3

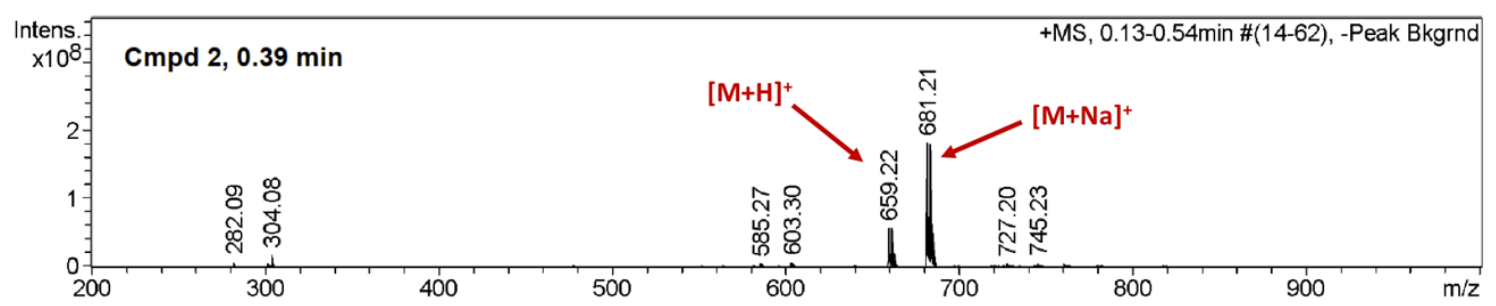

Fig. S6. IR (ATR) spectrum of compound 4

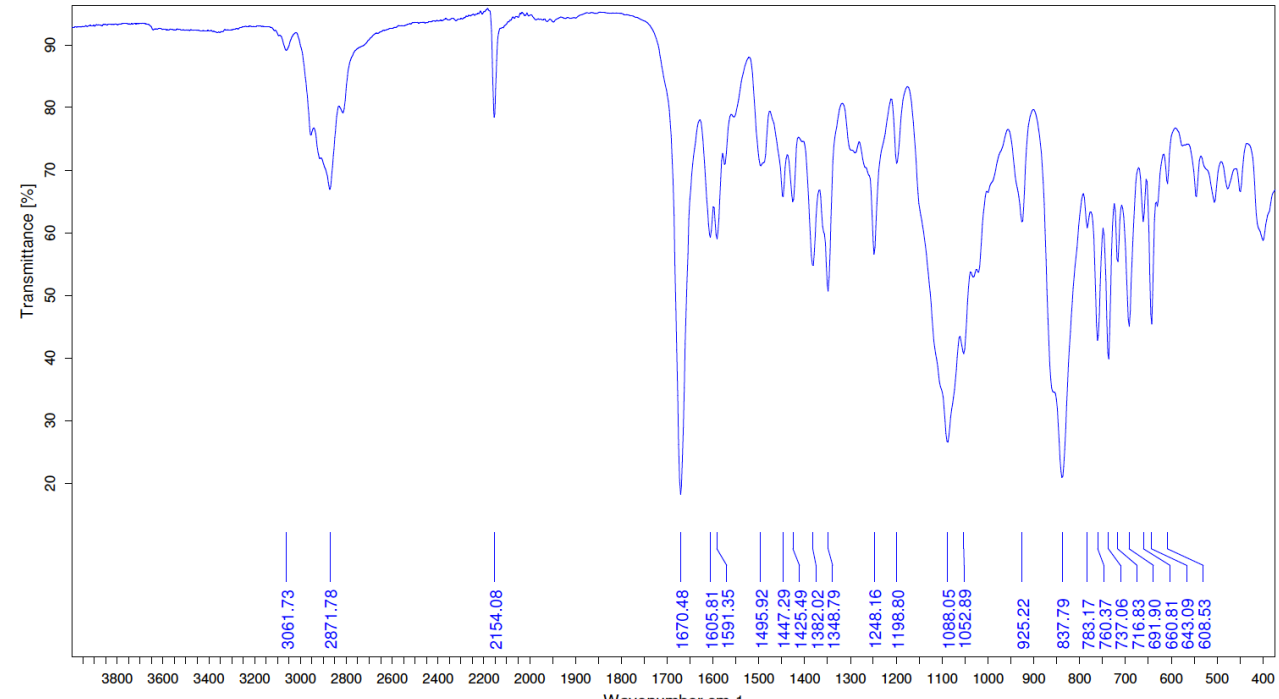

Wavenumber $\mathrm{cm}-1$ 
Fig. S7. ${ }^{1} \mathrm{H}$ NMR spectrum of compound 4 in $\mathrm{CDCl}_{3}(500 \mathrm{MHz})$

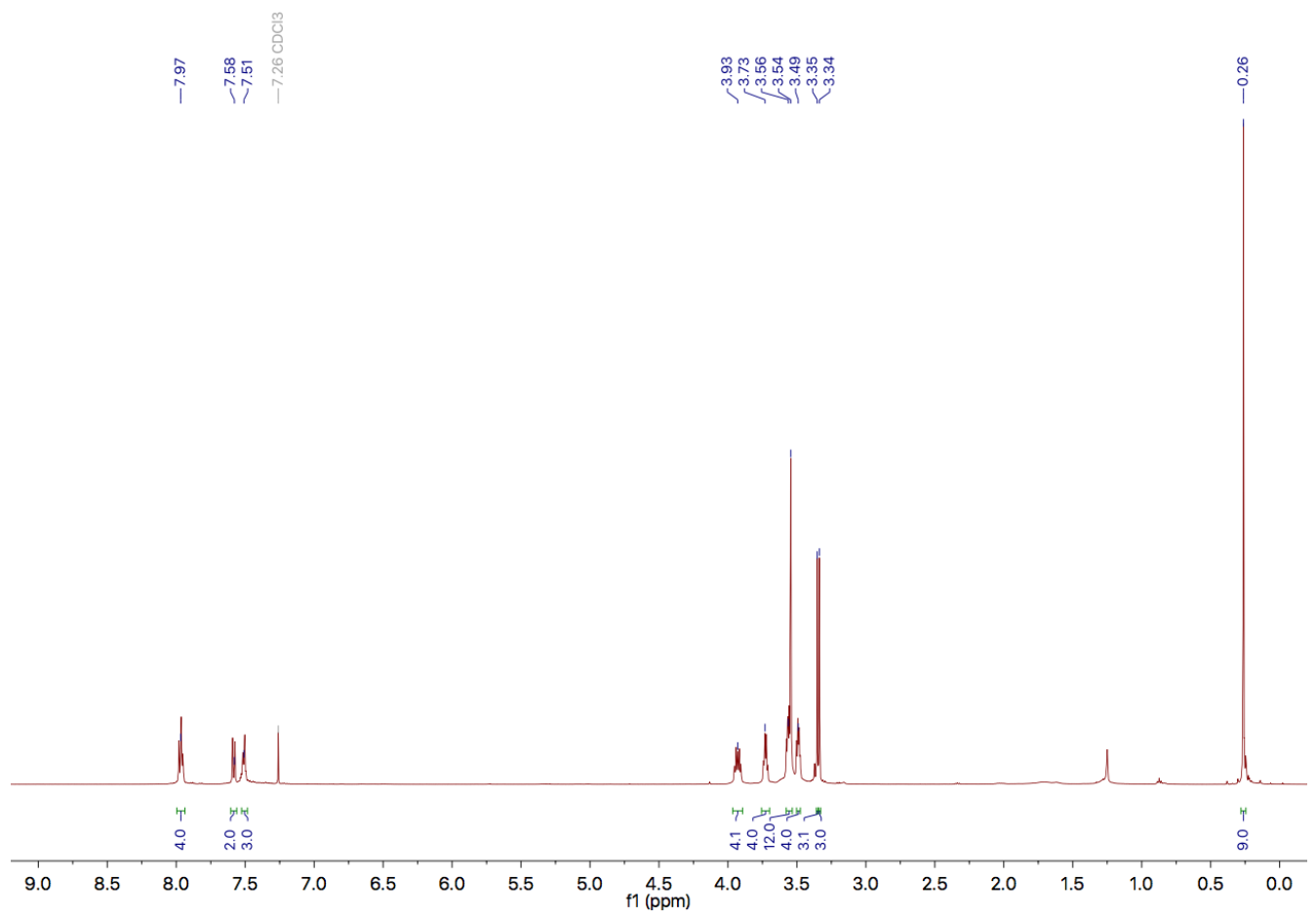

Fig. S8. ${ }^{13} \mathrm{C}$ NMR spectrum (JMOD) of compound 4 in $\mathrm{CDCl}_{3}(126 \mathrm{MHz})$

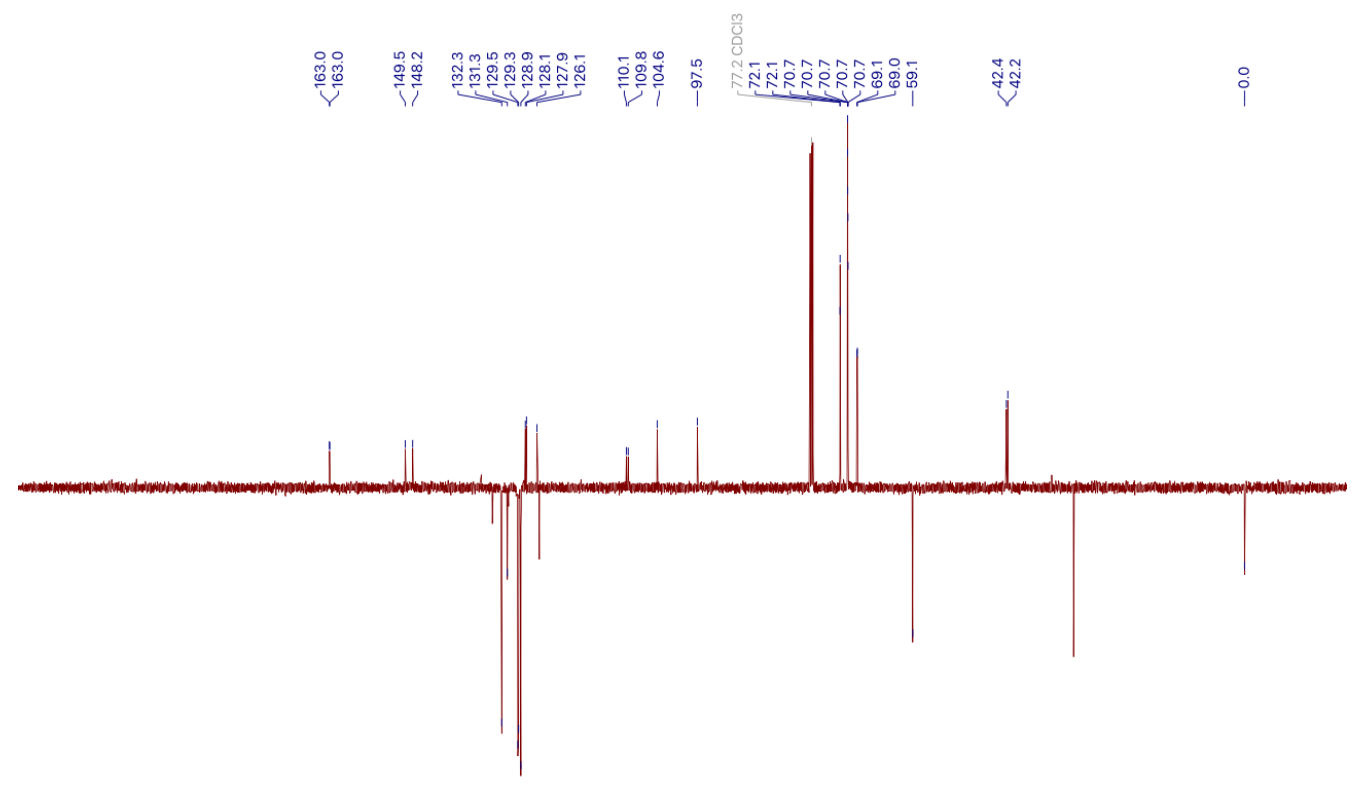

$\begin{array}{llllllllllllllllllllll}210 & 200 & 190 & 180 & 170 & 160 & 150 & 140 & 130 & 120 & 110 \underset{\mathrm{f} 1(\mathrm{ppm})}{100} & 90 & 80 & 70 & 60 & 50 & 40 & 30 & 20 & 10 & 0 & -10\end{array}$ 
Fig. S9. ESI+ mass spectrum (low resolution) of compound 4

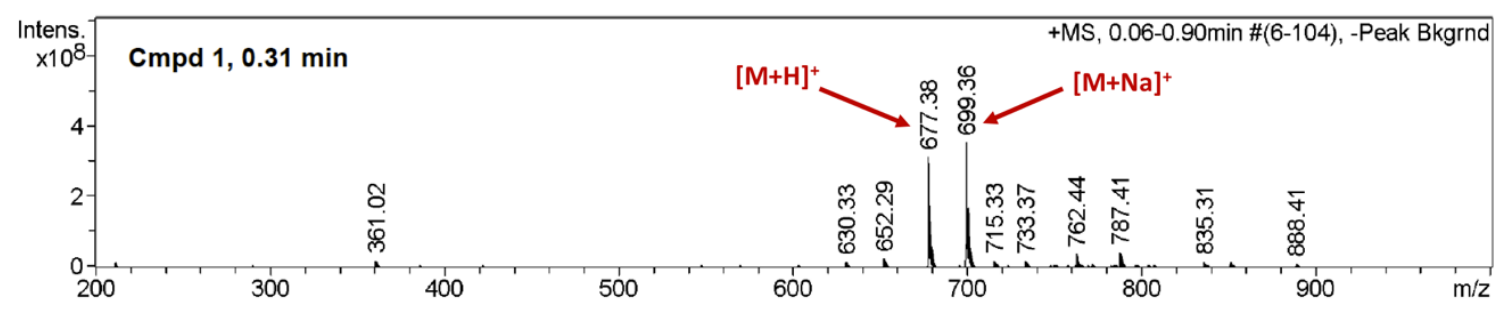

Fig. S10. IR (ATR) spectrum of compound 5

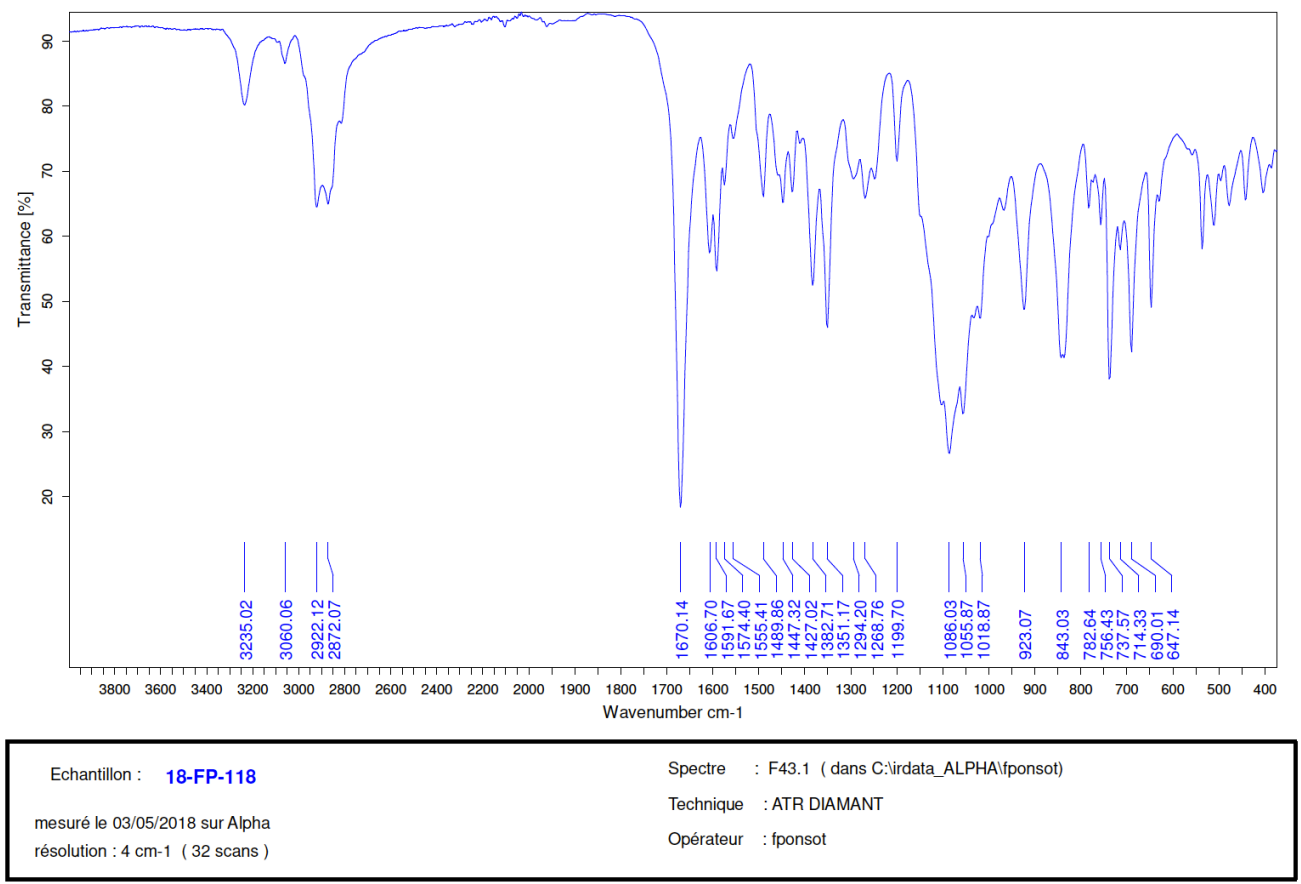


Fig. S11. ${ }^{1} \mathrm{H}$ NMR spectrum of compound 5 in $\mathrm{CDCl}_{3}(500 \mathrm{MHz})$

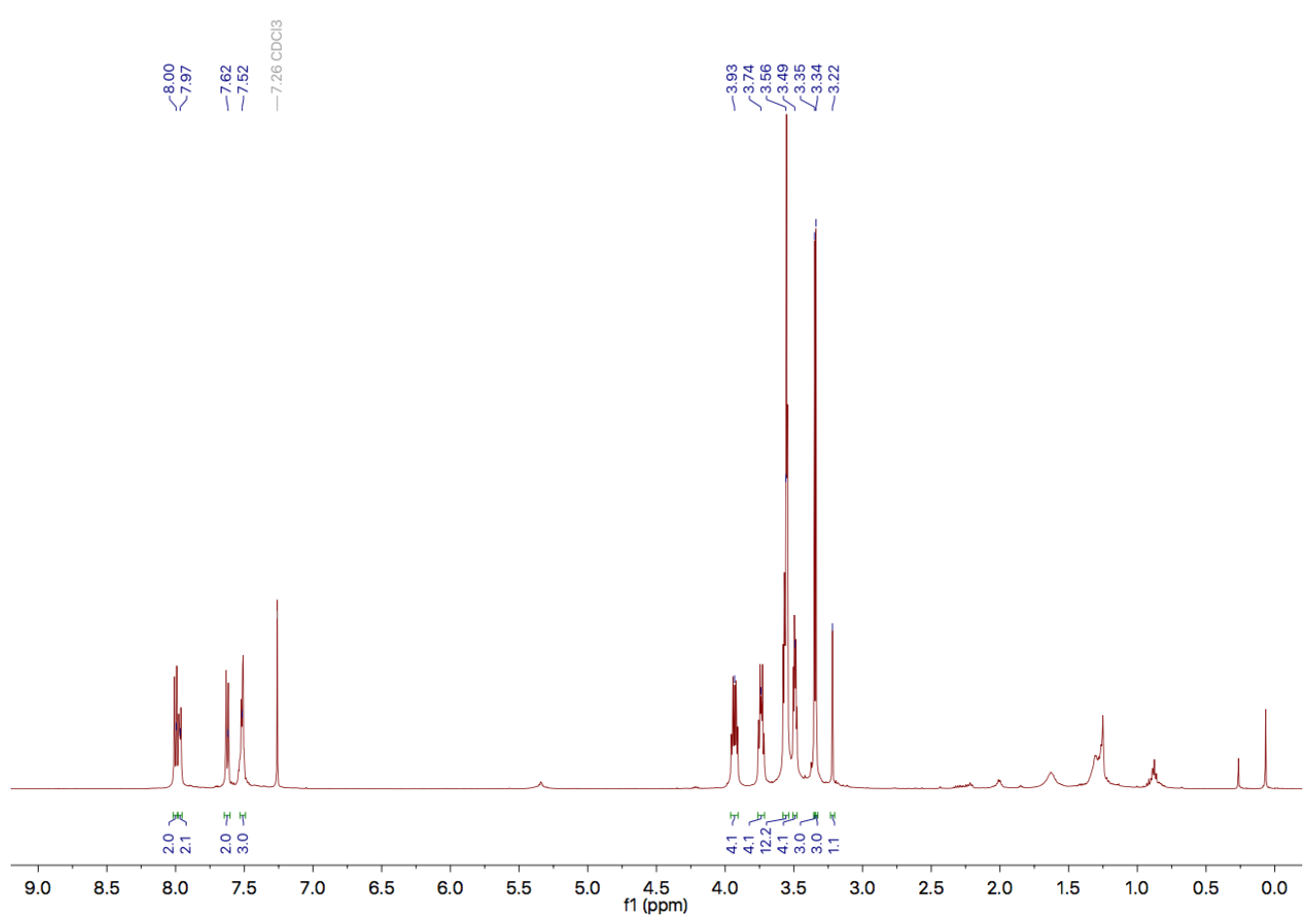

Fig. S12. ${ }^{13} \mathrm{C}$ NMR spectrum (JMOD) of compound 5 in $\mathrm{CDCl}_{3}(126 \mathrm{MHz})$

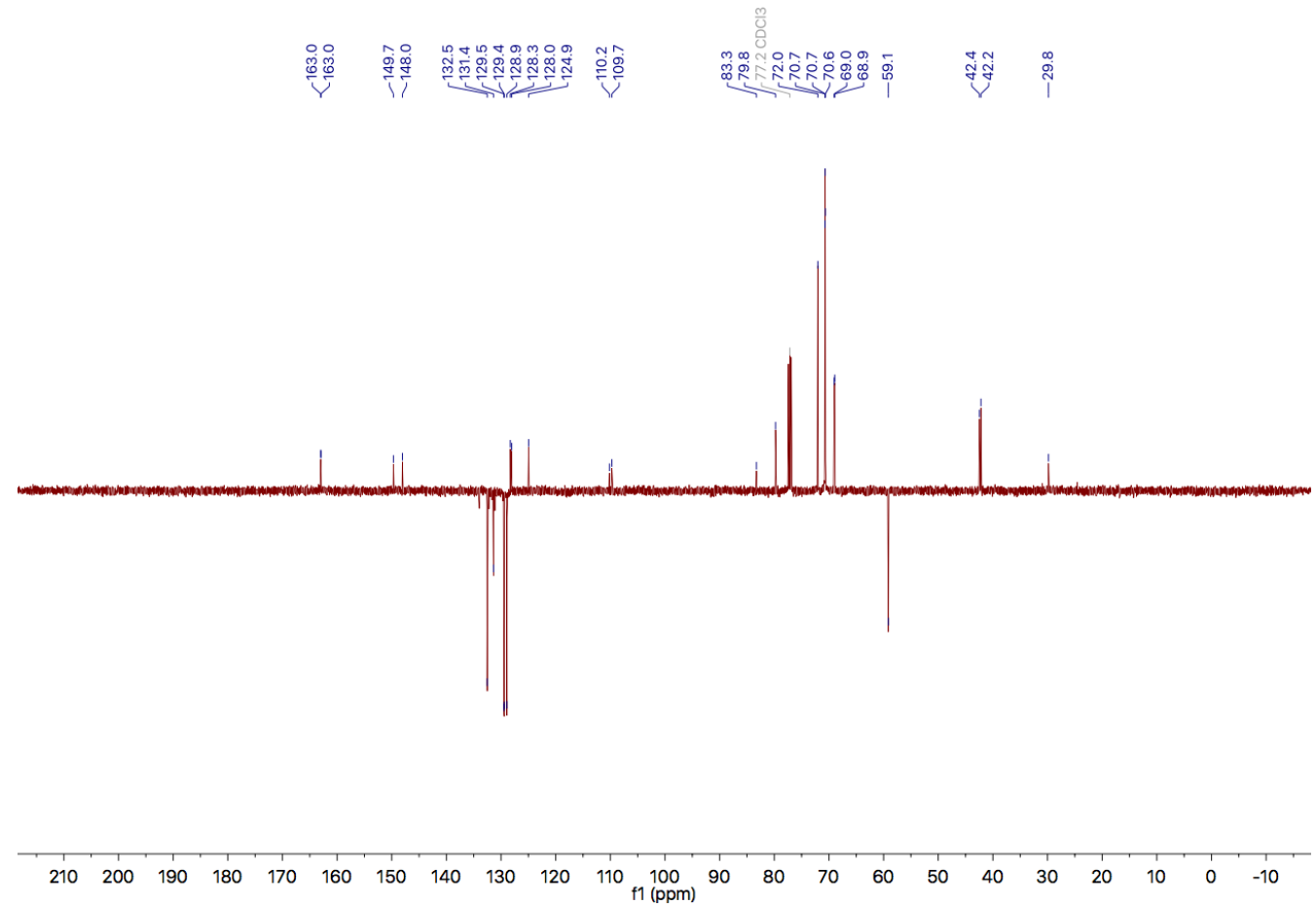


Fig. S13. ESI+ mass spectrum (low resolution) of compound 5

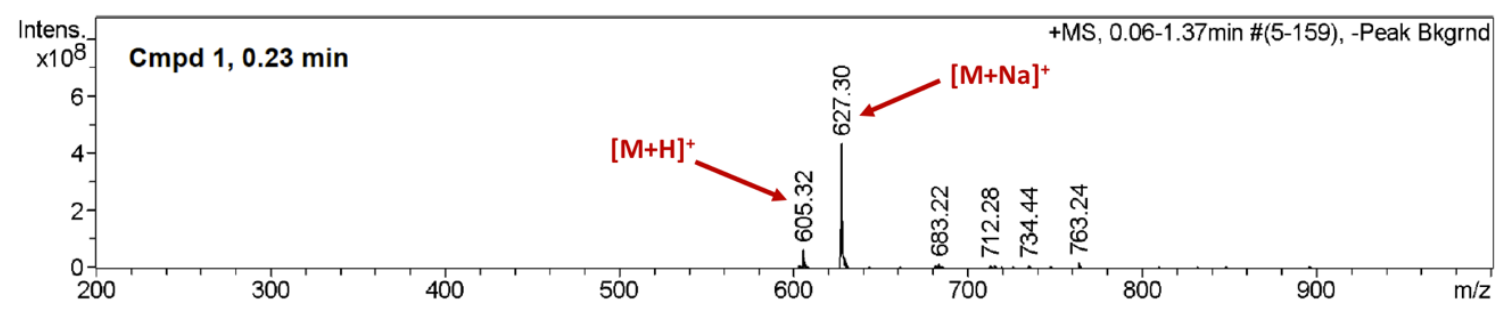

Fig. S14. IR (ATR) spectrum of compound 6

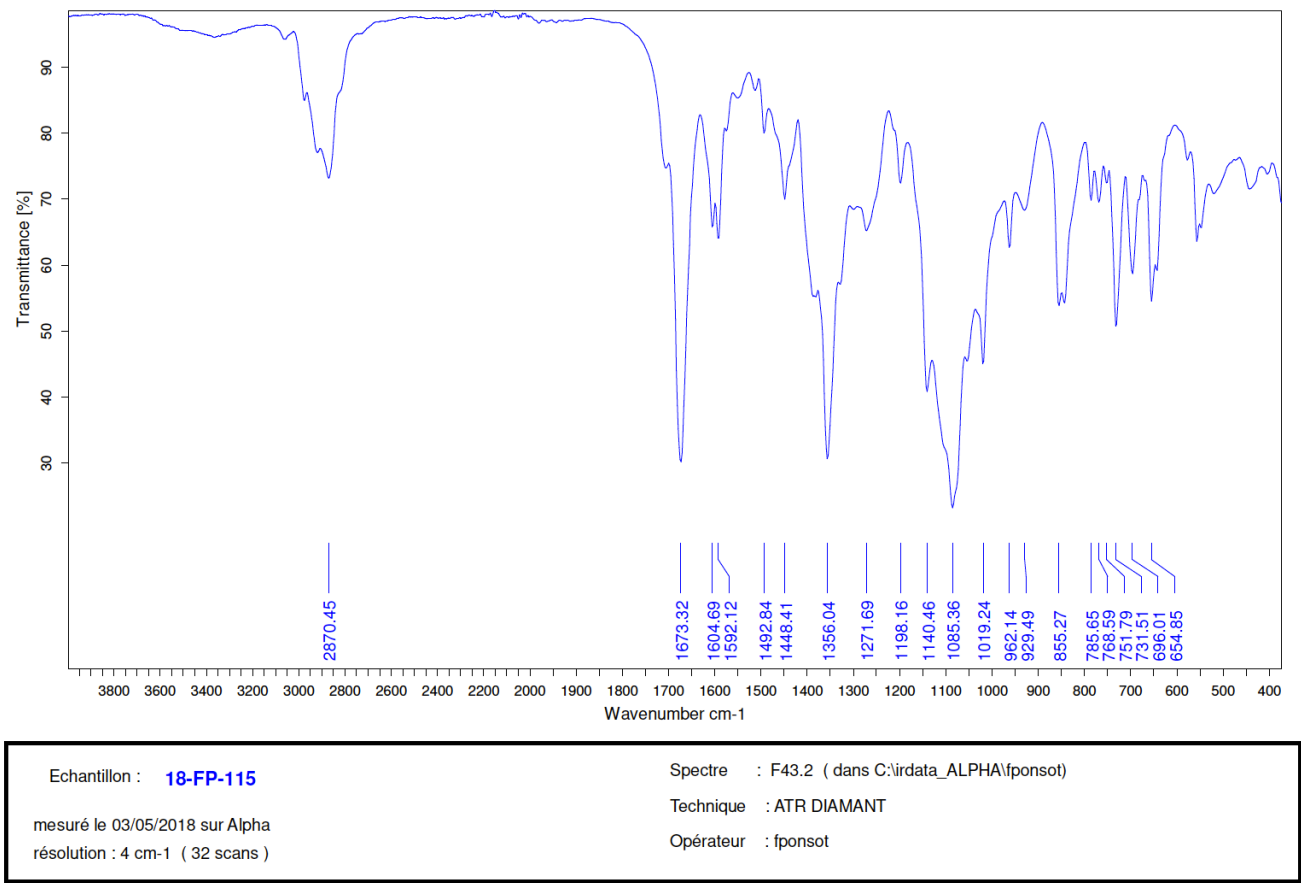


Fig. S15. ${ }^{1} \mathrm{H}$ NMR spectrum of compound 6 in $\mathrm{CDCl}_{3}(500 \mathrm{MHz})$

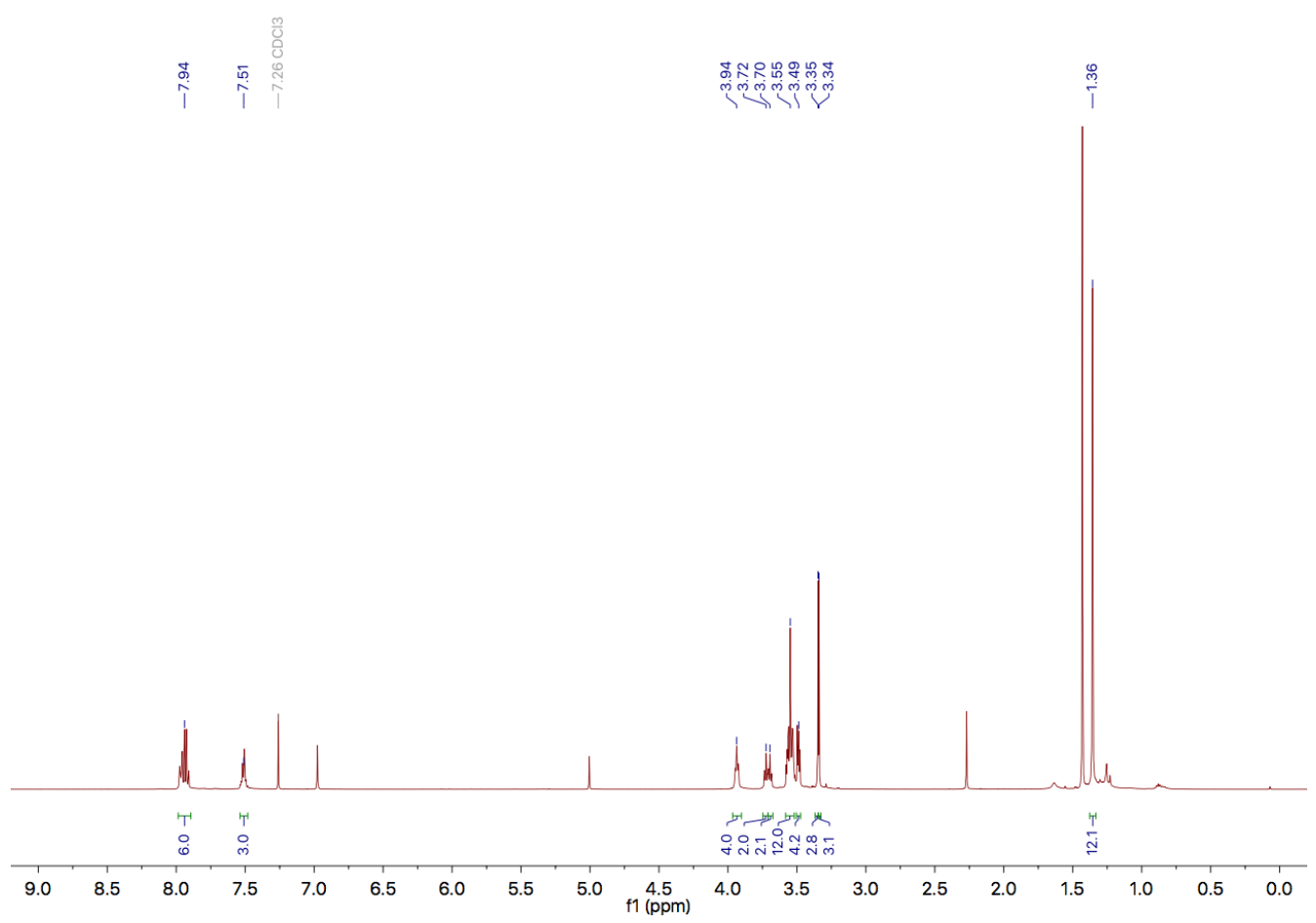

Fig. S16. ${ }^{13} \mathrm{C}$ NMR spectrum (JMOD) of compound 6 in $\mathrm{CDCl}_{3}(126 \mathrm{MHz})$

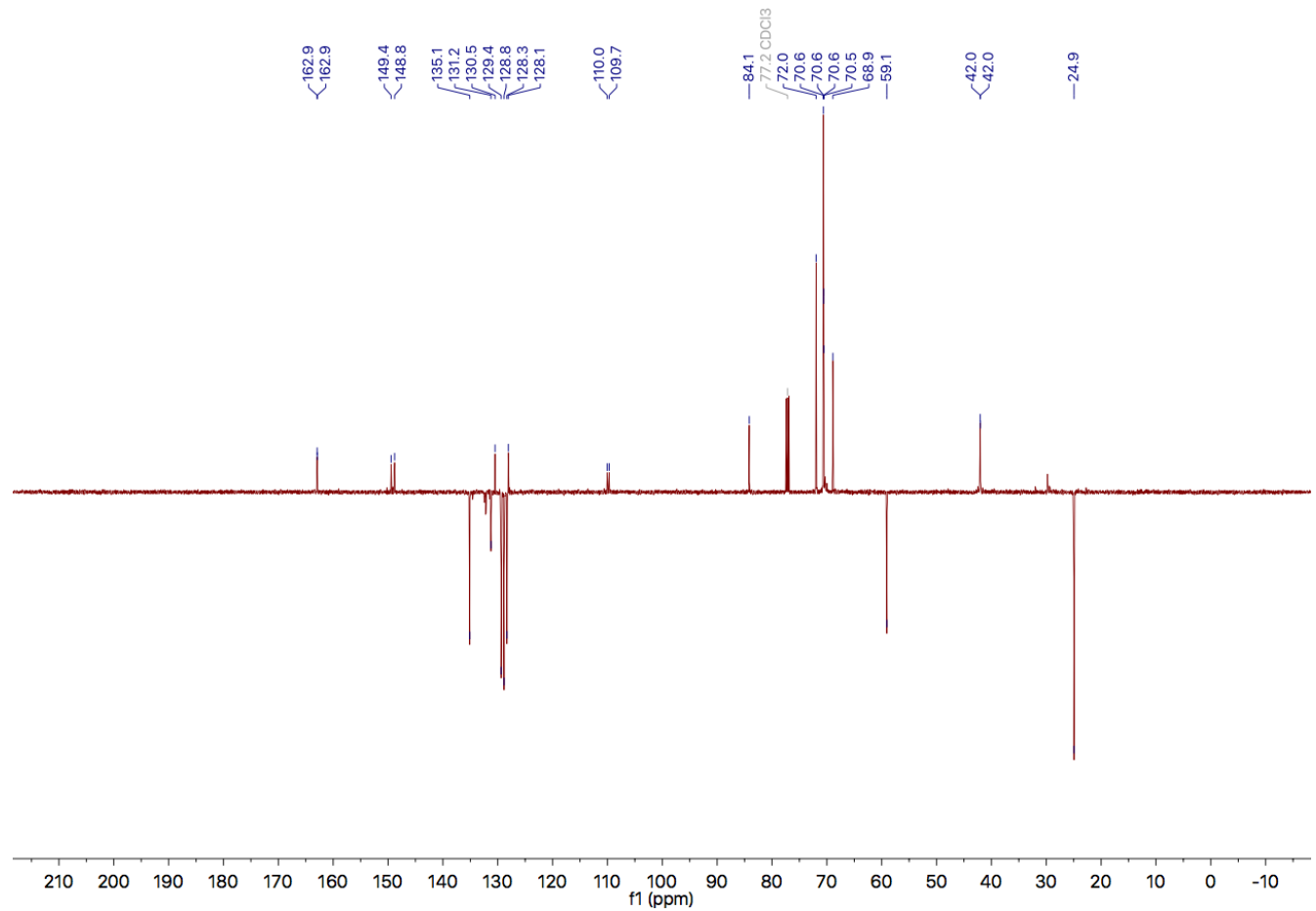


Fig. S17. ESI+ mass spectrum (low resolution) of compound 6

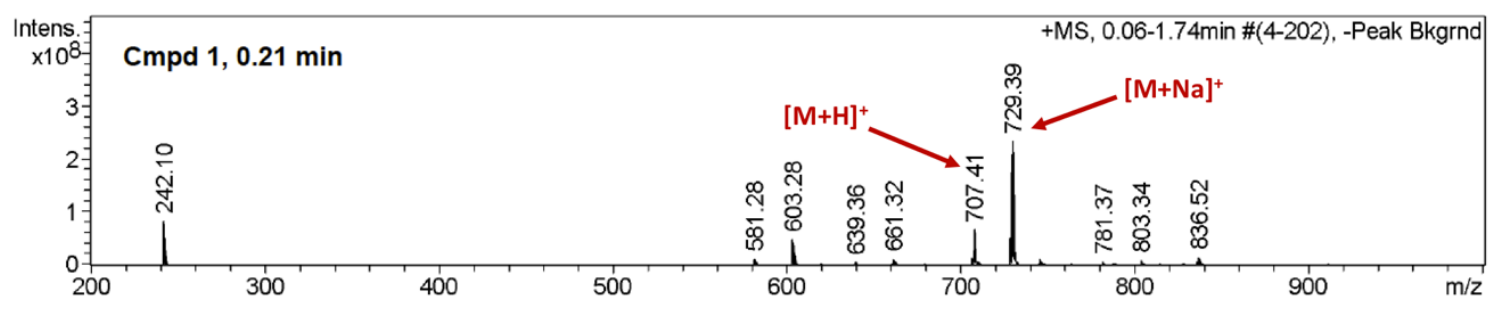

Fig. S18. IR (ATR) spectrum of compound 7

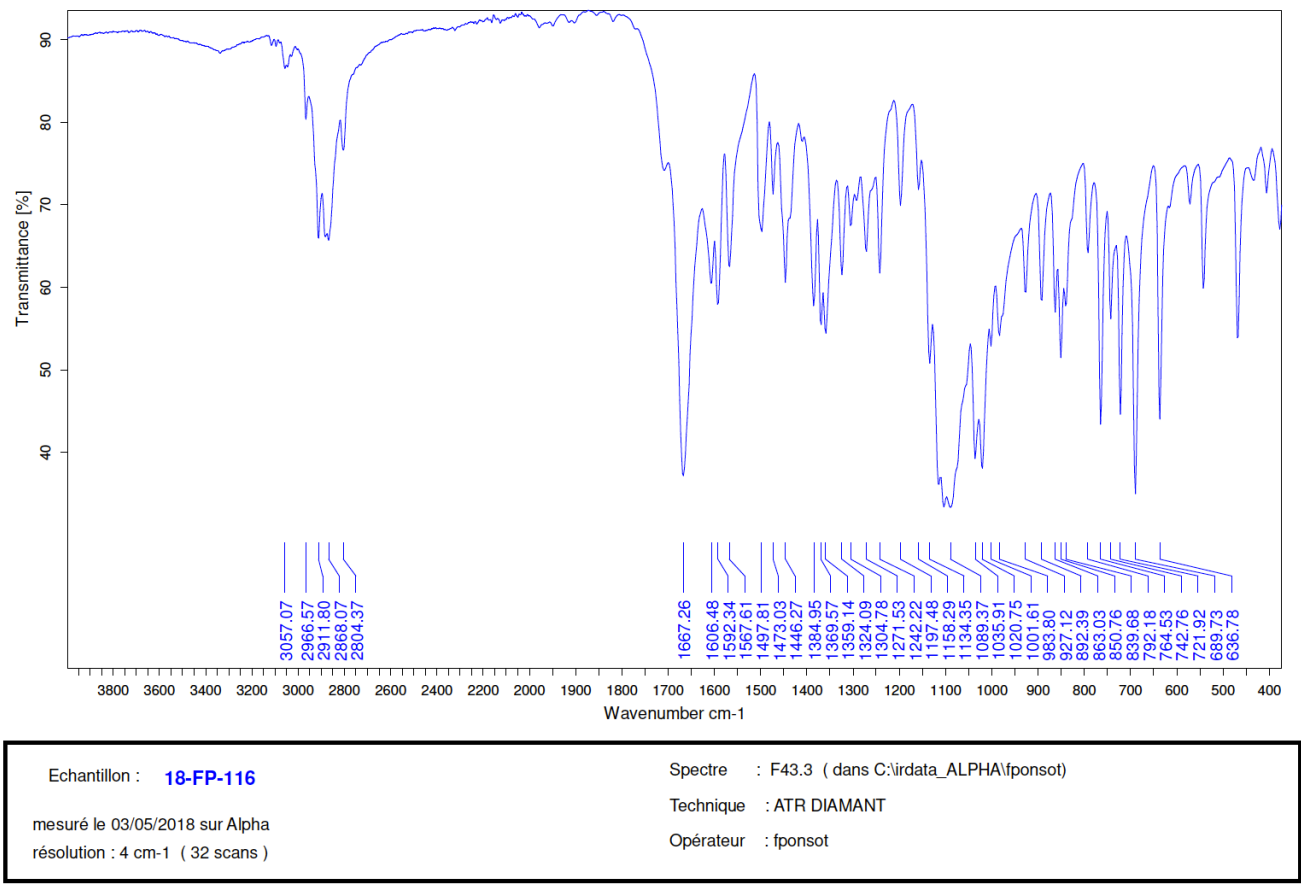


Fig. S19. ${ }^{1} \mathrm{H}$ NMR spectrum of compound 7 in $\mathrm{CDCl}_{3}(500 \mathrm{MHz})$

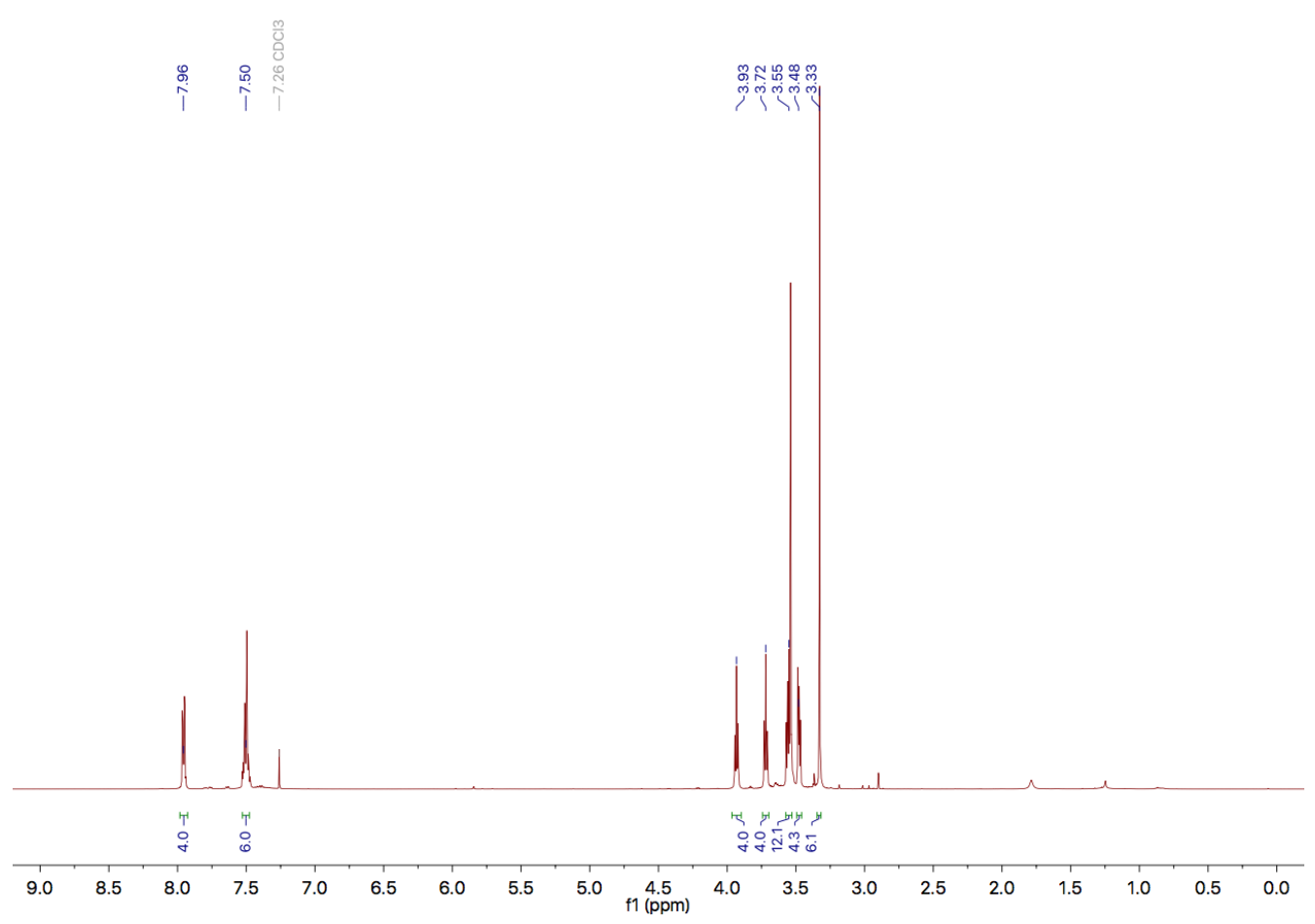

Fig. S20. ${ }^{13} \mathrm{C}$ NMR spectrum (JMOD) of compound 7 in $\mathrm{CDCl}_{3}(126 \mathrm{MHz})$
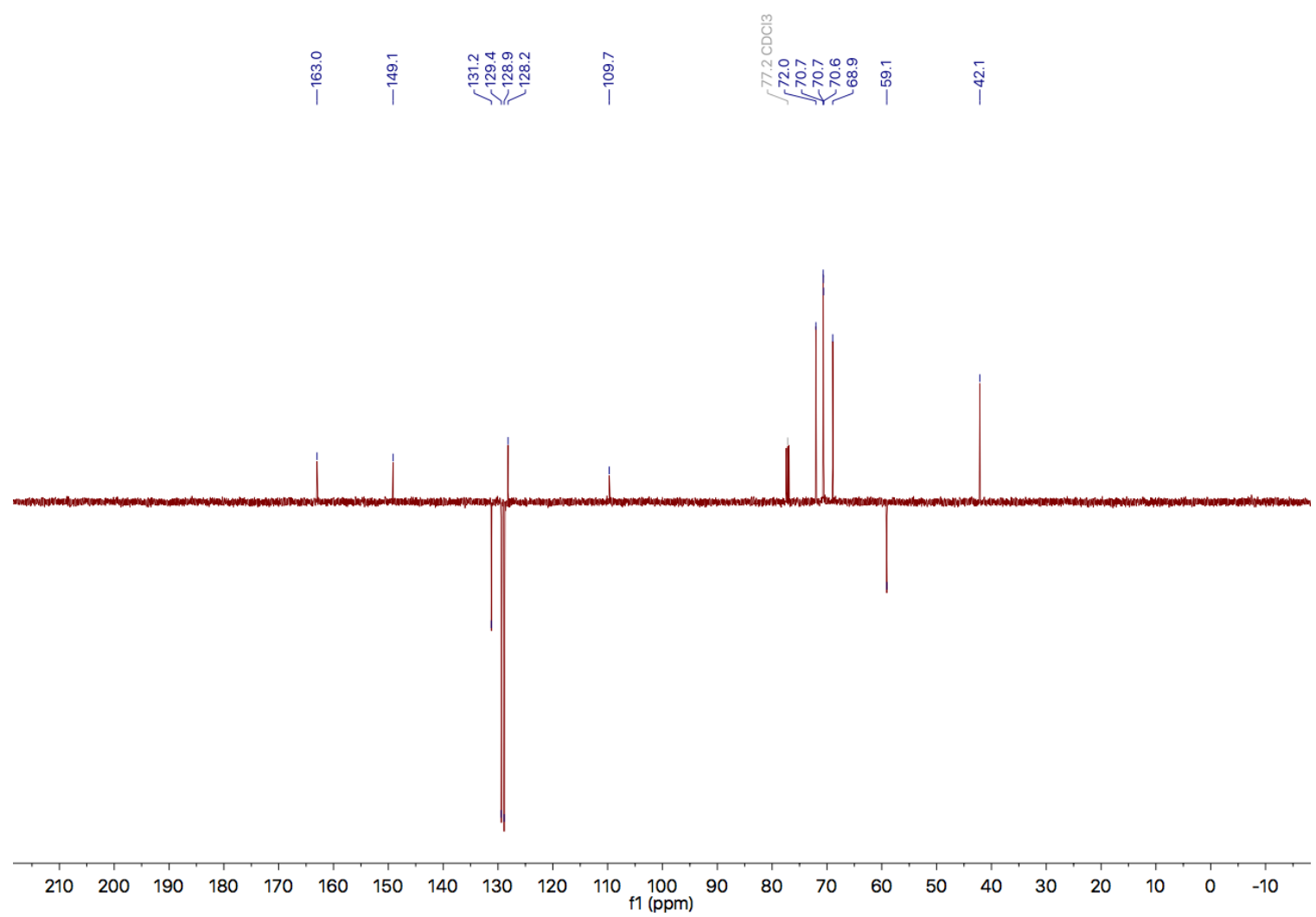
Fig. S21. ESI+ mass spectrum (low resolution) of compound 7

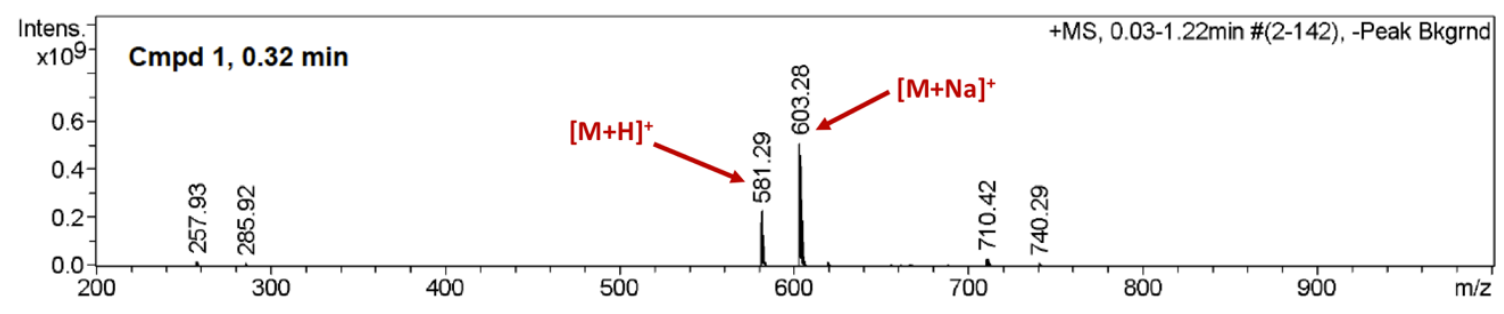

Fig. S22. ${ }^{1} \mathrm{H}$ NMR spectrum of triad BC-DPP-1 in $\mathrm{CDCl}_{3}(500 \mathrm{MHz})$

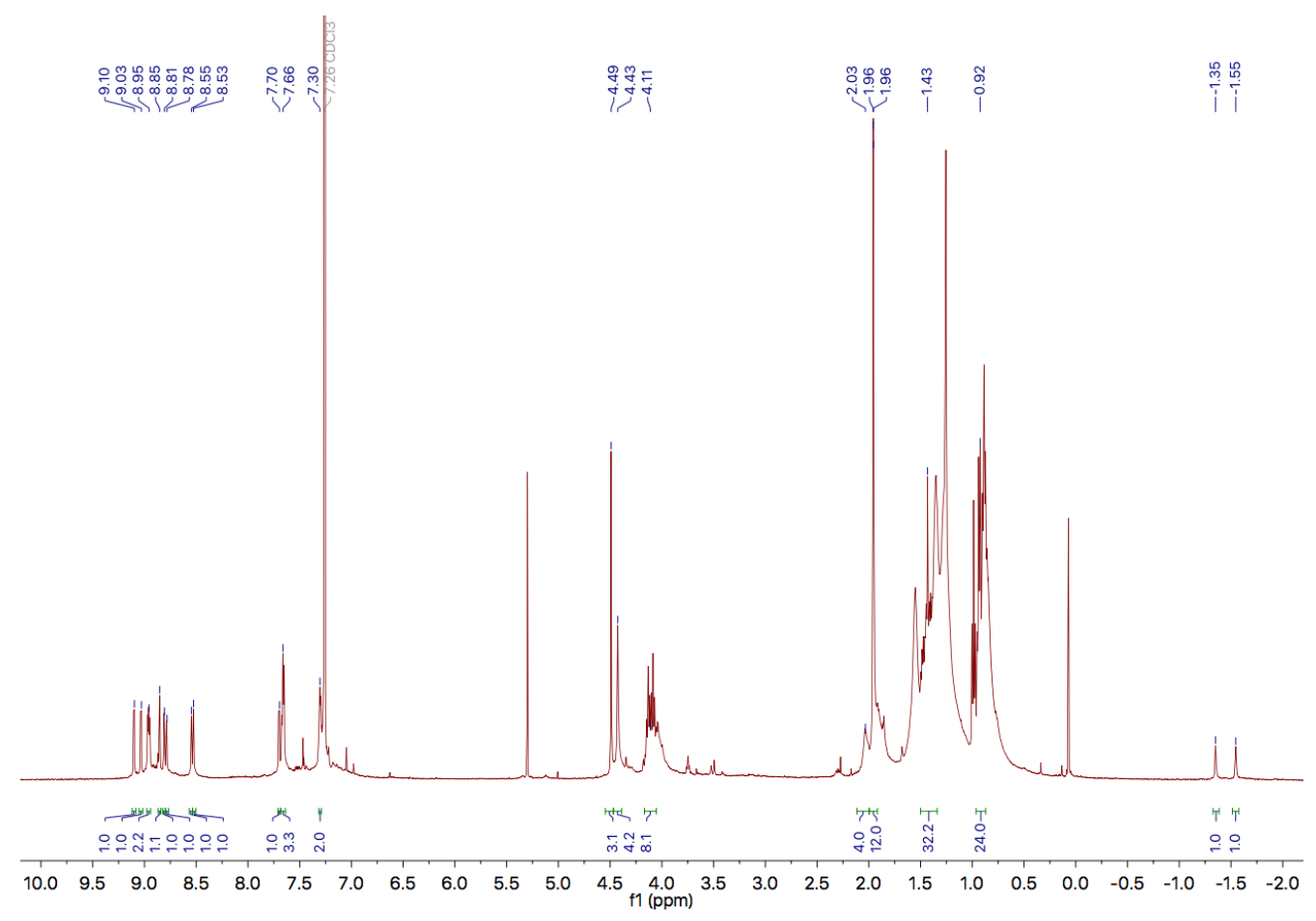


Fig. S23. MALDI-TOF mass spectrum (low resolution, positive mode) of triad BCDPP-1

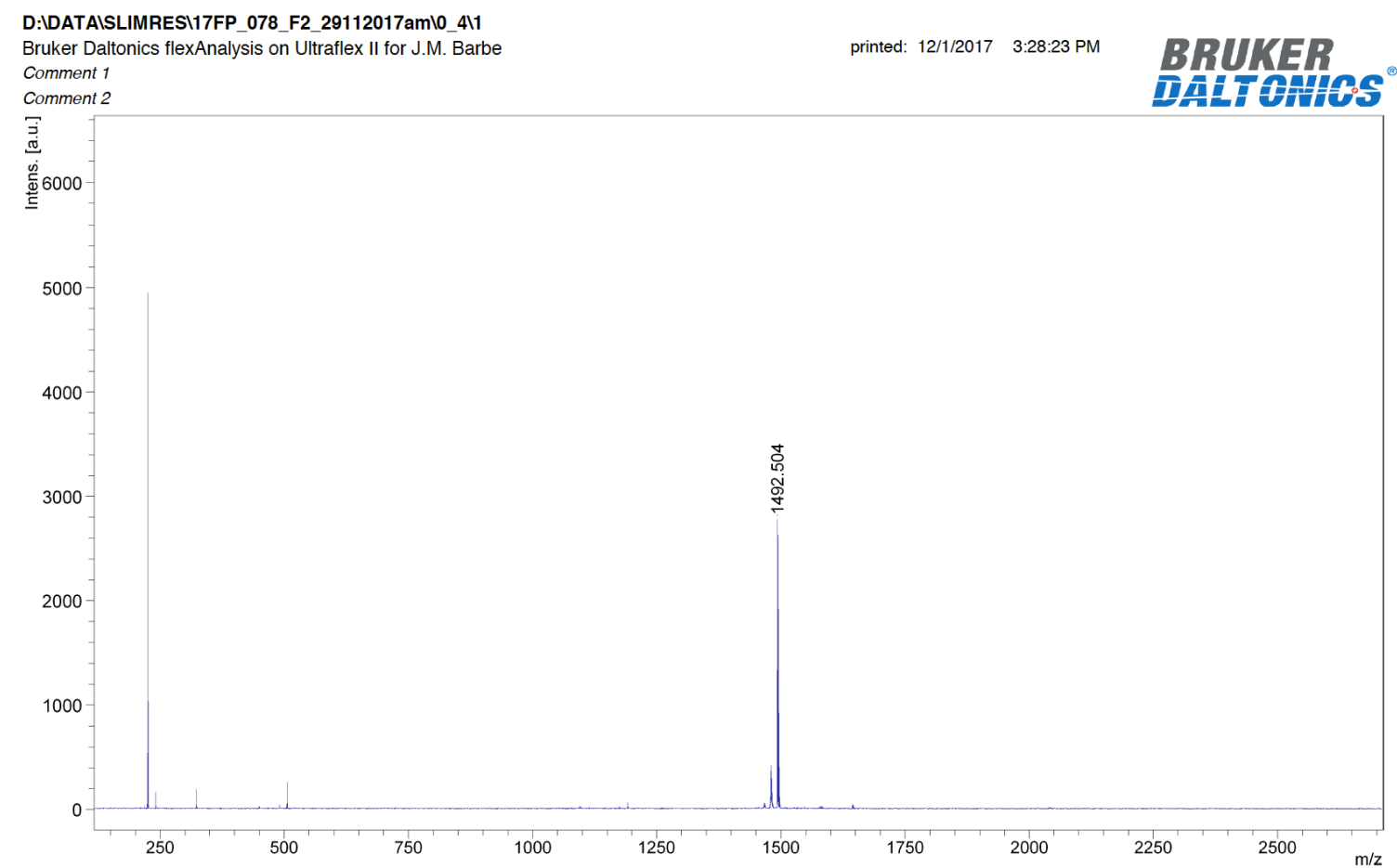

Fig. S24. MALDI-TOF mass spectrum (high resolution, positive mode) of triad BCDPP-1

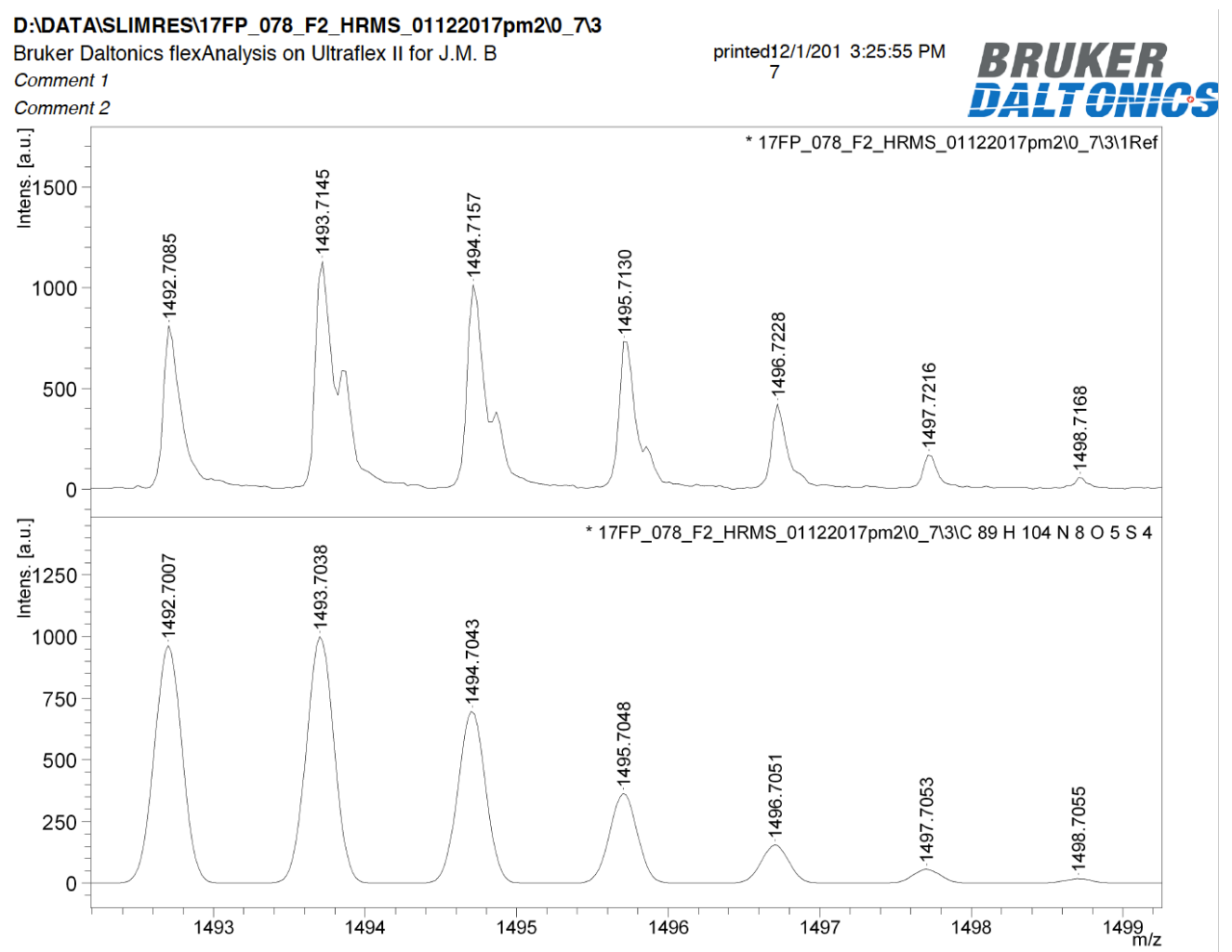


Fig. S25. ESI+ mass spectrum (low resolution) of triad BC-DPP-1

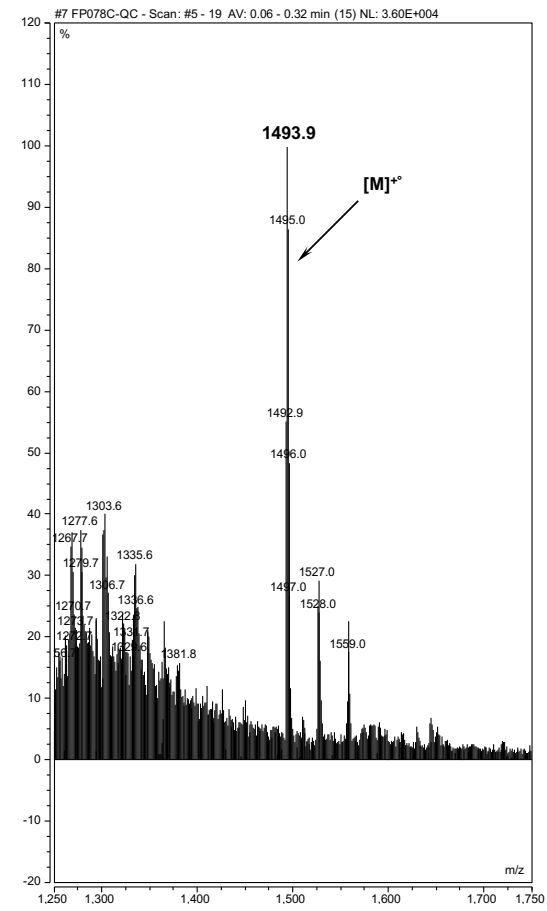

Fig. S26. ${ }^{1} \mathrm{H}$ NMR spectrum of triad $\mathrm{BC}-\mathrm{DPP}-2$ in $\mathrm{CDCl}_{3}(500 \mathrm{MHz})$

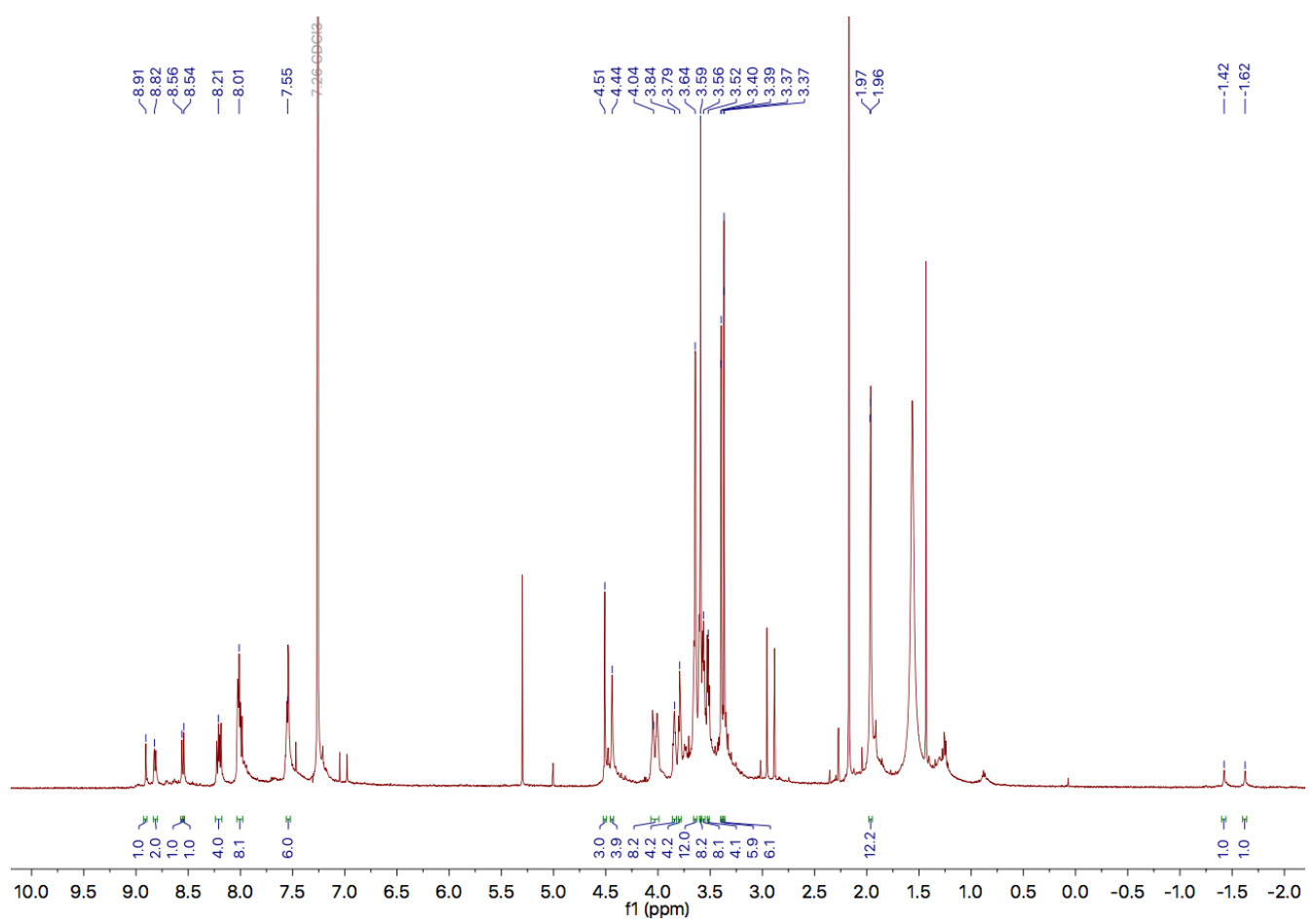


Fig. S27. MALDI-TOF mass spectrum (low resolution, positive mode) of triad BCDPP-2

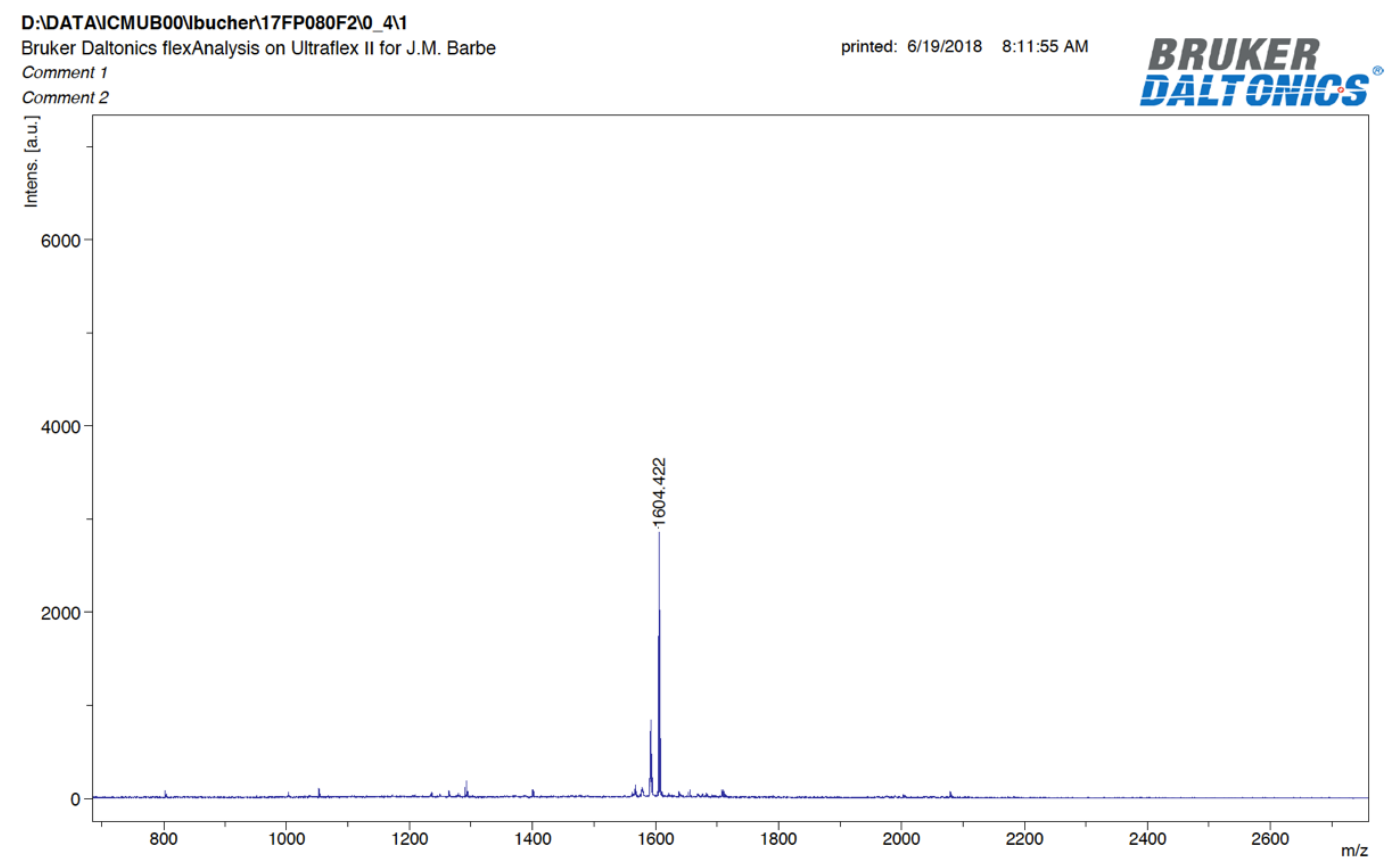

Fig. S28. MALDI-TOF mass spectrum (high resolution, positive mode) of triad BCDPP-2

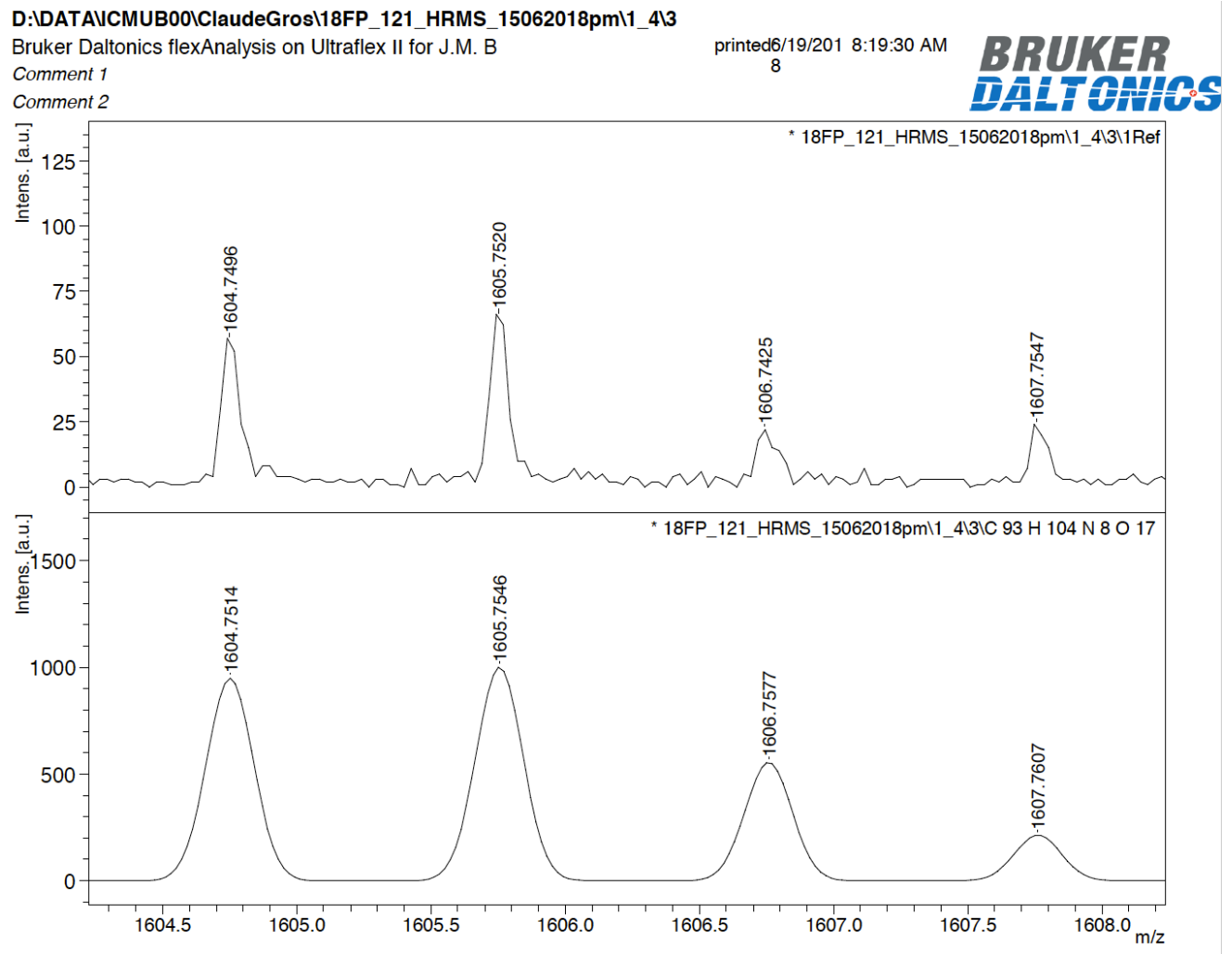


Fig. S29. ESI+ mass spectrum (low resolution) of triad BC-DPP-2

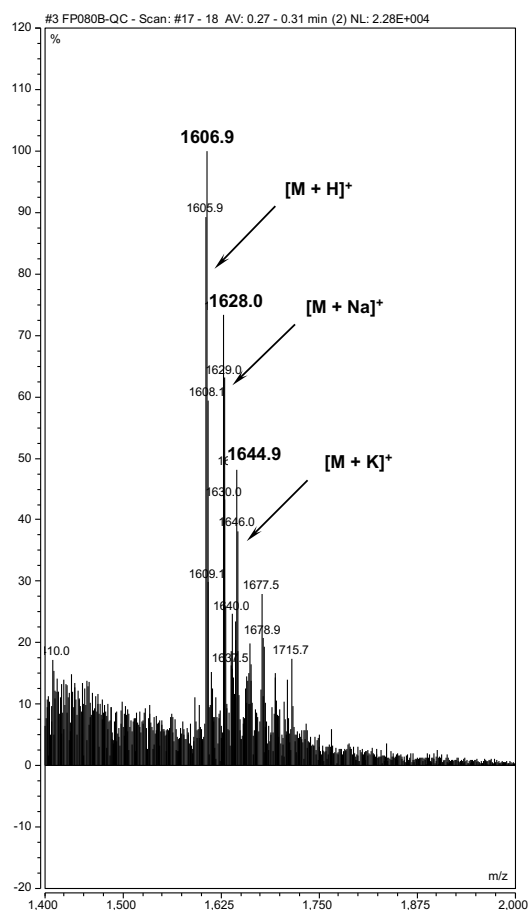

Fig. S30. ${ }^{1} \mathrm{H}$ NMR spectrum of triad $\mathrm{BC}-\mathrm{DPP}-3$ in $\mathrm{CDCl}_{3}(500 \mathrm{MHz})$

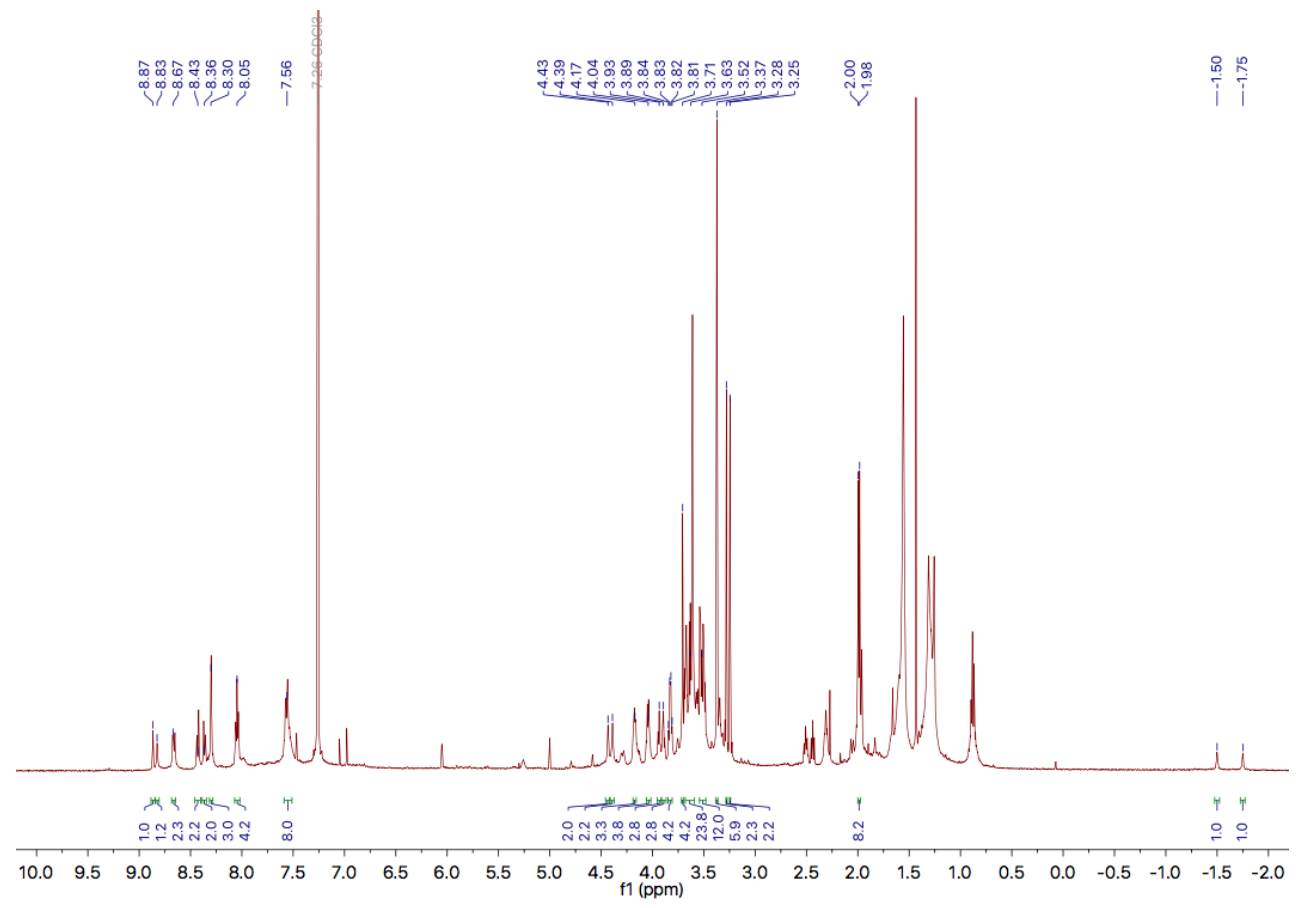


Fig. S31. MALDI-TOF mass spectrum (high resolution, positive mode) of triad BCDPP-3

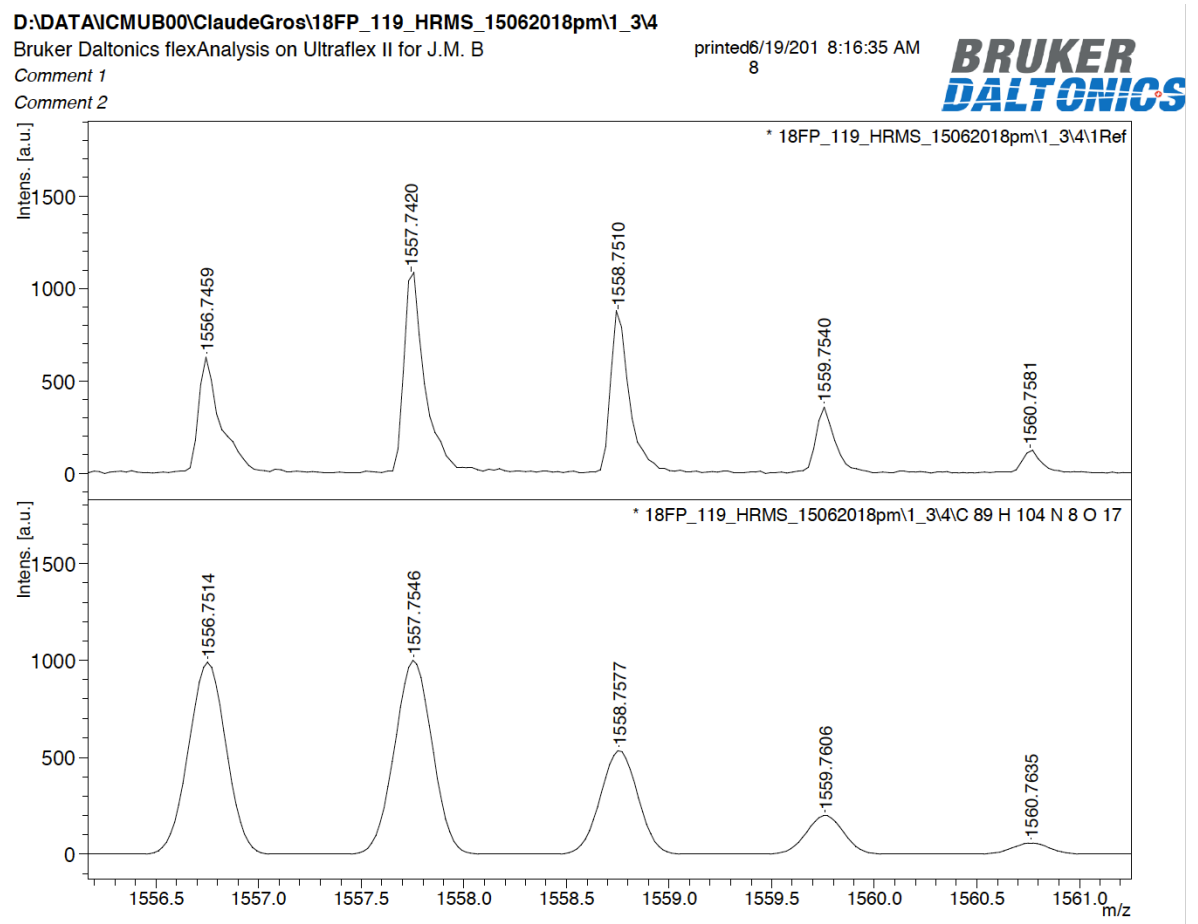

Fig. S32. ESI+ mass spectrum (low resolution) of triad BC-DPP-3

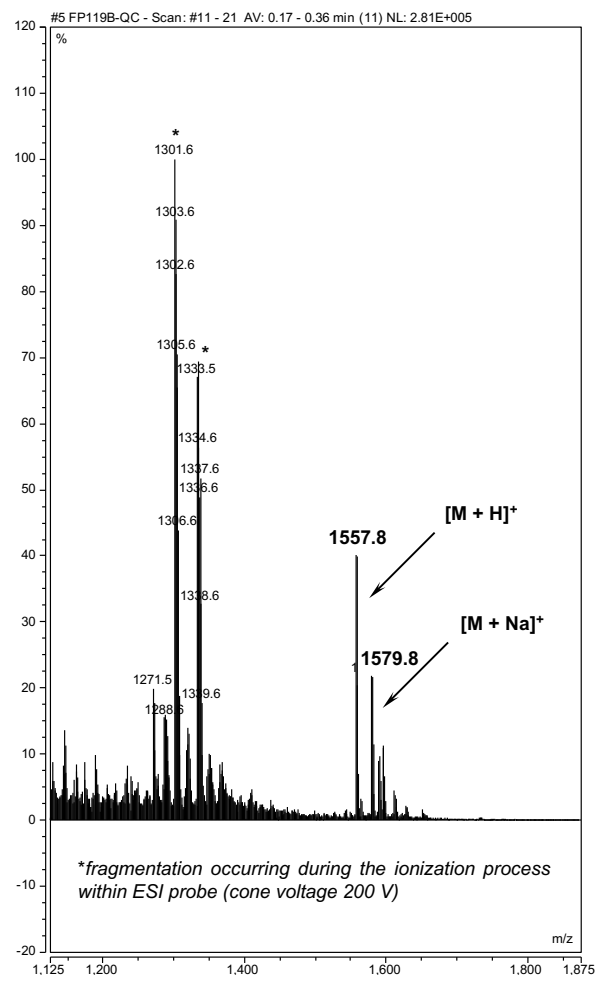




\section{S3 Photophyscial characterizations - Spectra}

Please note: For some excitation spectra, peak at 325/337 nm $\left(\lambda_{e x} / 2\right)$ assigned to Rayleigh scattering is observed. Emission spectra cannot be corrected in the range 850-900 $\mathrm{nm}$, which explains the artificat observed at $850 \mathrm{~nm}$ (this also the case with standard namely $I C G)$.

Fig. S33. Normalized absorption, excitation (Em. 675 nm, slit 5 nm ; Ex. 300-650 nm, slit $12 \mathrm{~nm}$ ) and emission (Ex. $550 \mathrm{~nm}$, slit $5 \mathrm{~nm}$; Em. 560-725 nm, slit $5 \mathrm{~nm}$ ) spectra of ethynyl-functionalized thienyl-DPP 1 in $\mathrm{CHCl}_{3}$ at $25^{\circ} \mathrm{C}$

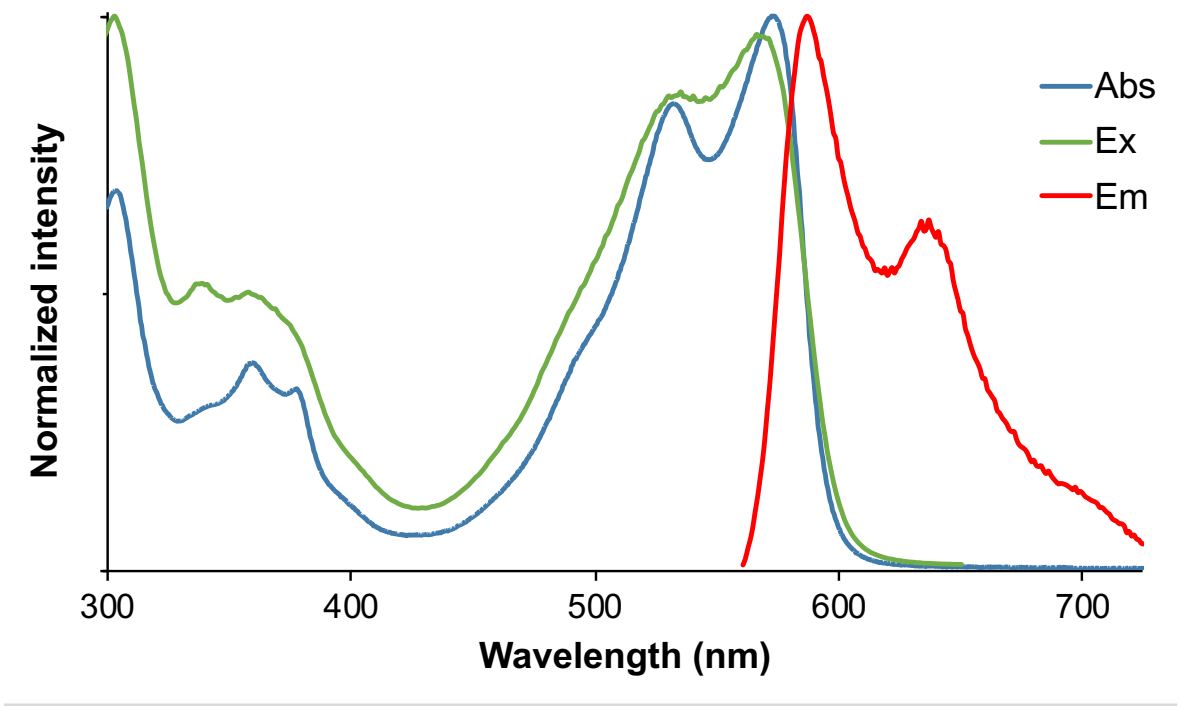

Fig. S34. Normalized absorption, excitation (Em. 675 nm, slit 5 nm ; Ex. 300-650 nm, slit $12 \mathrm{~nm}$ ) and emission (Ex. $550 \mathrm{~nm}$, slit $5 \mathrm{~nm}$; Em. 560-725 nm, slit $5 \mathrm{~nm}$ ) spectra of ethynyl-functionalized thienyl-DPP 1 in toluene at $25^{\circ} \mathrm{C}$

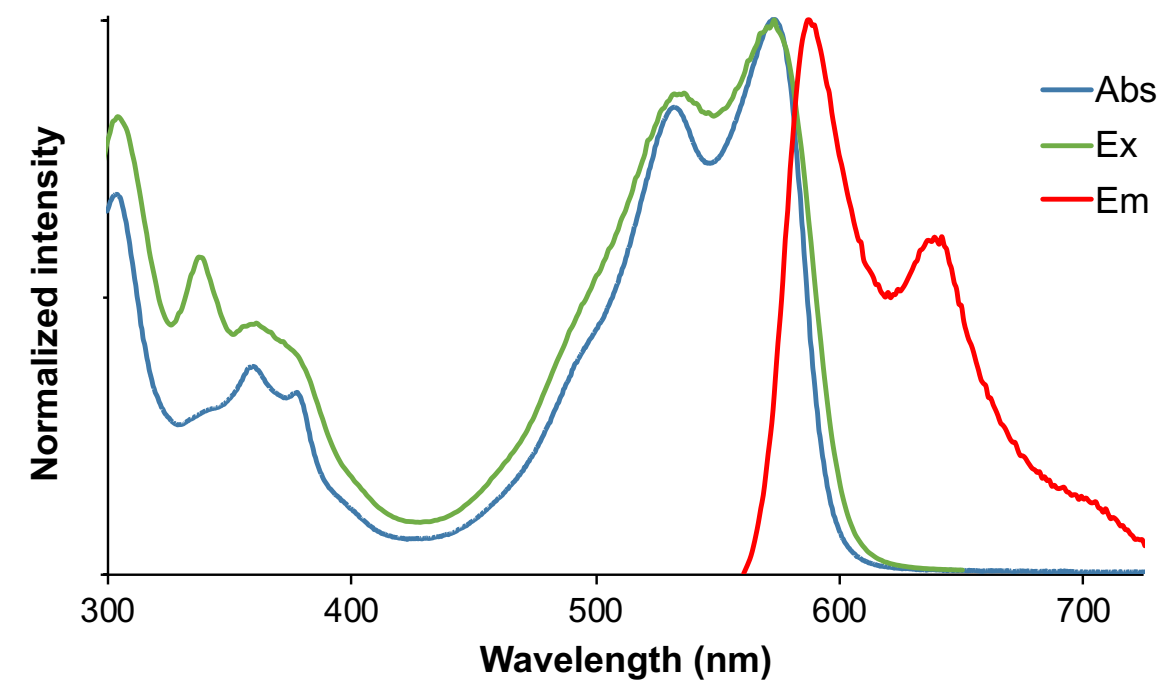


Fig. S35. Normalized absorption, excitation (Em. 650 nm, slit 5 nm ; Ex. 300-620 nm, slit $12 \mathrm{~nm}$ ) and emission (Ex. $450 \mathrm{~nm}$, slit $5 \mathrm{~nm}$; Em. 470-710 nm, slit $5 \mathrm{~nm}$ ) spectra of ethynyl-functionalized phenyl-DPP 5 in $\mathrm{CHCl}_{3}$ at $25{ }^{\circ} \mathrm{C}$

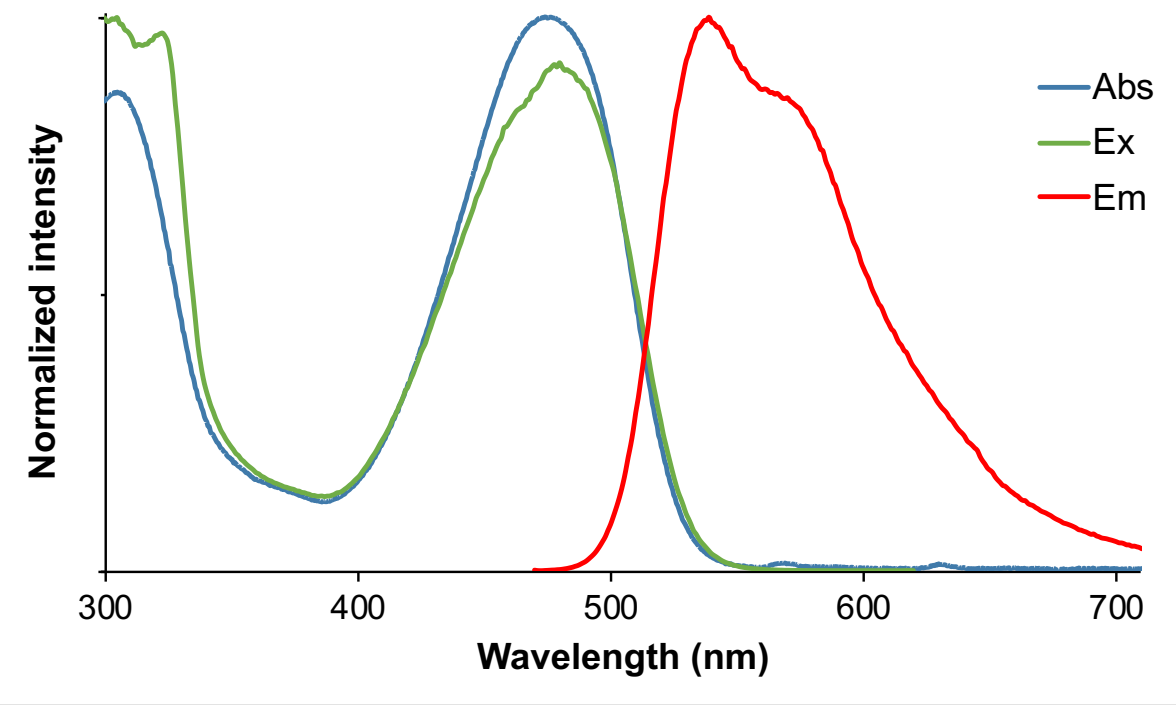

Fig. S36. Normalized absorption, excitation (Em. 650 nm, slit 5 nm ; Ex. 300-620 nm, slit $12 \mathrm{~nm}$ ) and emission (Ex. $450 \mathrm{~nm}$, slit $5 \mathrm{~nm}$; Em. 470-710 nm, slit $5 \mathrm{~nm}$ ) spectra of ethynyl-functionalized phenyl-DPP 5 in toluene at $25^{\circ} \mathrm{C}$

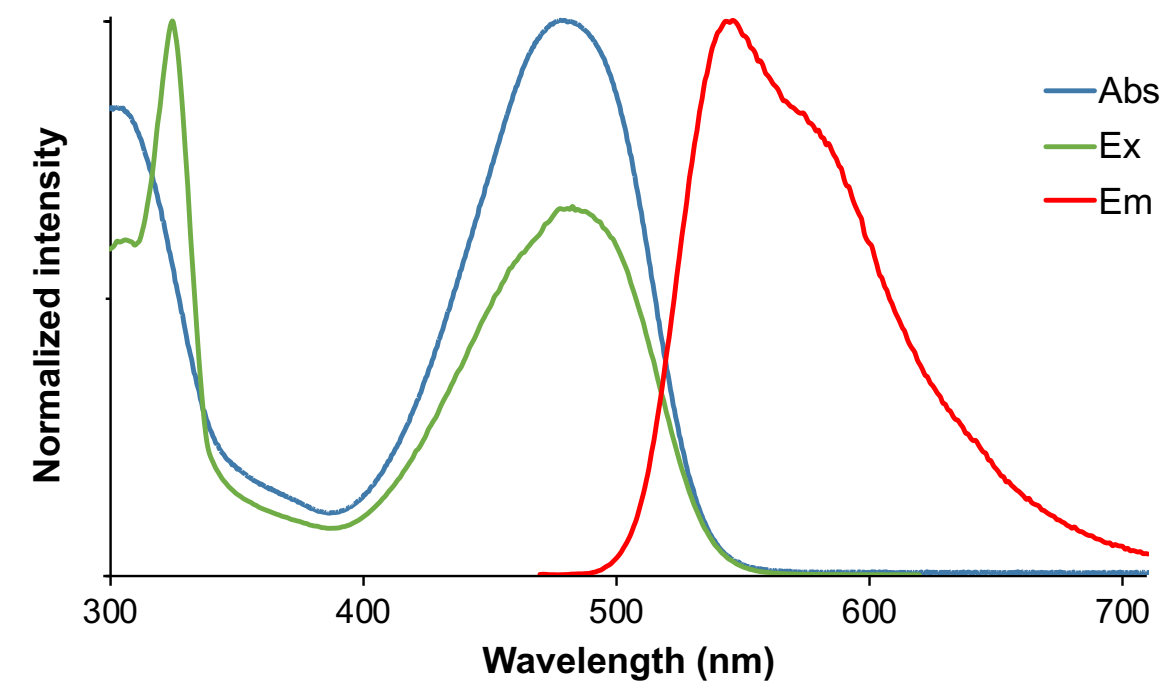


Fig. S37. Normalized absorption, excitation (Em. $650 \mathrm{~nm}$, slit $5 \mathrm{~nm}$; Ex. 300-620 nm, slit $12 \mathrm{~nm}$ ) and emission (Ex. $450 \mathrm{~nm}$, slit $5 \mathrm{~nm}$; Em. 470-710 nm, slit $5 \mathrm{~nm}$ ) spectra of 3,6-diphenyl-DPP 7 in $\mathrm{CHCl}_{3}$ at $25^{\circ} \mathrm{C}$

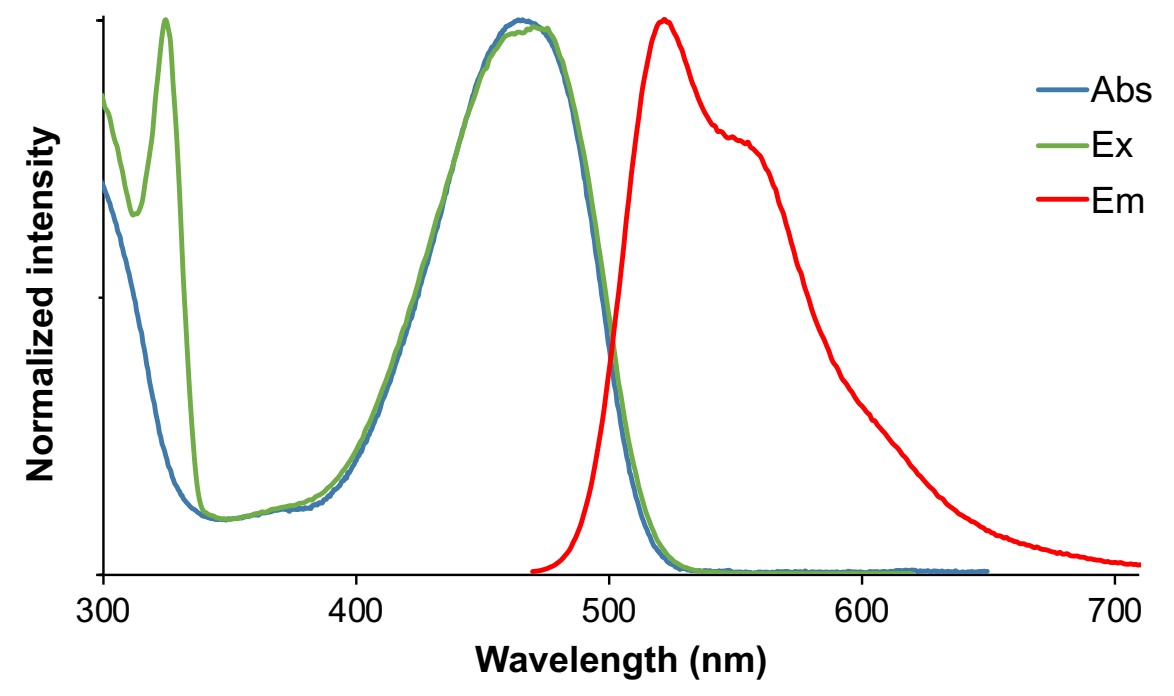

Fig. S38. Normalized absorption, excitation (Em. $650 \mathrm{~nm}$, slit $5 \mathrm{~nm}$; Ex. 300-620 nm, slit $12 \mathrm{~nm}$ ) and emission (Ex. $450 \mathrm{~nm}$, slit $5 \mathrm{~nm}$; Em. 470-710 nm, slit $5 \mathrm{~nm}$ ) spectra of 3,6-diphenyl-DPP 7 in toluene at $25^{\circ} \mathrm{C}$

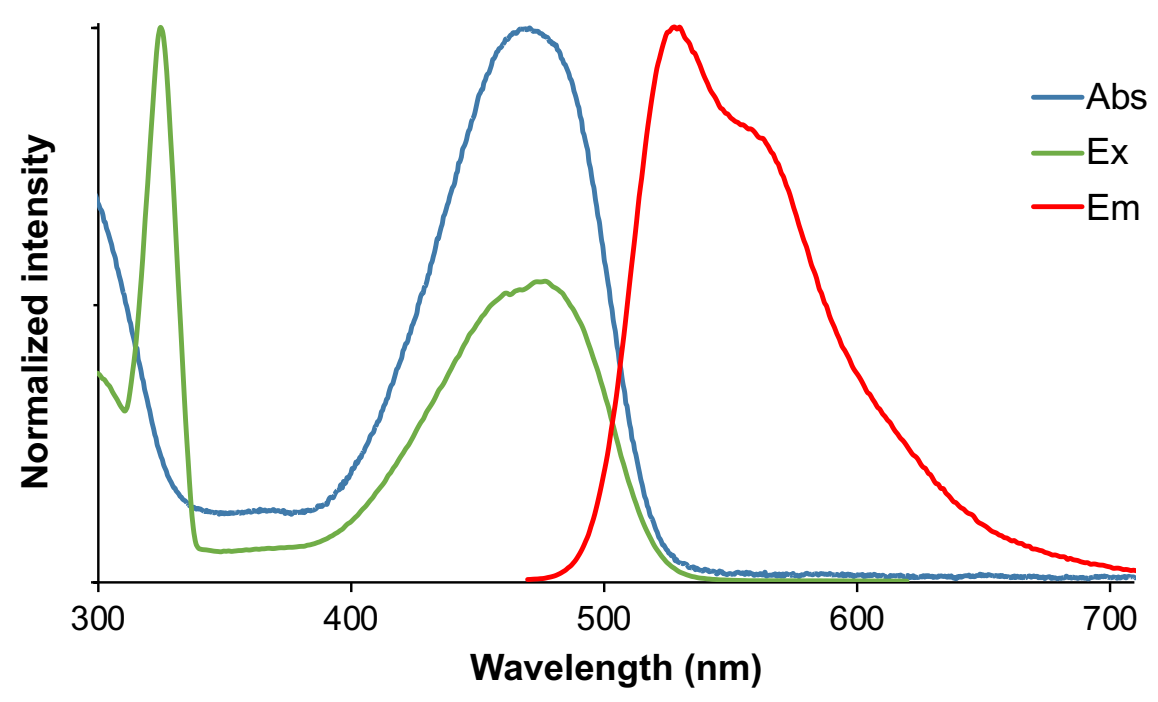


Fig. S39. Overlay of the absorbance spectra of diBr-BC, DPP 1 and BC-DPP-1 recorded in $\mathrm{CHCl}_{3}$ at $25^{\circ} \mathrm{C}$

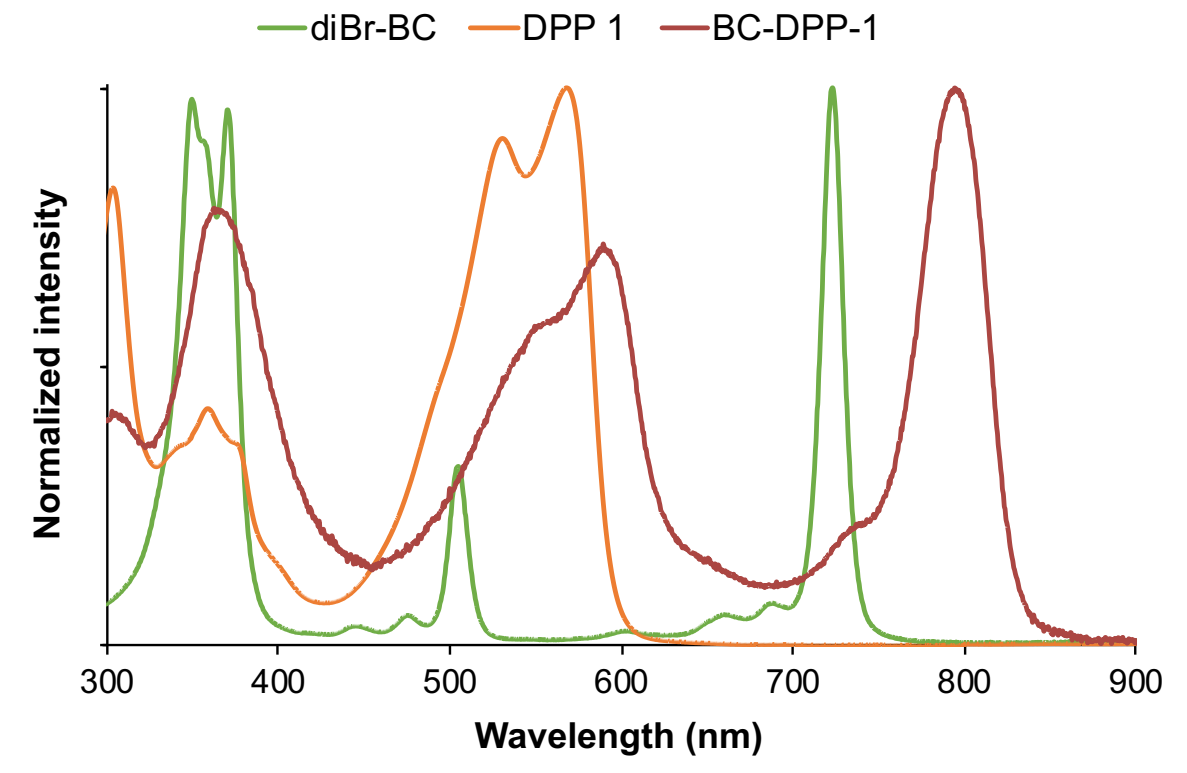

Fig. S40. Overlay of the emission spectra of BC-DPP-1 upon excitation at $550 \mathrm{~nm}$ (slit $5 \mathrm{~nm}$, Em. 560-900 nm, slit $5 \mathrm{~nm}$ ) and $720 \mathrm{~nm}$ (slit $5 \mathrm{~nm}$, Em. 730-900 nm, slit $5 \mathrm{~nm}$ ), recorded in $\mathrm{CHCl}_{3}$ at $25^{\circ} \mathrm{C}$

- - Em. BC-DPP-1 (Ex. 550) —Em. BC-DPP-1 (Ex. 720)

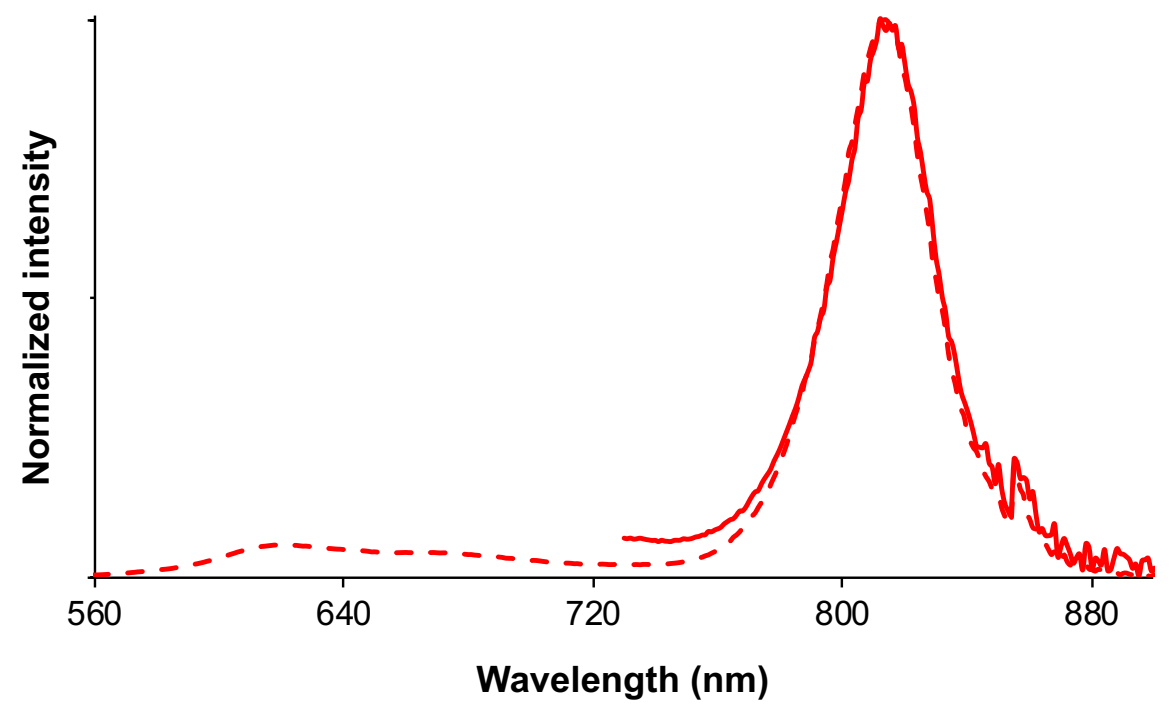


Fig. S41. Overlay of the absorbance spectra of diBr-BC, DPP 1 and BC-DPP-1 recorded in toluene at $25^{\circ} \mathrm{C}$

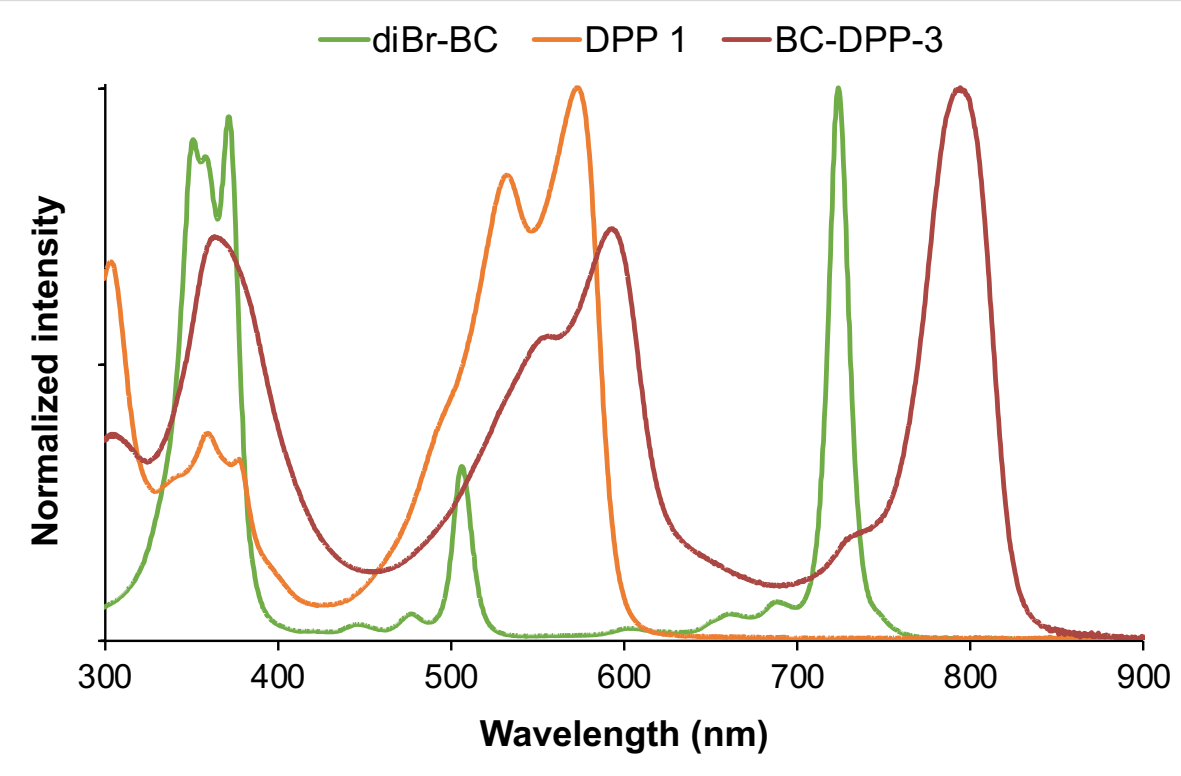

Fig. S42. Overlay of the emission spectra of BC-DPP-1 upon excitation at $550 \mathrm{~nm}$ (slit $5 \mathrm{~nm}, \mathbf{E m} .560-900 \mathrm{~nm}$, slit $5 \mathrm{~nm}$ ) and $720 \mathrm{~nm}$ (slit $5 \mathrm{~nm}$, Em. 730-900 nm, slit $5 \mathrm{~nm}$ ), recorded in toluene at $25^{\circ} \mathrm{C}$

- - Em. BC-DPP-1 (Ex. 550) —Em. BC-DPP-1 (Ex. 720)

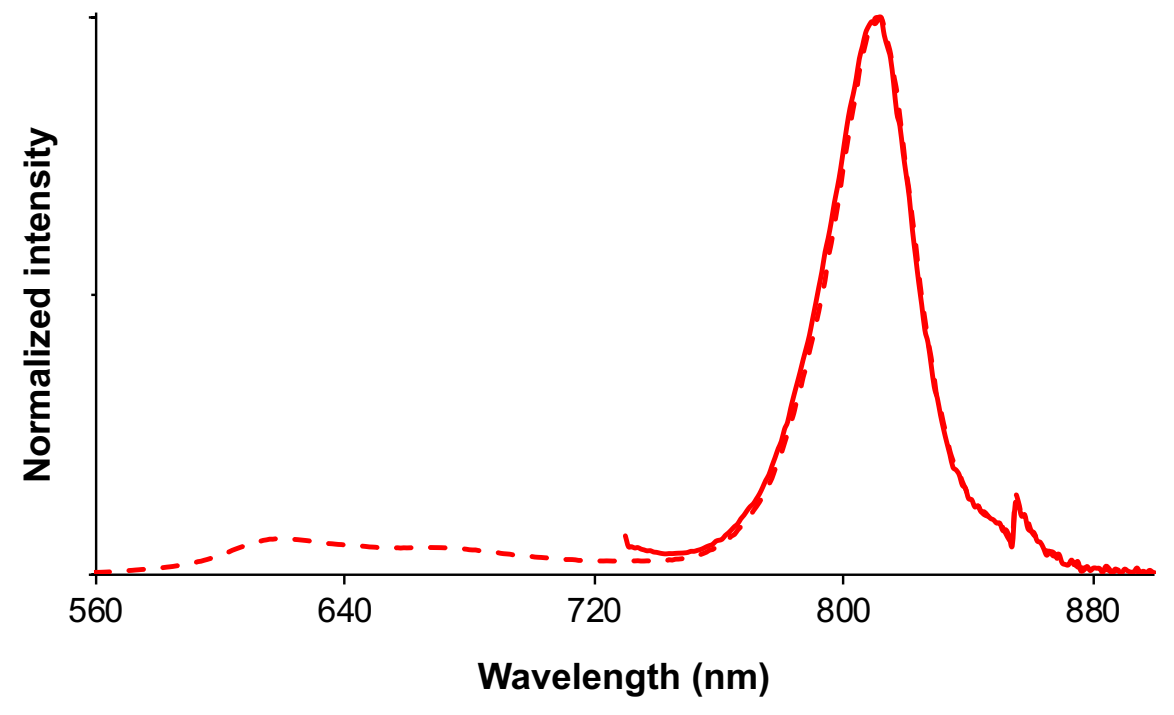


Fig. S43. Overlay of the absorbance spectra of diBr-BC, DPP 5 and BC-DPP-2 recorded in toluene at $25^{\circ} \mathrm{C}$

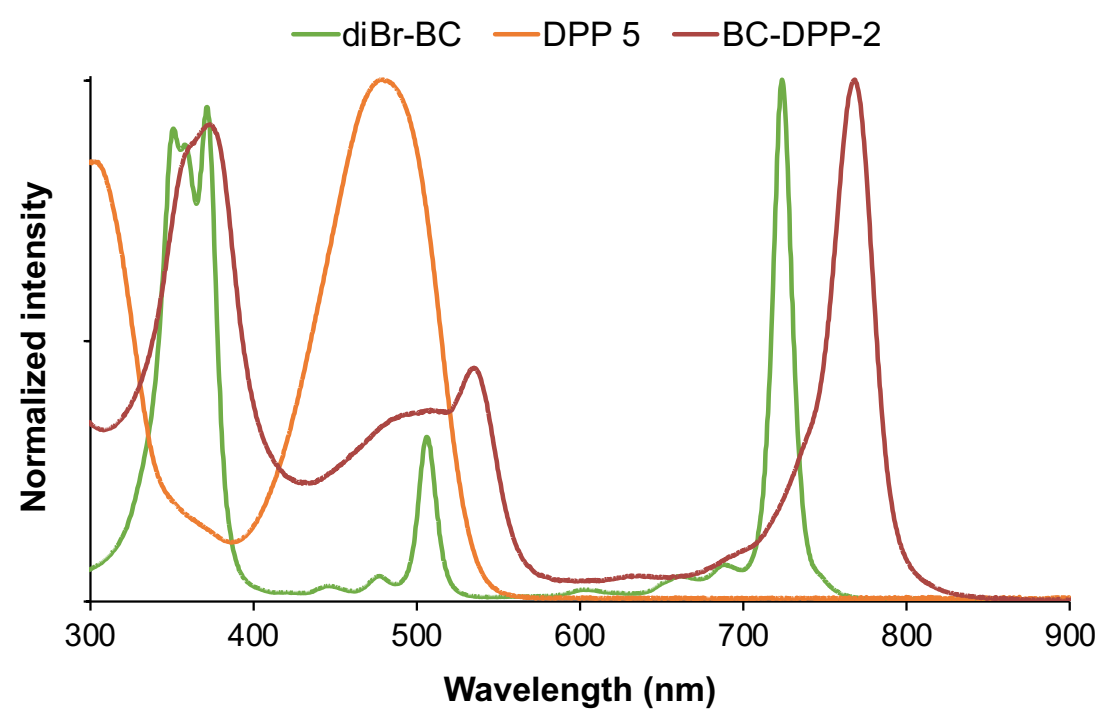

Fig. S44. Overlay of the emission spectra of BC-DPP-2 upon excitation at $450 \mathrm{~nm}$ (slit $5 \mathrm{~nm}$, Em. 470-900 nm, slit $5 \mathrm{~nm}$ ) and $690 \mathrm{~nm}$ (slit $5 \mathrm{~nm}$, Em. 700-900 nm, slit 5 nm), recorded in toluene at $25{ }^{\circ} \mathrm{C}$

- - Em. BC-DPP-2 (Ex. 450)

-Em. BC-DPP-2 (Ex. 690)

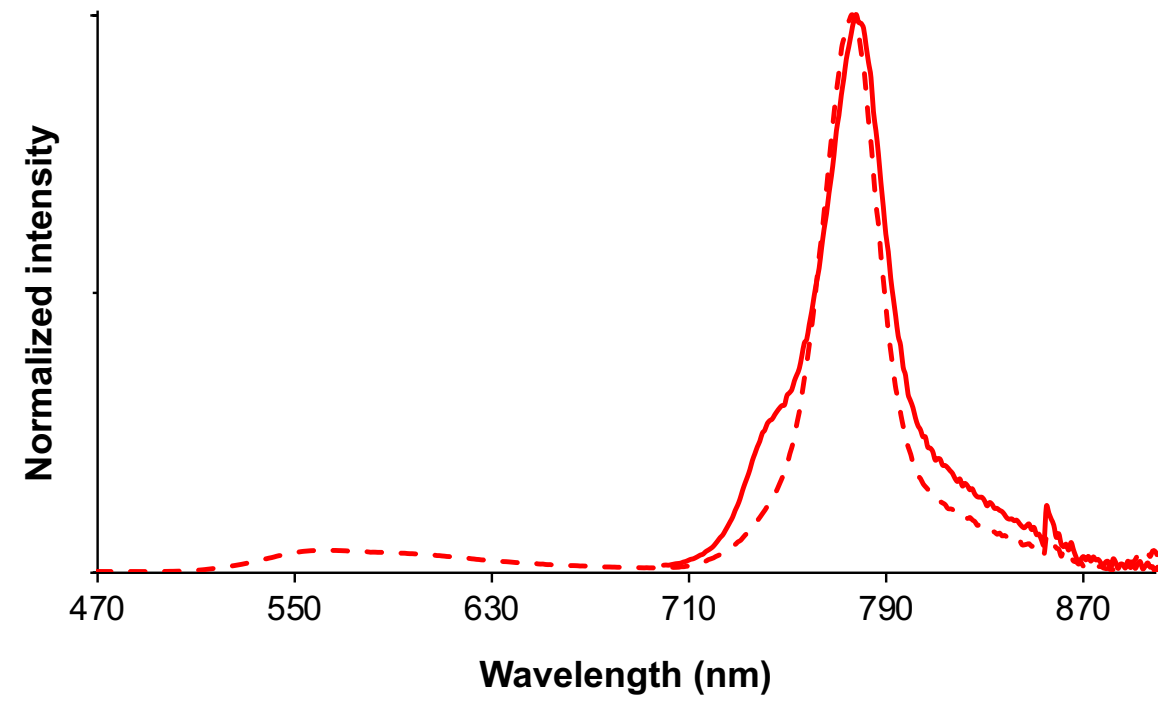


Fig. S45. Overlay of the absorbance spectra of diBr-BC, DPP 7 and BC-DPP-3 recorded in toluene at $25^{\circ} \mathrm{C}$

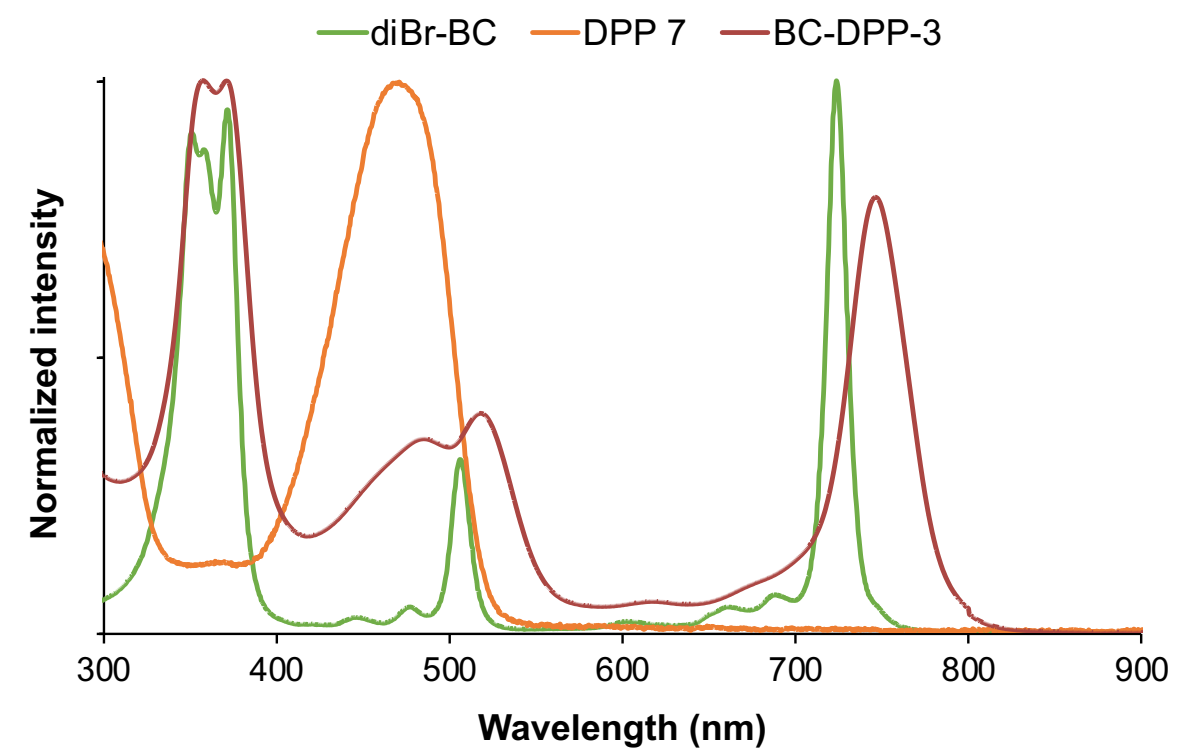

Fig. S46. Overlay of the emission spectra of BC-DPP-3 upon excitation at $450 \mathrm{~nm}$ (slit 5 nm, Em. 470-900 nm, slit $5 \mathrm{~nm}$ ) and $680 \mathrm{~nm}$ (slit $5 \mathrm{~nm}$, Em. 690-900 nm, slit $5 \mathrm{~nm}$ ), recorded in toluene at $25{ }^{\circ} \mathrm{C}$

- - Em. BC-DPP-3 (Ex. 450) —Em. BC-DPP-3 (Ex. 680)

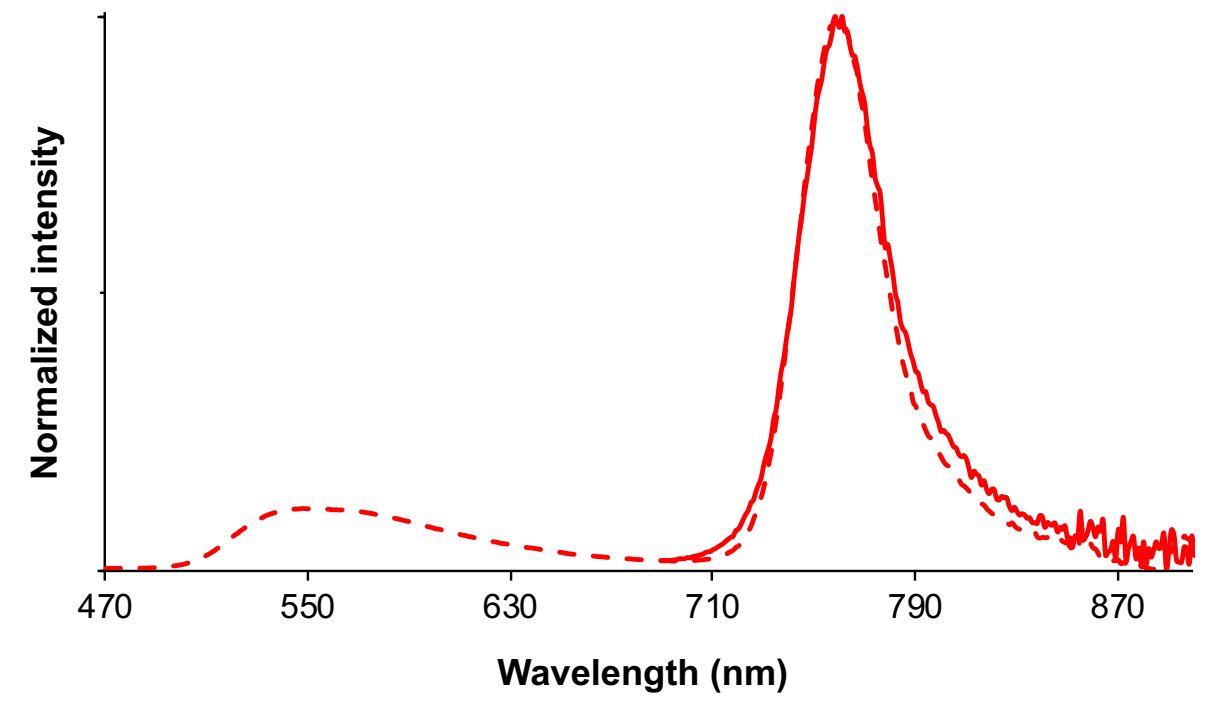


Fig. S47. Overlay of the absorbance and excitation (Em. $835 \mathrm{~nm}$, slit $5 \mathrm{~nm}$; Ex. 300$825 \mathrm{~nm}$, slit $12 \mathrm{~nm}$ ) spectra of $\mathrm{BC}-\mathrm{DPP}-1$ recorded in $\mathrm{CHCl}_{3}$ at $25^{\circ} \mathrm{C}$

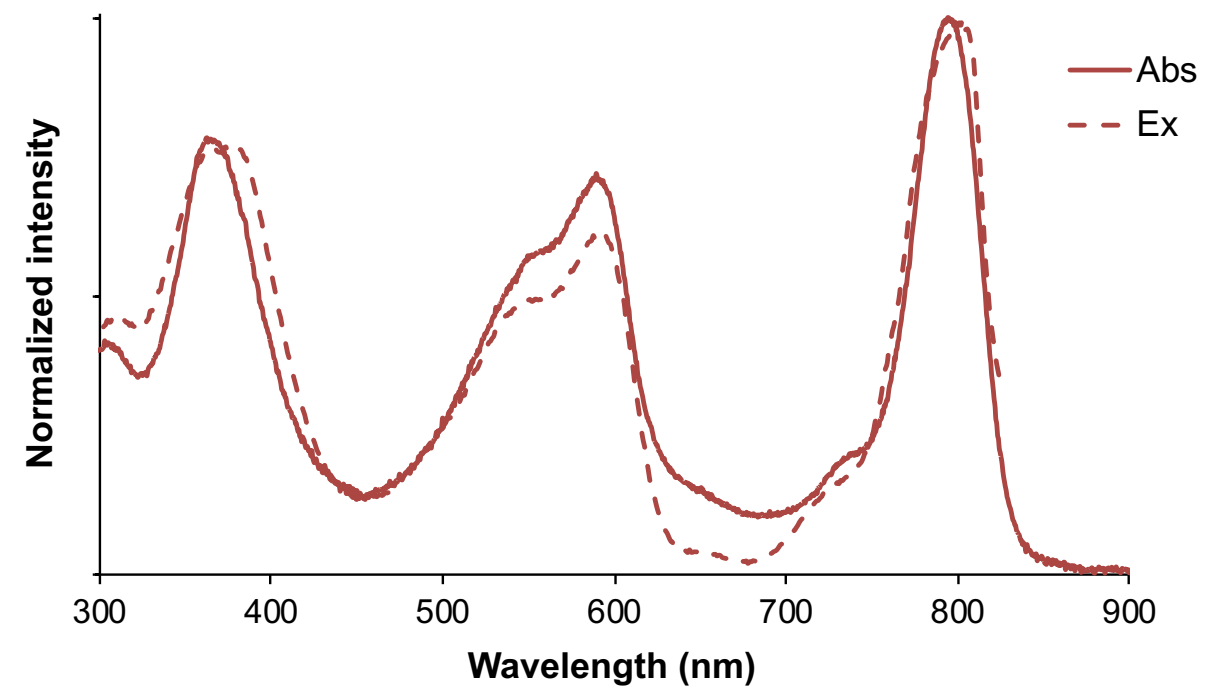

Fig. S48. Overlay of the absorbance and excitation $(\mathrm{Em} .835 \mathrm{~nm}$, slit $5 \mathrm{~nm}$; Ex. 300$825 \mathrm{~nm}$, slit $12 \mathrm{~nm}$ ) spectra of BC-DPP-1 recorded in toluene at $25^{\circ} \mathrm{C}$

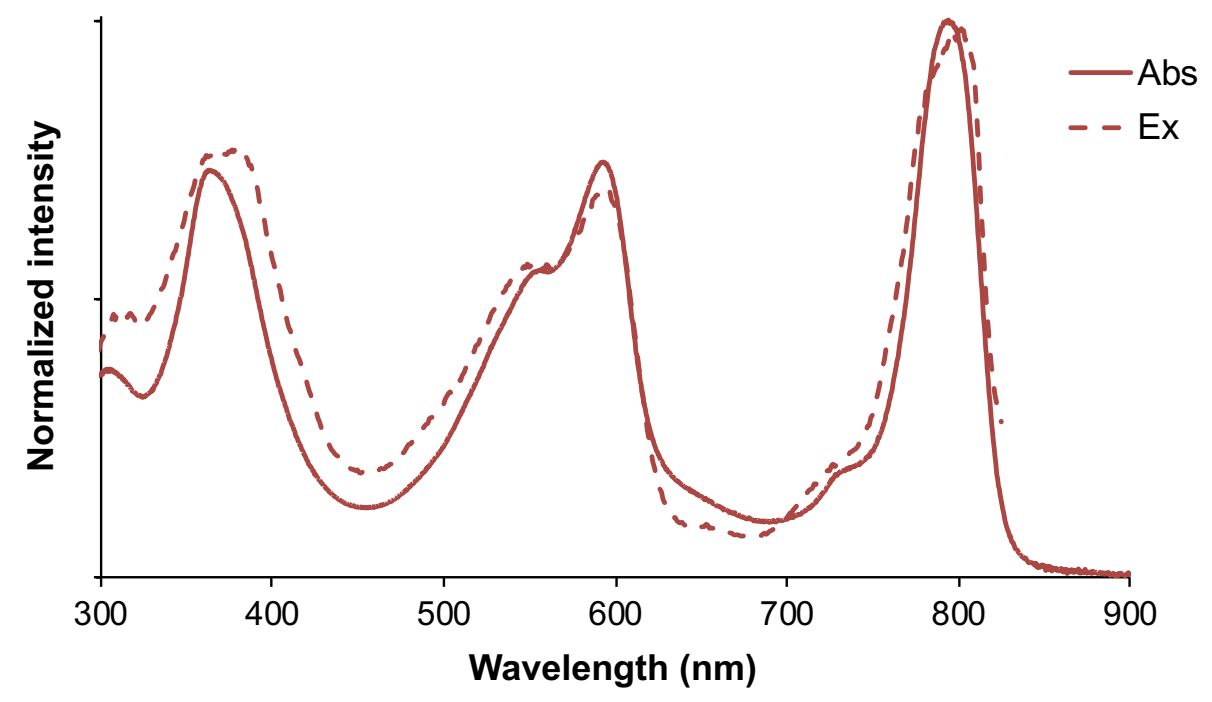


Fig. S49. Overlay of the absorbance and excitation (Em. $835 \mathrm{~nm}$, slit $5 \mathrm{~nm}$; Ex. 300$825 \mathrm{~nm}$, slit $12 \mathrm{~nm}$ ) spectra of $\mathrm{BC}-\mathrm{DPP}-2$ recorded in $\mathrm{CHCl}_{3}$ at $25^{\circ} \mathrm{C}$

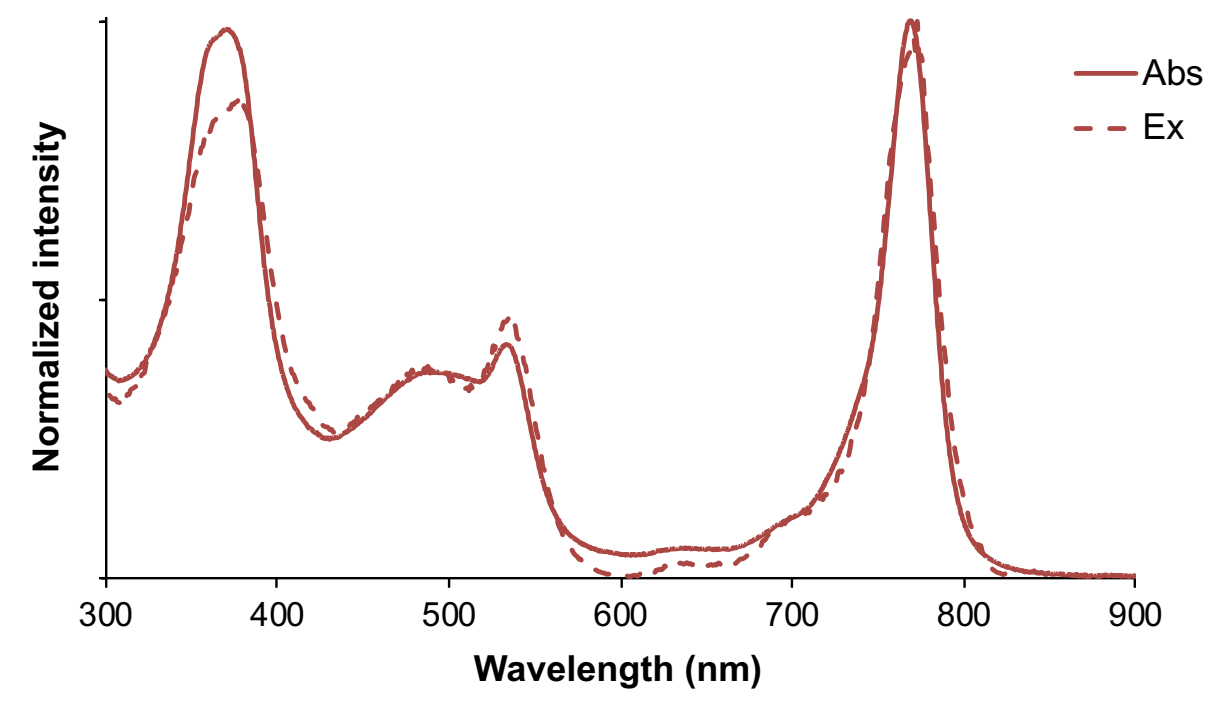

Fig. S50. Overlay of the absorbance and excitation (Em. $835 \mathrm{~nm}$, slit $5 \mathrm{~nm}$; Ex. 300$825 \mathrm{~nm}$, slit $12 \mathrm{~nm}$ ) spectra of BC-DPP-2 recorded in toluene at $25^{\circ} \mathrm{C}$

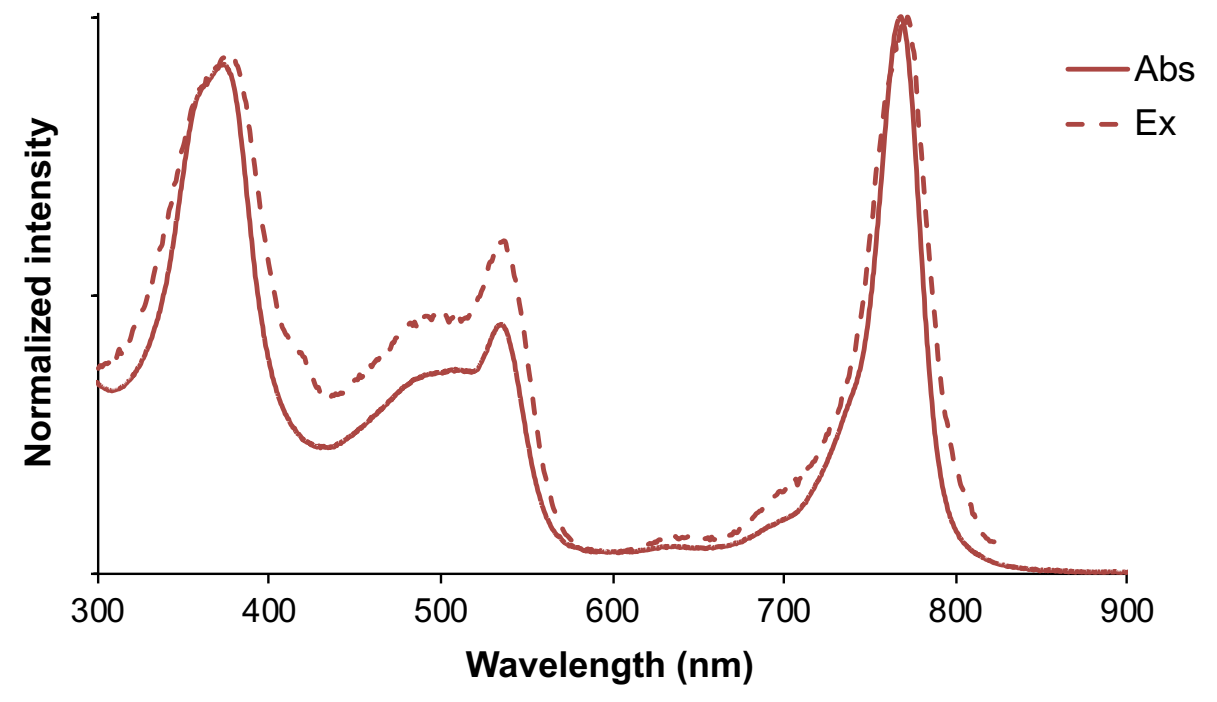


Fig. S51. Overlay of the absorbance and excitation (Em. $835 \mathrm{~nm}$, slit $5 \mathrm{~nm}$; Ex. 300$825 \mathrm{~nm}$, slit $12 \mathrm{~nm}$ ) spectra of $\mathrm{BC}-\mathrm{DPP}-3$ recorded in $\mathrm{CHCl}_{3}$ at $25^{\circ} \mathrm{C}$

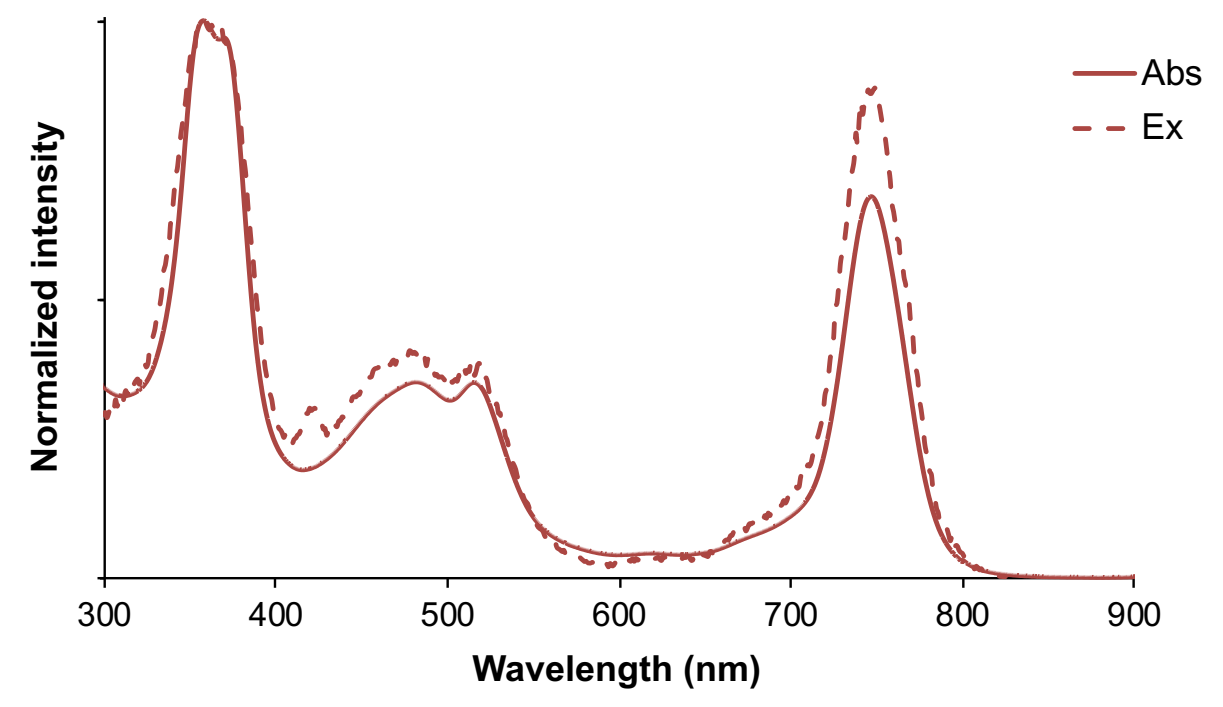

Fig. S52. Overlay of the absorbance and excitation (Em. 835 nm, slit 5 nm ; Ex. 300$825 \mathrm{~nm}$, slit $12 \mathrm{~nm}$ ) spectra of BC-DPP-3 recorded in toluene at $25^{\circ} \mathrm{C}$

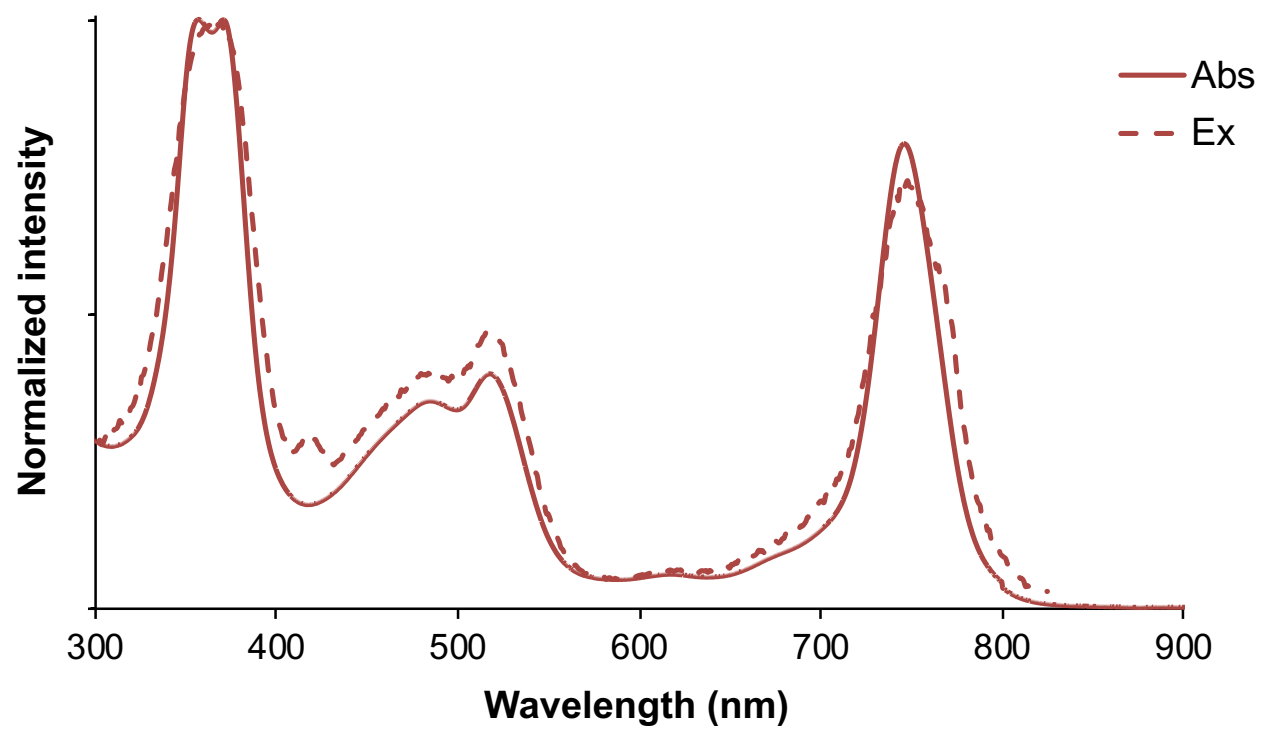

